\title{
Street appeal:
}

\section{the value of street improvements}

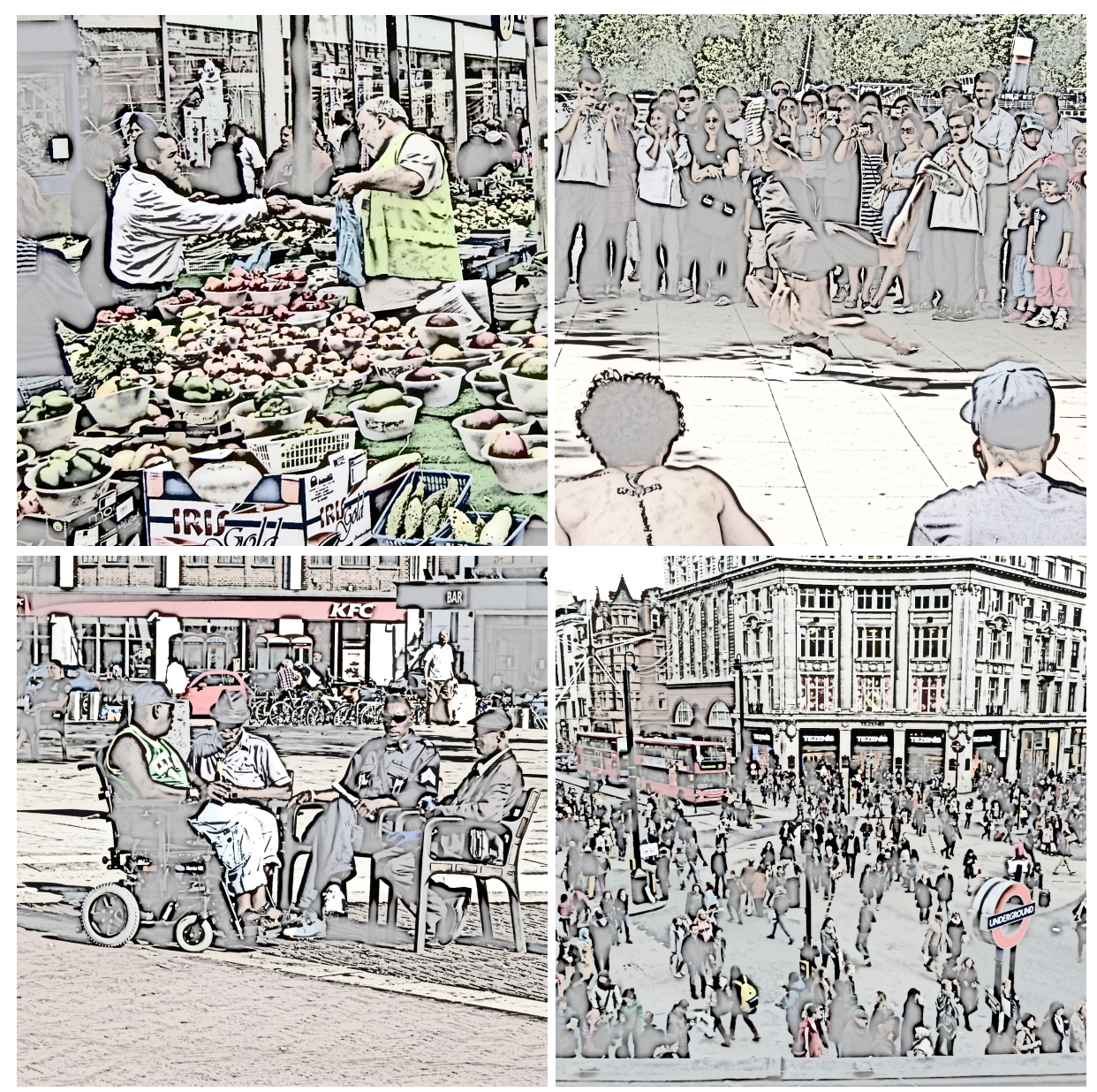




\title{
Contents
}

1.0 Investing in street appeal

2.0 Researching the value of design

3.0 Researching the value of street improvements $\quad 15$

$\begin{array}{ll}4.0 \text { Physical fabric } & 26\end{array}$

5.0 Real estate $\quad 34$

6.0 Movement $\quad 59$

$\begin{array}{ll}7.0 \text { Exchange } & 69\end{array}$

8.0 Conclusions $\quad 80$

9.0 References $\quad 90$

10.0 Acknowledgements 95

\begin{abstract}
The planning for and design of streets around the world have been undergoing a radical change via a move from a network efficiency model to a movement and place-based one. This is a fundamental change, and it is important to understand both the benefits and drawbacks that result. This research represents an attempt to capture and understand these impacts and to address the question, what is the 'value', in the widest sense of the word, of place-based improvements in street design. The key features of the approach adopted here were, the use of pairwise comparisons of five improved and five unimproved streets across London, a holistic analytical framework to represent the complexity of urban streets, and the use of diverse qualitative and quantitative data to understand the diverse forms of value that might accrue from interventions. As well as important methodological innovations and insights, the research revealed that in relation to street improvements in the sorts of mixed local high street locations investigated, investments in the quality of the street environment return substantial value to the everyday users of streets, and to the occupiers of space (to business) and investors in surrounding property in multiple ways.
\end{abstract}




\subsection{Investing in street appeal}

Those cities that have failed to integrate the multi-functionality of streets tend to have lesser infrastructure development, lower productivity, a poorer quality of life... social exclusion and generate inequalities in various spheres of life

(UN-Habitat 2013)

The quality of the street environment effects us all. Whether we are walking to school, waiting at a bus stop, cycling to work, shopping, or even driving through a city, how streets handle and balance the various, complex and often conflicting needs of users has a profound impact on our daily lives and wellbeing. At the same time streets in traditional cities are often highly constrained physically, and this means that we need to make hard choices about which functions to prioritise and where.

These are choices that cities around the world are having to make, and increasingly such choices are coming down on the side of seeing streets as more than just movement corridors that facilitate the passing of traffic. The Complete Streets movement in the US provides a case-in-point, where, since 2003 advocates have been advancing (increasingly successfully) the idea that we need to plan for and design our streets differently with the needs of all users (not just car users) in mind. Also, and importantly, that this needs to have political buy-in (McCann \& Rynne 2010: 4). In the parlance of urban design, streets also have a vital 'place' function reflecting their role as environments within which we meet and socialise, where businesses are located, where we walk and cycle, and where the public life of the city carries on.

London, for example, has for at least ten years been investing in the quality of its street environment as part of a long-term strategy for securing a better balance between the 'movement' and 'place' based functions of streets. Thus Transport for London's (TfL) key Streetscape Guidance argues "Streets are places for people. Successful streetscapes are inclusive and provide for the competing requirements of their users, including pedestrians, cyclists, motorcyclists, bus operators, bus passengers, private vehicle owners, and freight vehicle operators" (TfL 2016: 1). In other words a balance needs to be struck between their role connecting up

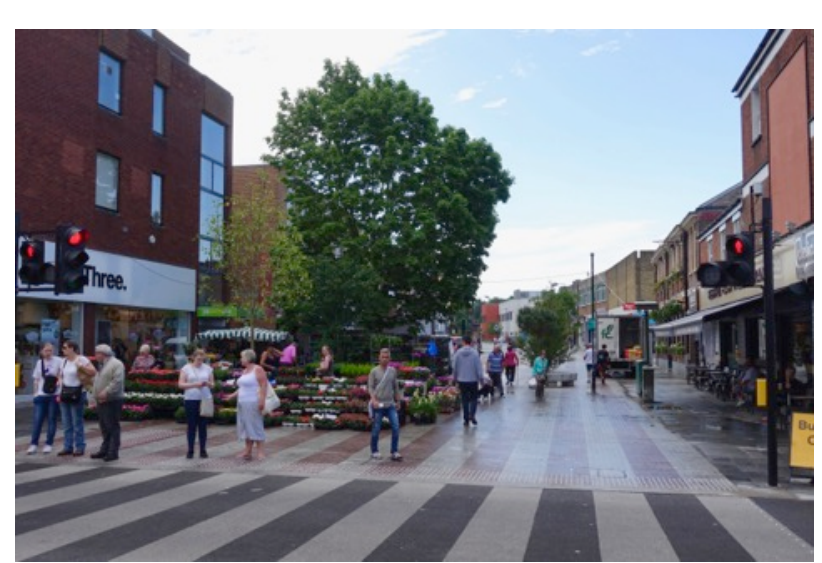
pedestrian, cycle and vehicular movement, and a role as a venue for the social, economic and cultural life of the city (Figure 1).

Figure 1: Investing in London's streets, reclaimed road space, Eltham, London (Matthew Carmona) 
Yet, as with all changes to streets, space is limited and better provision for one street function may have knock on impacts on others. More space for cyclists, for instance, may mean less space for cars or pedestrians, or simply that their ability to move is in someway constrained by the new infrastructure, as controversies over the creation of Cycle Superhighways across London have shown in recent years (Stops 2015). The re-design of the urban realm in streets is also likely to bring with it concerns from businesses or residents along the route who may be worried that parking, servicing and other amenities will be compromised, or that gentrification pressures may be stoked (Kahne 2015). The danger is that such concerns drown out consideration of less obviously tangible and hard to measure benefits such as more space to socialise and enjoy the environment, greater encouragement to walking with associated health benefits, or knock on impacts on private investment in an area.

Infrastructure schemes have traditionally been justified on the basis of cost benefit analysis (CBA), which attempts to quantify the benefits of a new intervention against the dis-benefits and infrastructure costs. But CBA can be very partial (van Wee 2012), reflecting only the impacts that can be easily quantified and these are unlikely to reflect the whole story. In London, TfL's recent innovations in street design and management move beyond such a narrow cost-based view of the street environment ${ }^{1}$. They encompass a shift from a network efficiency model to a movement and place-based one in which streets are viewed as places of complex social and economic exchange as well as channels for movement (Figure 2). This is a fundamental change reflected in the Street Types Matrix against which every street in London has been mapped for their movement and place functions as a means to help decision makers understand the amount of change needed when planning for their future (Roads Task Force 2015: 8). Yet whilst such moves reflect a growing awareness of the importance of thinking more broadly about the functions of streets, arguably they are not yet underpinned by a comprehensive understanding of the

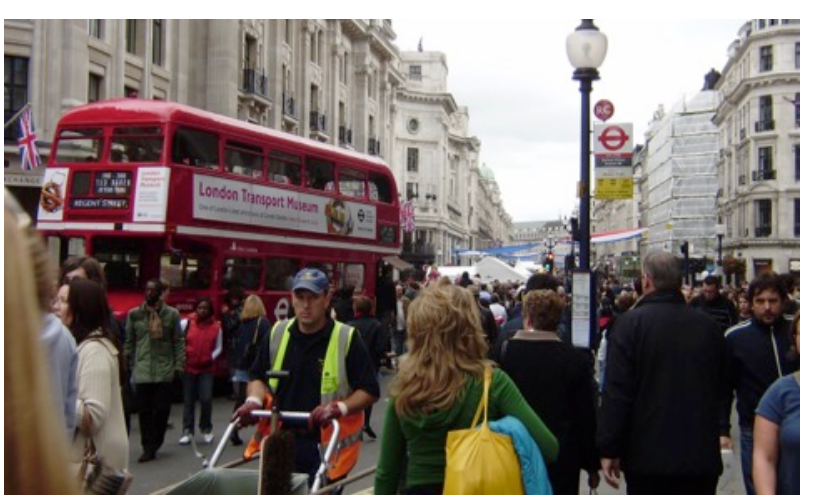
potential benefits (and dis-benefits) that might flow from this.

The case for making new investments in the street environment should better capture the full range of positive benefits that might be added by the intervention, and any negative externalities. Knowing this type of information will help deliver more informed investment decisions relating to the urban realm in cities around the world and will ensure that, when delivered, investments in the local street environment will help to maximise the place-based benefits. The research that

\footnotetext{
${ }^{1}$ For example TfL's Toolkit for Valuing the Urban Realm
} 
underpins this paper represents an attempt to capture and understand these impacts for London and to address the question, what is the 'value', in the widest sense of the word, of place-based improvements in street design.

The paper begins by discussing some of the methodological and conceptual challenges in addressing this subject, before presenting a 'holistic' framework for analysis in order to give a more rounded and nuanced picture of value than previously attempted in much 'design value' research. Next ten streets from across London, five cases of streets that have been improved and five unimproved comparators, are introduced. The evidence gathered through various related but distinct sources of data on these ten streets follows, and from this findings are extracted relating to the physical fabric, real estate, movement and exchange dimensions of street value. Finally overarching conclusions are presented that reveal a convincing case for continuing to invest in the quality of streets as places, not just as movement corridors.

The research found that improvements to the quality of the publically owned and managed areas of London's mixed streets, such as high streets and town centres, return substantial benefits to the everyday users of streets, and to the occupiers of space and investors in surrounding property in multiple ways. In the study these included:

- A one third uplift in the physical quality of the street as a whole from interventions in the publically owned street space.

- An uplift in office rental values equivalent to an 'additional' $4 \%$ per annum. This helps to support investment in business space in the face of pressures to convert to more profitable residential uses.

- A larger uplift in retail rental values equivalent to an 'additional' $7.5 \%$ per annum. This results from the more attractive retail environment that has been created and the encouragement this is giving to investment in these locations despite competition from on-line retail and 'out-of-town' shopping centres.

- A strongly related decline in retail vacancy leading to a sizable $17 \%$ per annum difference in vacancy rates between improved and unimproved street environments.

- A growth in leisure uses, and a greater resilience in the improved streets of traditional (A1) and comparison retail; all bucking the common trend of decline in such uses that is often seen elsewhere.

- An almost negligible impact on residential values, helping to counter concerns that street improvements, by themselves, will further inflate house prices and encourage gentrification.

- Inconsequential impacts, from the street improvements alone, on traffic flows or the modal choices made by individuals when travelling (unless road capacity is deliberately removed as part of an improvement scheme), but a reduction in serious or fatal accidents on those streets with higher preexisting levels of collisions. 
- A large $96 \%$ boost in static (e.g. standing, waiting, and sitting) and $93 \%$ boost in active (e.g. walking) street behaviours in improved over unimproved areas, with strong potential health benefits in the resulting more active lifestyles.

- A particularly large $216 \%$ hike in the sorts of leisure based static activities (e.g. stopping at a café or sitting at a bench) that only happen when the quality of the environment is sufficiently conducive to make people wish to stay.

- Very strong perceptions amongst both everyday street users and local property occupiers that street improvement schemes significantly enhance street character, walkability, ease of crossing, opportunities for sitting, and general street vibrancy. 


\subsection{Researching the value of design}

Over the last 20 years a considerable body of 'value of design' studies have been built up relating to the built environment. These include studies that are similar in aim and/or scope to the current study and academic papers discussing empirical research or, more often, the methodologies through which design attributes can be valued. Studies typically begin by establishing a general framework that defines the key qualities of the urban realm with which they are dealing and the types of 'value' that are being ascribed to it.

Usually that entails breaking those concepts down into categories of qualities or aspects which in turn can be further distilled into sets of measurable or observable indicators. In some cases (Nase et al. 2015; Mulgan 2005) the formulation of those frameworks is explored in detail and on the basis of theory, making it clear how holistic or partial is the conceptualisation of the urban realm and its value. In others, attention focuses only on the precise definition of the indicators to be used (e.g. increases in sales tax returns as a cipher for street quality - NYC Department of Transportation 2013), and the authors' conceptualisation of what is meant by quality and value has to be inferred from this.

\subsection{Quality and value}

Simple parameter studies

In attempting to link those two fundamental concepts - quality and value - most studies explicitly isolate one or more parameters from each 'side' to focus on. A popular combination, for example, is the study of the effect of green spaces and natural elements such as trees on residential prices (CJC Consulting 2005; Cho et al. 2008; Herath et al. 2015; GLA Economics 2003; Smith 2010; CABE Space 2005; Luttik 2000; Varma 2003), while other approaches take the reverse route, starting from the

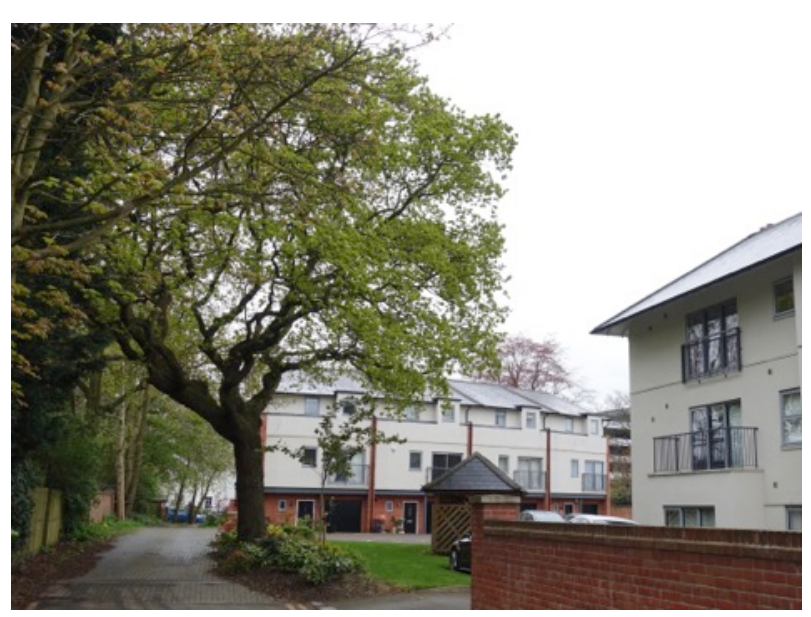
housing market and relating its trends to built environment variables (Diao \& Ferreira 2010; Song \& Knaap 2003) (Figure 3).

If taken as a spectrum, at one end are studies that focus on a single particular urban element or intervention in its local context. Examples include: Stantec Consulting (2011) who undertook a business impact evaluation of the creation of two separated bicycle lanes in downtown Vancouver; Ahlfeldt \& Mastro (2012) were concerned with the value placed by homebuyers in Oak Park on proximity to Frank Lloyd Wright's 
iconic buildings; and Gibbons (2015) linked the visibility of wind farm developments to a decrease in local housing prices across England and Wales.

Wider benefits studies

Expanding the scope are studies that investigate the wider benefits (economic, social, environmental) of particular approaches to urban realm improvement, focusing for example on walkability (Sinnett et al. 2011) or conservation (Department of National Heritage et al. 1996; English Heritage 1999). Other studies adopt a narrow definition of value to show correlations between a range of built environment qualities and specific economic metrics, most commonly property prices. These include: Ahlfeldt \& Holman (2015) between distinctive architectural qualities and residential property prices in 47 conservation areas; or Nase et al. (2013a; 2013b) between urban design quality and the real estate value of retail and office properties respectively.

In such studies typically it might be expected that an increase in urban quality would present itself in an increase in monetary value, as was the case in the influential Paved with Gold study in the UK which compared the impact of public realm improvements on residential property prices (CABE Space 2007); but this simple causal relationship may not always be the case. If, for example, improvements in the quality of an historic residential environment leads to its gentrification, then, whilst economic value may have been added for some, namely owner occupiers, for others, such as those who don't own their homes and have to pay more in rents, the economic value they derive from living in such an area may have declined. This may go hand in hand with a decline in social value if long-established communities are broken up and move away. Thus the economic consequences of changes to the built environment need careful interpretation in the light of local circumstances, and a failure to understand this has led to some such studies being criticised as too focussed on promoting better design for limited economic / market ends (Carmona et al 2017: 245).

\section{Holistic studies}

At the other end of the spectrum are projects that have tried to approach both the concepts of quality and value in a more holistic manner, in the sense that they have attempted to consider multiple dimensions of urban space interventions as well as different sorts of value. Examples include the much-quoted CABE reports (Carmona et al. 2001; CABE 2006; CABE Space 2007) and a handful of other similar projects from the UK (Amion Consulting \& Taylor Young 2007; Sheldon et al. 2007) and elsewhere (Ministry for the Environment 2005).

These (and other similar) studies differ in a wide variety of ways, most notably in their type of methodology (e.g. qualitative or quantitative); the evidence/data used (e.g. case study-based or theoretical / methodological discussions); and in their disciplinary origins (e.g. economics, architecture, heritage, etc.). Despite this, they all focus on correlating dimensions of 'quality' and 'value', two concepts that are now 
unpacked further in order to establish lessons useful to explore the relationship between street improvements and place-based value.

\subsection{Place-based quality}

The trouble with the many studies that focus on specific elements or qualities of the built environment in isolation is that they present a rather fragmented or partial picture of a complex phenomena. The counter argument is that this narrow focus offers the opportunity to isolate the affect of particular elements and is therefore often the preferred approach when trying to make the case for investment in particular types of improvements (e.g. walkability or conservation initiatives) or when testing the application of specific econometric models (e.g. Ahlfeldt \& Mastro 2012; Ahlfeldt \& Holman 2015; Cho et al. 2008). However, when the concern is with the public realm at large, this fragmentation contrasts with the multi-faceted nature of both urban design interventions and the urban areas themselves, as well as with the potential value added by improvements: "the value people will place upon [an urban] environment will depend not so much on any one element but upon the relationship of these elements to each other - the whole realm of urban design" (The Young Foundation and UCL 2006b:14).

What is important is not a theoretical examination of what 'place' or urban design is, but rather of what constitutes a quality place, i.e. what kind of qualities are hypothesised to be desirable in an urban area. When considering urban realm improvements, the chosen definition of quality is therefore particularly relevant but also poses a series of questions reflecting the sorts of challenges already touched upon, namely how to treat the different perceptions of different stakeholders; how to make objective judgments of quality based on measurable attributes; and whether to focus solely on outcomes of design or whether the process of getting to the outcomes is also important (Carmona et al. 2001: 14-24). Moreover, in this sort of research the relationship between those questions is not a linear one (going from definitions to indicators, for example), but rather one of interdependence. Consequently the discussion around what can be measured or observed and how needs to run in parallel to, not after, the one on the nature of 'good urban space'.

\section{Defining quality attributes}

The logic that most value of design studies follow is to establish the presence of a set of (environmental) features and then relate this presence to economic trends in the area. When the focus is relatively narrow, as in the case of green spaces, for example, this can be done by simply measuring the number of those elements and/or their proximity to, say, residential areas. The same holds true when the focus is a bit wider but based on pre-defined parameters, as in the work of Song \& Knaap (2003) who examine the value added by the adoption of New Urbanist principles in urban neighbourhoods. Elsewhere some assessment of quality is needed to specify what exactly will be analysed against economic measures. To define what they take to be "good office building design", for instance, Vandell and Lane (1989) employed a panel of architects that evaluated the features of each of their case studies. But this "expert opinion" approach is less suited to urban environments, much less the street 
environment, as the qualities of such places do not clearly belong to the jurisdiction of any single discipline, and, as noted above, perceptions of good urban space will vary significantly for different stakeholders (Carmona et al. 2002).

The complex nature of urban space and its impacts is both a strength and a potential weakness for value of design studies seeking to establish cause-and-effect relationships. Thus while the overarching framework should ideally reflect the complex nature of the contexts being examined, trying to simultaneously account for all the physical and social aspects in the analytical phase can lead to a lack of focus. To that end some authors propose that emphasis should be placed on only the more tangible physical characteristics and spatial relationships (Australian Ministry for the Environment 2005: 7).

There have been some attempts at creating comprehensive models of analysis, primarily under the Space Syntax theory and its notion of 'accessibility', measured on the basis of the urban grid layout (Chiaradia et al. 2008; Webster 2010). Here, accessibility is taken as an all-encompassing indicator, simultaneously referring to spatial, social and economic dimensions; yet the complexity of the underlying theory in these cases makes it very hard to understand what exactly is measured and what is not. It is also not very clear whether and how this measure can be adapted to a micro-level analysis of detailed street design.

\section{Context-specific evaluations}

Instead, the approach taken in most case study based research is one of 'checklists': sets of indicators that can be measured or codified so that a particular space is assigned some form of score that can be used in comparative analyses. The possible variations of such checklists can be practically endless (Southworth 2003; Clifton et al. 2008) and indeed each past study seems to have formulated their own. What is important to note, however, is that each of these variations is largely context-specific: metrics are specified to evaluate improvements against the goals set in a particular city (e.g. NYC Department of Transportation 2012) or the general priorities for urban development in a particular context (e.g. Savills 2007 on sustainable growth as understood in the UK). While this may limit the potential for generalisation of findings, building on previously developed work in the context of case studies does create a coherent link between the way place quality is framed and the specific metrics used for the evaluation of interventions. The clearer this link is, the easier it will be to acknowledge and even counteract the inevitable degree of bias inherent in the way indicators are chosen.

To give an example, an intervention aimed at improving cycling routes may score high in metrics designed from the standpoint of the pedestrian / cyclist, but have negative impacts on other groups such as car users (see Stantec Consulting Ltd. 2011) (Figure 4). Having a broad holistic, but also context-specific framework linked to analytical and objective metrics allows for the same data to be read from different perspectives, aided by subjective inputs collected within the same framework but outside the metrics themselves. 


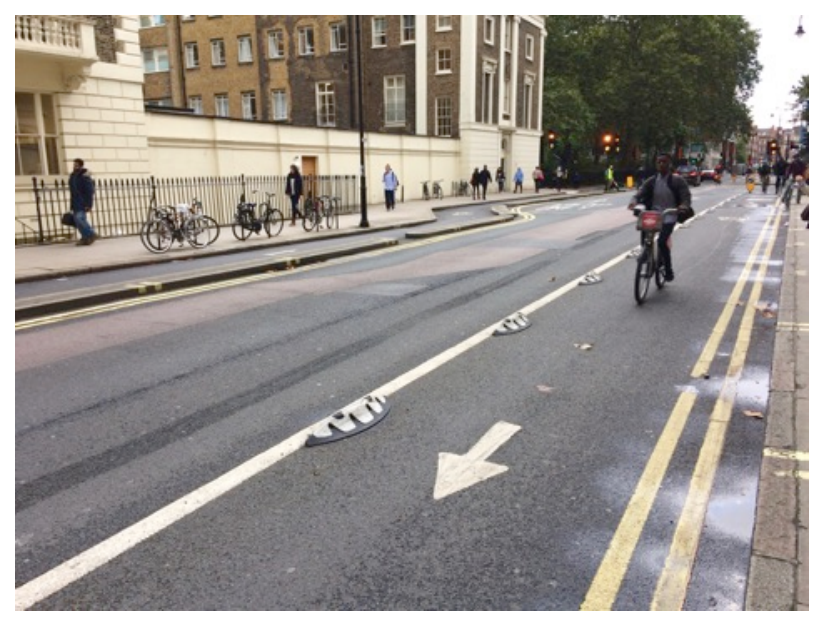

Figure 4: New cycle lanes in Bloomsbury, London, have been added following the removal of vehicle lanes (Matthew Carmona)

\subsection{Place-based value}

The discussion around the value of urban interventions follows a similar pattern to that around the quality of place. While a common approach, particularly in the economics focused papers, is to consider narrow definitions of exchange value for specific types of property (primarily residential, with some work on office and retail), case study-based research focusing on the public realm has tried to incorporate different sorts of value. This encompasses both exchange and use value with direct monetary benefits as well as more intangible, indirect forms of value (Chee Keng Lee et al 2015). Again the conceptual and practical questions run in parallel so that it is not just a case of defining what value is, but also relating that to what can be measured and what kind of data is available. Again, it seems, contextspecific methodological approaches are the best answer to the conceptual complexities.

\section{Tangible and intangible value}

On the more theoretical side, one key debate in the literature revolves around the 'optimal' definition of value in urban realm improvements. Henneberry et al. (2010) recognise the existence of varied sorts of value: social, economic and environmental, accruing to a range of actors over both the short and long-term. They then go on to argue against adopting such wide definitions in value of design studies for the simple reason that "most of these various streams of value are not captured by the developer" Henneberry et al. (2011: 221). Less directly, other authors too adopt the argument that the value of good place design lies first and foremost in the added monetary benefits it can create for the developer (Tiesdell \& Adams 2011), proposing that those can then be redirected towards the provision of public goods (Hack \& Sagalyn 2011).

This is a view that looks at urban design as part of the private development process and, perhaps because of that, contrasts with studies that place their focus on the design of the public realm, not as a by-product of development but in its own right. The latter treat the quality of place (and its design) as a 'public good', therefore turning their attention to questions of externalities and ways of pricing non-market benefits. That approach necessitates a wider framework, capturing all those different, not directly measurable sorts of value (Figure 5). 


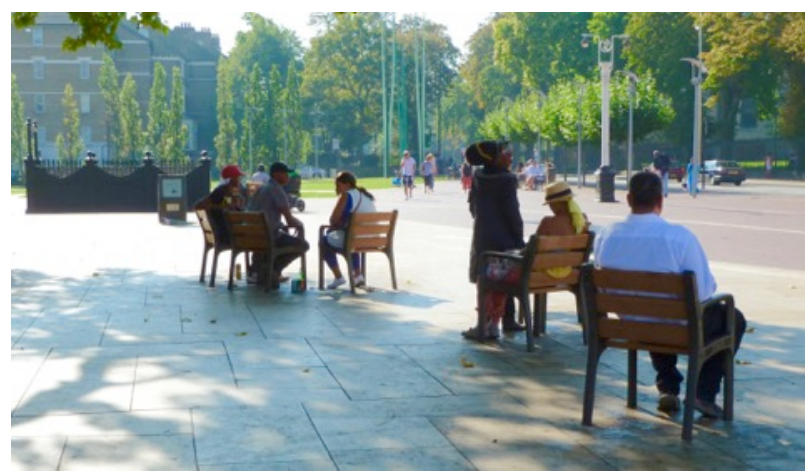

Figure 5: Not every sort of value is directly measurable, such as the value of somewhere to rest and contemplate, Brixton, London (Matthew Carmona)

framework to include tangible as well as intangible benefits is b oth a strength and a potential weakness. On the one hand, it can cause a degree of confusion in focus and significant conceptual challenges, as most of these benefits are hard to define, measure and assess. Yet a wider framework more accurately accounts for a reality where all these impacts are interrelated (ECOTEC 2007: 39) and provides a greater flexibility to select the correct parameters that need to be included, or controlled for, in the analysis.

\section{Market vs. non-market value}

Methodologically, a primary distinction that is usually made is between qualitative and quantitative studies. Qualitative design value studies are defined as those that look at the value of urban design as perceived by a range of stakeholders (e.g. DoE \& RICS 1996; Carmona et al. 2002). By contrast quantitative ones try to translate the quality of the urban realm into monetary values. This distinction can be initially useful to broadly categorise the literature, with most of the research reviewed here belonging to the latter camp. In practice, however, the methodologies followed in value of design studies, particularly case study-based ones, tend to be mixed. Thus qualitative data and observations are used to both define factors entering the quantitative analysis and to interpret results and vice versa. This recognises the complexity of the various dimensions of value (tangible and intangible) and factors influencing the economic performance of urban areas.

In more practical terms, there is a range of methods that can be used to assess value in the context of street design, and within those an even greater range of possible indicators to be considered. Valuing non-market goods often takes the indirect route of examining people's preference (McConnell \& Walls 2005), either stated (willingness to pay for those goods) or revealed (assuming they are in fact implicitly traded in sectors of the market). One exception is a report by CABE Space (2009) that proposed a variation of the asset management accounting method to assign value to parks, calculating how much it would cost to recreate them from scratch. However it is difficult to imagine how that approach could be applied to streetscape improvements, and how useful it would be given that most are already here and are consequently 'sunk costs' that no longer feature in decision-making (public or private).

Beyond that exception, the general idea is that if the urban realm is a public good then it should be assessed in terms of 'public value' whereby "it is the public who 
determine what is valuable - rather than professional economists advising government" (The Young Foundation and UCL 2006b: 16). The question then becomes how does the public show what is valued and how to gauge that, hence the stated/revealed preference models.

Another review by The Young Foundation and UCL (2006a) provides a detailed examination of valuation methods spanning the economic, environmental, and social dimensions of value, including preference models under the general term of 'environmental economics'. These are considered the most relevant for the current study since they deal with completed schemes and real world impacts rather than with future development options, in other words a revealed preference model roughly along the lines of hedonic pricing. In research commissioned by Transport for London ( $T f L)$, hedonic pricing has been used to determine the private benefits of the urban realm by incorporating PERS (Pedestrian Environment Review System²) scores associated with the quality of the street on which a property is situated into a hedonic price function (Sheldon et al 2010).

\section{Pragmatic context-specific methodologies}

From this point on, however, the literature shows wide variations similar to those encountered when looking at ways to quantify place-based qualities. Thus each case study-based project presents, first, a different set of indicators, often with a very wide initial range that was subsequently limited to fit data availability, and, second, custom-made ways of linking those to design to produce findings (see for example the methodological sections of CABE Space 2007; CABE Space 2009; NYC DoT 2013, among others).

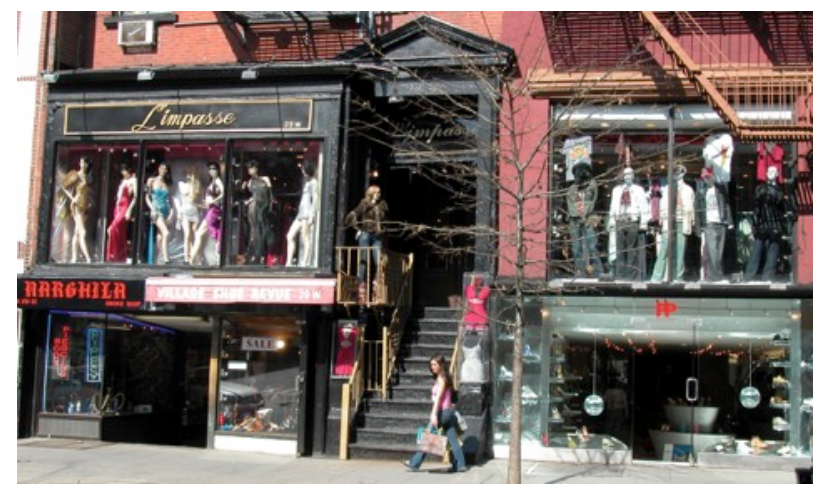

Figure 6: The New York study used retail sales data to trace the value added by urban interventions. These were filtered so that the selection of business was limited to locally based "mom-and-pop" stores and independently operated franchises (Matthew Carmona)

These variations again point to context-specific solutions. Thus, in principle, there is no particular theoretical reason why the CABE Space (2007) Paved with Gold study, used retail rents and house prices while The Economic Benefits of Sustainable Streets (NYC DoT 2013) study focused on retail sales tax data, or indeed for the various further filters that the latter study applied to its original dataset (Figure 6). In practice, of course, it was local knowledge of the market structure and the type of objective third-party data that was available, juxtaposed with on-the-ground observations, that enabled the researchers to judge which data best described the

\footnotetext{
${ }^{2}$ PERS is Transport for London's walking audit tool, see: http://content.tfl.gov.uk/pedestrian-environment-reviewsystem-factsheet.pdf
} 
actual situation (or was simply readily available to use). On a higher level, the same goes for methodological choices. Thus within a wide 'value of design' framework as outlined above, it is the specifics of the selected case studies that guide the balance between, say, property values and user feedback, or the way metrics are weighted in a multi-criteria analysis. 


\subsection{Researching the value of street improvements}

At this point it is interesting to note that each of the studies citied so far have been able to demonstrate tangible links between higher place/design quality and added value, either directly or in a couple of cases (CABE 2006; Carmona et al. 2001) by also taking the reverse route and highlighting the costs of bad design. However, the discussion has deliberately not engaged with specific findings expressed in numbers and percentages, rather turning its attention to the frameworks under which those were produced and their potential for the current study. In this context the case study based methodologies that underpin many of the studies have been able to successfully offer the necessary insights and methodological prototypes required to also underpin the current study.

\subsection{A mixed comparative methodology}

Moving forwards, a key issue that has been discussed concerns the challenge of balancing wide frameworks against an analysis with a narrower focus. For research based on case studies there is a need to have multi-layered definitions of both place and value, while at the same time actual data collection and analysis inevitably needs to be narrowed down to a more manageable scope, to reflect data availability, time restrictions and so on. That points towards a mixed methods model where the accuracy of description for each of the case studies takes priority over methodological purity. Without sacrificing consistency and robustness, a mix of qualitative and quantitative data can be used in a framework that best accounts for the reality of urban streets, in this case London's.

Finally some factors of the framework are variables to be controlled for rather than measured, and this holds true both for quality aspects as well as for value ones. In practical terms this means that there is a need for comparative analysis of case studies both against wider reference areas and similar sites. Reference areas offer the opportunity to control for larger economic trends, while similar sites compare for all the factors other than design that can influence economic performance. No comparison will be perfect but, building upon the two previous points, it is important to note that in value of design studies absolute numbers do not mean much. Instead it is relational measures that can best capture the value impacts of an intervention.

Reflecting on the discussion above, and in an attempt to address head-on the considerable conceptual and practical challenges that the literature review reveals are associated with value of design studies (see Table 1), a mixed comparative methodology was adopted. Whilst it is difficult to entirely overcome the conceptual and practical challenges associated with this sort of research, the aim was to sufficiently overcome them in order to deliver robust and testable results. The starting point to achieve this was to develop a rigorous research methodology. 


\section{Challenges}

Challenges in understanding place-based impacts

\section{Challenges in capturing changes to value}

Challenges in establishing causal links between intervention and impacts

Challenges in making tradeoffs between types of value

Ascribing value to intangible qualities

\section{Challenges in} selecting dimensions and indicators of value

\section{Explanation of the challenges}

Even if value is reliably measured in one location, it does not follow that similar interventions elsewhere will drive the same benefits or dis-benefits. Urban areas are hugely varied and complex and understanding the local dynamics underpinning change is necessary in order to properly interpret the evidence. Marylebone High Street in London, for example, is much discussed as a particularly successful shopping street, but its qualities flow from a combination of unique locational, ownership, catchment, accessibility, physical and social factors. Variations in any one of these may lead to a very different account of value.

Impacts from interventions in the built environment take time to materialise and/or settle down after the disruption caused by construction. This means that methods that examine only a single point in time (postintervention) are likely to be problematic. Ideally a longitudinal element should be included in the analysis, for example, measuring how space is used before and after intervention.

There are also problems of ascribing changes in value to particular interventions. The fact that a shop opens or closes or does better or worse, for example, could be related to changes to the street environment and how these encourage or discourage shoppers. Equally it may simply reflect changes in the larger economic environment, to shopping catchments (e.g. more housing built close by), or simply better management within the shop.

There are many different sorts of value and a completely comprehensive view of the impact of a street intervention would need to capture and compare each of them. Practically this raises issues concerning how any one method can deal with this complexity, for example, capturing impacts relating to changes to retail custom, changes to traffic flow, changes to the social environment (more or less convivial) and changes to property values. They are each different things and impact differently on different people.

Traditionally we measure value in monetary terms which is how decisions about the future benefits of street projects are typically evaluated (e.g. via CBA) but many benefits of street improvements are unlikely to be directly measurable in such terms: the intangible benefit of a more convivial walk to the shops, for example, or the psychological and social benefits from increased walking which a better street environment might encourage?

A final issue concerns what sorts of value is included in assessments and what is excluded. In any one street different forms of economic, social, environmental, health, cultural, and aesthetic value can be captured and accounted for, and against each of these numerous subcategories can be chosen. By selecting indicators of value, judgments are being made about what is important and what is not, or pragmatically, about what is easy to measure and what is not. The danger is that the selection of indicators may only tell a partial story.

\section{Overcoming the challenges}

Detailed case studies can be a particularly effective means of getting under the skin of such factors in order to interpret them. Conducting sufficient numbers of contrasting case studies (e.g. reflecting different socio-economic contexts) can help to reveal the degree to which findings can be generalised beyond individual cases.

Practically, because this requires long study periods in order to gather the necessary data, the longitudinal element may need to be limited to available data that spans the intervention period. In London this includes key property and traffic data.

Examining and comparing streets that are, as far as possible, similar in all respects with the exception of the street improvements can help to overcome this. In effect the approach adopts a control-based experimental technique in order to discount non-intervention related effects.

This implies that multiple forms of data and methods for its analysis may be required to comprehensively understand the impact of interventions. Ultimately the need is not to make trade-offs at all, but instead to capture as many diverse forms of value as possible in order that a full understanding can be gained.

The adoption of combined qualitative and quantitative methods has the potential to help here, both to capture the diverse forms of tangible and intangible evidence, but also to assist in interpretation, one of the other.

\section{Adoption of a broad holistic} framework against which to structure the types of evidence gathered against a comprehensive account of the dimensions of value can help to overcome this. Indicators can be selected in order to avoid (as far as possible) a misrepresentation of (or partial accounting for) the impact of street interventions.

Table 1: The conceptual and practical challenges of value of design studies and how they were overcome 
This focussed on a common analytical structure bringing together diverse data in order to compare the impact of street improvements across comparative pairs of cases. It encompassed: longitudinal econometric and transport data, a holistic range of street qualities and forms of value, the combining of qualitative and quantitative evidence, and the selection, for analysis, of street segments from a range of different socio-economic and physical contexts across London. The key features are described below.

\subsubsection{Pairwise comparisons}

The use of paired schemes to explore questions of value and design has a long history and was first used to conduct research on the Value of Urban Design for CABE (2000) and more recently to measure the Economic Benefits of Sustainable Streets in New York (NYC DoT 2012). The method poses significant challenges but in the absence of transaction and other data gathered over an extended timeframe for many locations, pairwise comparisons provides a robust alternative means to track the impact of design interventions (good against bad, or intervention against no intervention) in comparable locations. The key, in this methodology, is to ensure that paired cases are as similar as possible (physically and socio-economically), with the exception of the intervention; the impact of which can then be measured. Comparators will never be perfect, and results will always need careful interpretation, but the more similar they can be, the more legitimate the comparison is likely to be.

\begin{tabular}{|c|c|c|c|c|c|c|}
\hline Pair & Case & Borough & $\begin{array}{l}\text { Improvement } \\
\text { completion } \\
\text { date }\end{array}$ & $\begin{array}{l}\text { Median } \\
\text { household } \\
\text { income 2012/13, } \\
\text { Ward / Borough } \\
\text { (London: } 39,110 \text { ) }\end{array}$ & $\begin{array}{l}\text { Employment } \\
\text { Rate } 2011 \\
\text { Ward / } \\
\text { Borough } \\
\text { (London: 69.2) }\end{array}$ & $\begin{array}{l}\text { Well-being } \\
\text { score, } \\
2013 \\
\text { Ward }\end{array}$ \\
\hline \multirow[t]{2}{*}{01} & $\begin{array}{l}\text { Bromley (North } \\
\text { Village) }\end{array}$ & Bromley & 2014 & $43,460 / 43,060$ & $78,6 / 74.4$ & High (+ 6.71) \\
\hline & $\begin{array}{l}\text { Orpington } \\
\text { (Town Centre) }\end{array}$ & Bromley & - & $38,090 / 43,060$ & $72.8 / 74.4$ & $\begin{array}{l}\text { Average (- } \\
0.26)\end{array}$ \\
\hline \multirow[t]{2}{*}{02} & $\begin{array}{l}\text { Hornchurch } \\
\text { (Town Centre) }\end{array}$ & Havering & 2013 & $38,130 / 36,670$ & $76.1 / 72.8$ & $\begin{array}{l}\text { Average (+ } \\
2.52)\end{array}$ \\
\hline & $\begin{array}{l}\text { Upminster } \\
\text { (Town Centre) }\end{array}$ & Havering & - & $47,580 / 36,670$ & $76.4 / 72.8$ & High (+ 7.04) \\
\hline \multirow[t]{2}{*}{03} & $\begin{array}{l}\text { Clapham (Old } \\
\text { Town / Venn } \\
\text { Street) }\end{array}$ & Lambeth & $\begin{array}{l}2011 \text { (Venn } \\
\text { Street) / } 2014 \\
\text { (Old Town) }\end{array}$ & 44,960 / 38,490 & $80.0 / 72.9$ & Low (- 5.25) \\
\hline & $\begin{array}{l}\text { Camberwell } \\
\text { (Camberwell } \\
\text { Green) }\end{array}$ & Southwark & - & $31,840 / 37,100$ & $64.6 / 68.3$ & Low (- 6.58) \\
\hline \multirow[t]{2}{*}{04} & $\begin{array}{l}\text { Woolwich (Town } \\
\text { Centre) }\end{array}$ & Greenwich & $\begin{array}{l}2008-2012 \text { for } \\
\text { various sub- } \\
\text { areas }\end{array}$ & $33,540 / 35,350$ & $64.7 / 66.8$ & Low $(-7.20)$ \\
\hline & $\begin{array}{l}\text { Catford (Town } \\
\text { Centre) }\end{array}$ & Lewisham & - & $34,670 / 35,900$ & $66.2 / 69.4$ & Low (- 3.96) \\
\hline \multirow[t]{2}{*}{05} & $\begin{array}{l}\text { Walworth } \\
\text { (Walworth Road) }\end{array}$ & Southwark & 2008 & $34,190 / 37,100$ & $66.3 / 68.3$ & Low (- 5.43) \\
\hline & $\begin{array}{l}\text { East Greenwich } \\
\text { (Trafalgar Road) }\end{array}$ & Greenwich & - & $41,840 / 35,350$ & 74.2 / 66.8 & $\begin{array}{l}\text { Average (+ } \\
0.85)\end{array}$ \\
\hline
\end{tabular}

Table 2: Improved streets and their comparators 
In this research five pairs of case studies (ten cases in total) were selected (Table 2). In each pair one case featured a recent $T f L$ funded streetscape intervention classified as significant in TfL's $(2013 ; 2016)^{3}$ own scale of street intervention; in other words that typically involved recreating the public realm, rethinking traffic management, relocating and/or merging street functions, and general tidying up and de-cluttering. This scale of intervention was considered significant enough to generate an impact that was clearly measurable.

Each pair consisted of two mixed-use local 'high street' environments, chosen to represent different geographic localities across London, although a completely free choice from the many improvement schemes now implemented in the city was impaired by the need to find strong comparators. Instead, data was examined on: the position of likely projects in the Greater London Authority (GLA) Town Centre Hierarchy (reflecting their importance as a retail / services location); the Public Transport Accessibility Level (PTAL) ${ }^{4}$ score (reflecting accessibility to public transport); the Street Type ${ }^{5}$ (reflecting TfL's assessment of the movement and place functions of the street); and a basket of socio-economic data from the Local Data Company (LDC) and London Data Store database including medium household income for 2012/13, employment and unemployment for 2011 and a well-beng score made up of a basket of local indicators collected by the GLA. An initial analysis of the office market in each areas using CoStar ${ }^{\mathrm{TM}}$ data was also conducted as an early indicator of the commonality between property markets.

\subsubsection{A holistic analytical framework}

Once selected, comparative analysis demanded the collection of suitable available data to represent both the quality and value aspects of street interventions. To overcome a key challenge encountered in previous value of design research, a holistic conceptualisation of the nature of streets was advanced. This extended the simple place / movement street typology already widely adopted in London (TfL 2016) into a four part framework that pulls 'place' apart into three further constituent functions of streets: as built fabric, for social/economic exchange and as real estate (Figure 7). This framework was developed and used in research examining the nature and development of London's high streets (Carmona 2015). Whilst it would be impossible to cover every impact stemming from large scale public realm improvements as they effect such complex streets environments, the framework's holistic nature was found to better represent the multi-layered complexities of such mixed urban streets and so was adopted for the current research.

\footnotetext{
${ }^{3}$ As an earlier scheme, Walworth Road was not included in these documents, but the interventions there were considered comparable.

${ }^{4}$ See: https://tfl.gov.uk/info-for/urban-planning-and-construction/planning-with-webcat/webcat?scenario=2021 (Forecast)\&Type $=$ PTAL

${ }^{5}$ All London streets are mapped according to TfL's nine-part movement / place matrix, see: https://tfl.gov.uk/infofor/boroughs/street-types?intcmp=24919 - on-this-page-0
} 


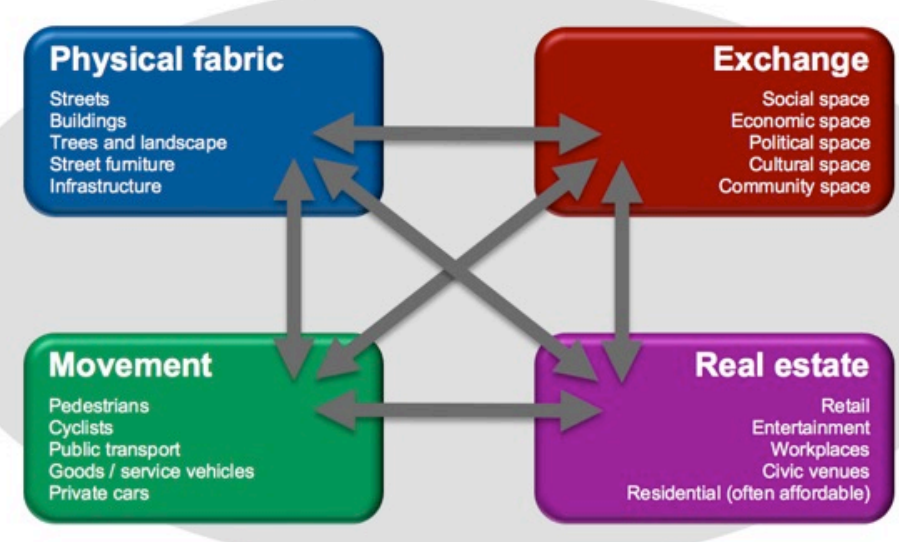

Figure 7: The four-part holistic framework for analysis

\subsubsection{Data selection, gathering and analysis}

The data selected was focussed on achieving an in-depth understanding of each dimension and the trends apparent in each case and across pairs as a consequence of investing (or not) in the street environment. The detail of the constituent analytical techniques and associated data requirements for each of the four street functions represented in the framework are discussed at the start of the sections that follow, but to summarise, Figure 8 shows the type of assessments adopted in each of the four dimensions and the quantitative and qualitative data utilised.

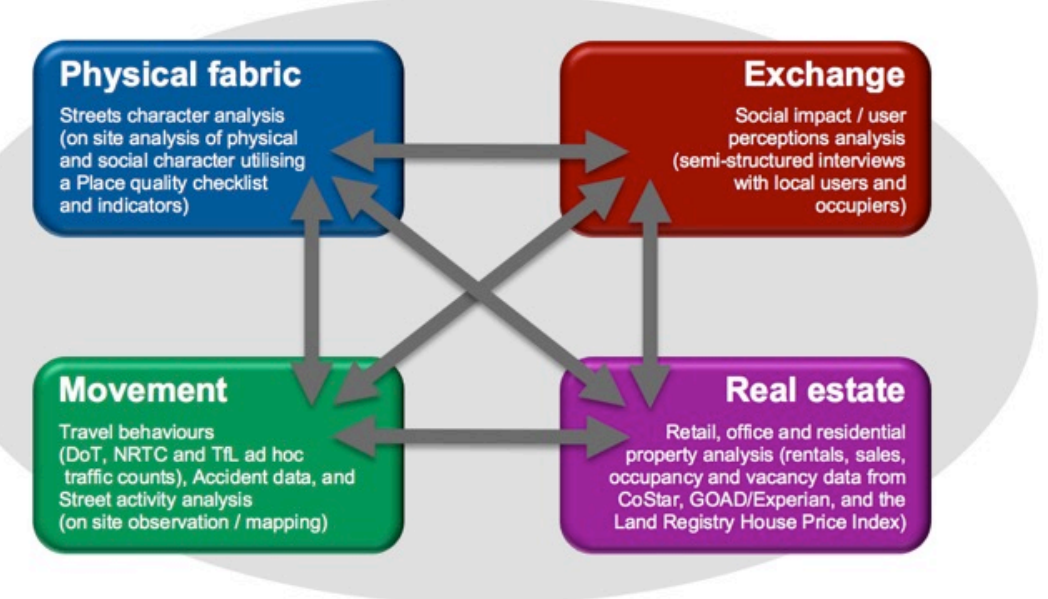

Figure 8: Types of assessment and data

Once the data had been gathered and analysed, both across the pairs and within the confines of each dimension of the analytical framework, a final task involved bringing the findings together from the constituent data series (physical fabric, movement, exchange and real estate) in order to understand them comparatively. In this process a full understanding of the quantitative data was enabled through its interpretation in the light of the qualitative evidence from the physical fabric and exchange quadrants of the adopted framework. 


\subsection{Ten mixed street environments}

The five improved street environments in Bromley, Hornchurch, Clapham, Woolwich and Walworth encompassed street environments in inner and outer London, in more and less prosperous parts of the city, and streets of varying accessibility and prominence as retail destinations (Figure 9). The bias towards south and east London reflects the availability of suitable pairs for comparison and was not considered significant in research terms given the observed similarities in such mixed high street environments across London (Carmona 2015). High street locations were selected in order to gauge the impact of the improvements on the fine grained mix of property types present in such areas and because these complex street environments are amongst the most important streets in the city if judged by their social and economic functions at the heart of communities across the metropolis. A brief description of the street improvements follows.

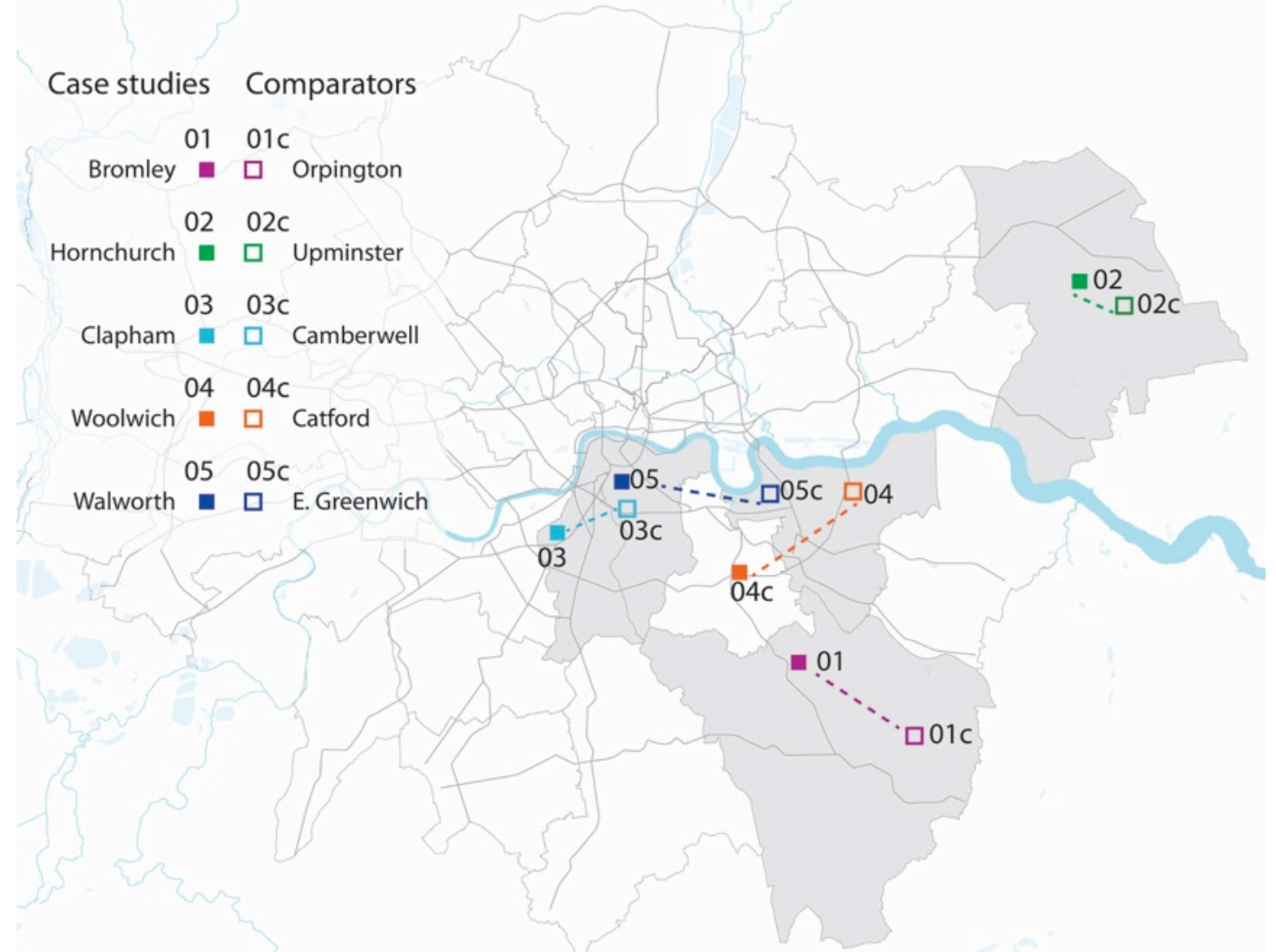

Figure 9: Location of the improved cases and their comparators

\subsubsection{Bromley}

As part of the Bromley Town Centre Area Action Plan, the improvement works in Bromley North Village aimed to create a more pedestrian-friendly leisure and shopping area and to better integrate the northern part of the High Street with the Market Square and an already pedestrianised part of the High Street leading to Bromley South. The scheme involved the re-routing of some local buses and the introduction of new paving, street furniture and improved pedestrian crossings in three main areas. 
First, East Street was repaved as a shared street surface, for the most part without kerbs, and with a single-lane allowance for traffic. Bus routes were transferred out of the street to free up space and give local restaurants/cafes more opportunity for outdoor seating. New greening and lighting elements were introduced (Figure 10a). Second, the same paving design covered the whole of the Market Square area around the small core of buildings and was integrated into the pedestrian area of central High Street. The redesign of Market Square also included new trees, lighting and seating elements (Figure 10b). Finally, better links were created between Market Square and High Street North, by using the same paving materials to improve the pavements on High Street and to provide multiple new level crossings to Market Square. The continuity of materials, the removal of railings and the addition of new street furniture at the northern edges of Market Square all work to give pedestrians priority over traffic (Figure 10c).

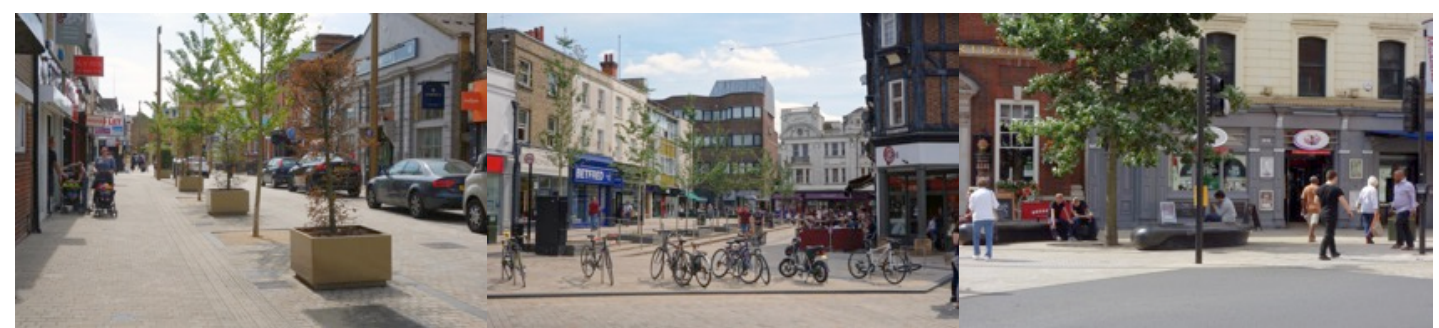

Figure 10a, b, c: Bromley street improvements

\subsubsection{Hornchurch}

Hornchurch is a district centre in the borough of Havering, a suburban area with a street network largely oriented towards motor traffic. Guardrails line the side of all key junctions and the pedestrian space is rarely inviting or attractive. Within this larger setting, the improvement works on the High Street focused on enhancing pedestrian accessibility and providing features to encourage more social uses of the space, beyond just passing through.

On the central part of the High Street, pavements were widened and traffic separated by a median strip with frequent raised crossings and distinctions in paving materials to provide implied priority to pedestrians throughout (Figure 11a \& b). Traffic flows at a $20 \mathrm{mph}$ limit and cyclists are intended to use the full lane, as there is no overtaking space (footways are kerbed except for at the crossings). The new street layout also features more trees, lighting and a range of street furniture (benches, bins etc.) with a consistent design across the High Street. These elements extend beyond the central part into the surrounding pavements, with the street furniture clustered mostly around bus stops and the new paving material gradually introduced onto the pre-existing road layout at the edges (Figure 11c). 


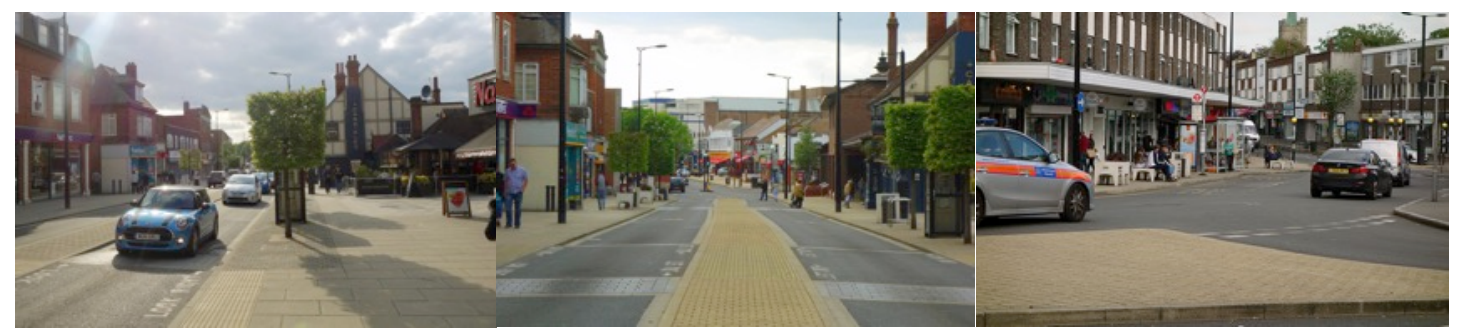

Figure 11a, b, c: Hornchurch street improvements

\subsubsection{Clapham}

The first intervention around the area of Clapham Old Town was the repaving of Venn Street into a level shared surface, with increased footway space while retaining limited car access and parking spaces (Figure 12a). The scheme included a shared maintenance agreement with businesses on the street who contribute largely through the renting of outdoor space. The works on Venn Street were completed in 2011 and received positive feedback from locals, prompting the launch of a wider plan for Clapham Old Town aimed at improving the connectivity and overall quality of the public realm.

The core of a second phase of improvements was around The Pavement where a cluster of bus stands used to occupy the majority of the space and vehicles generally dominated the public realm. The scheme limited the bus stands and removed the pre-existing gyratory, opening up a new small square. This space was designed with a range of greening and seating elements and was linked to the surrounding pedestrian network via improved crossings (Figure 12b \& c). The paths connecting the Old Town to Clapham Common and the High Street were also improved with widened pavements, new cycling provisions and renewed paving (Figure 12d).

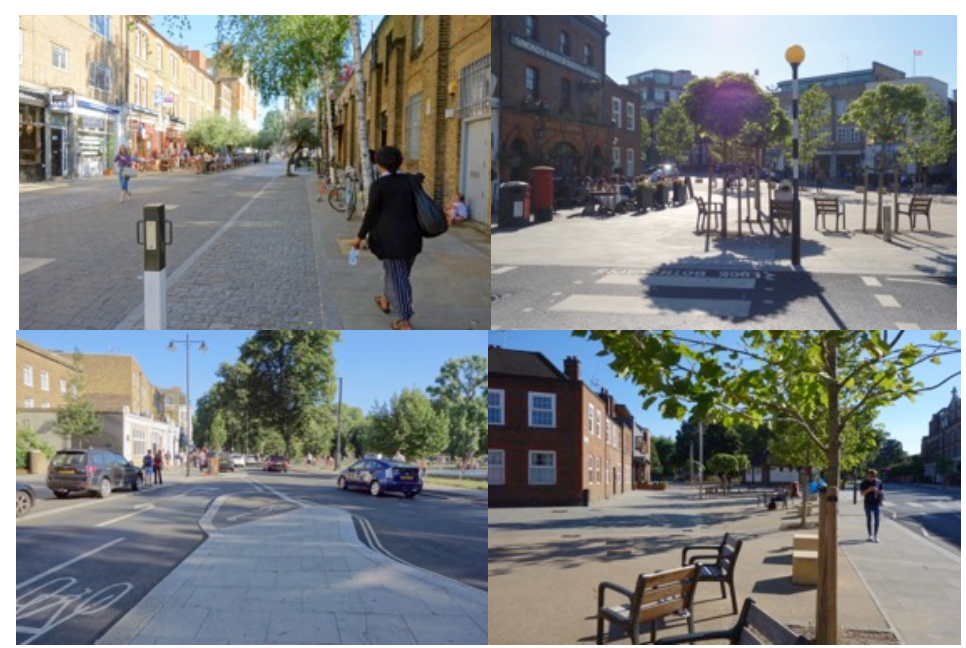

Figure 12a, b, c, d: Clapham street improvements

\subsubsection{Woolwich}

The regeneration of Woolwich Town Centre was a major scheme consisting of various interconnected sub-areas at the core of which was the design of General Gordon Square into a terraced park and the repaving of the market area in the adjacent Beresford Square into a large, pedestrian-only space (Figure 13a). The latter 
hosts street market stalls that extend south along Greens End, while General Gordon Square acts as the local centre and often hosts events and screenings (on the BBC Big Screen placed at the edge of the square) (Figure 13b).

Alongside, and to enable these, works were undertaken in the surrounding roads (Woolwich New Road, Plumstread Road, Thomas Street, Wellington Street) to rearrange bus circulation and improve pedestrian connectivity, especially around the DLR station. Bus stops were clustered together at the south and east sides of General Gordon Square, along Thomas Street and Woolwich New Road (Figure 13c), and the pedestrian space at Woolwich New Road / Plumstead Road was widened and fitted with new seating arrangements and street furniture (Figure 13d).

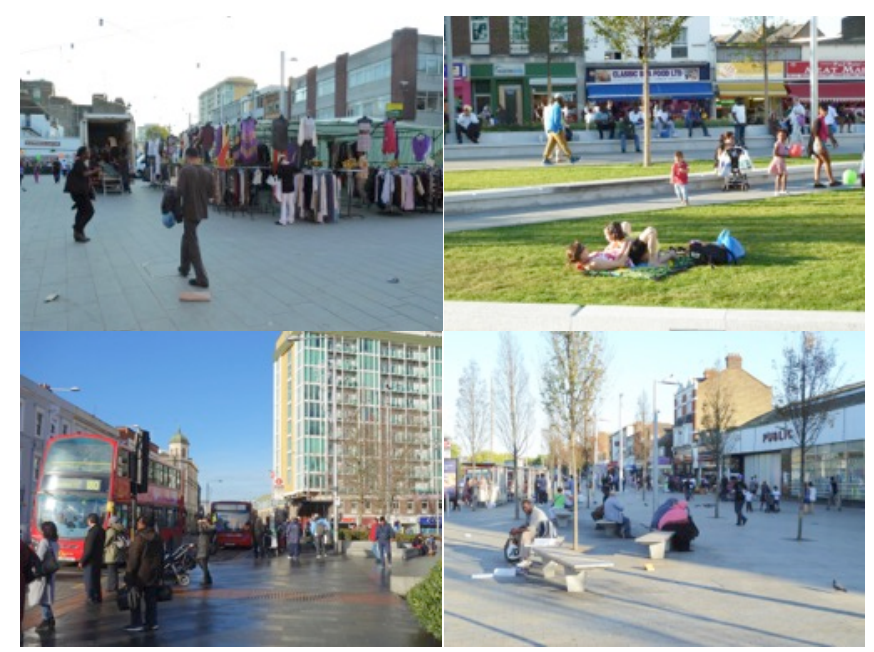

Figure 13a, b, c, d: Woolwich street improvements

\subsubsection{Walworth}

Walworth Road is a busy traffic corridor running south from Elephant \& Castle towards Camberwell, which used to be laid out as a wide dual carriageway with separate bus lanes along almost its entire length. It is also an important local high street with a range of businesses and a street market along East Street. Pedestrians were, for a long time, squeezed into narrow pavements at either side of the road and constrained by railings at all crossings. The road was generally congested and had high injury collision rates; many involving pedestrians and cyclists.

The redesign to address these problems aimed to improve the safety and comfort of pedestrian paths, while retaining the road's ability to accommodate the necessary volume of traffic. The traffic lanes were reduced in width and the bus lanes were removed, leaving only 'bus gates' at either end of the road (horizontal deflections via small islands that give buses priority over traffic - Figure 14a). This allowed the pavements to be significantly widened and opened up space for street furniture, as well as for dedicated loading bays and limited parking (Figure 14b). Attention was paid to the design of details such as kerb heights, paving materials and crossing islands along the length of the road, with slight differentiations to indicate changes in priority. The central part around the junction with East Street is now the most pedestrian-friendly, with more frequent and convenient crossings and more provision 
for seating (Figure 14c), while towards the edges of the intervention area priority is gradually returned to motor traffic.

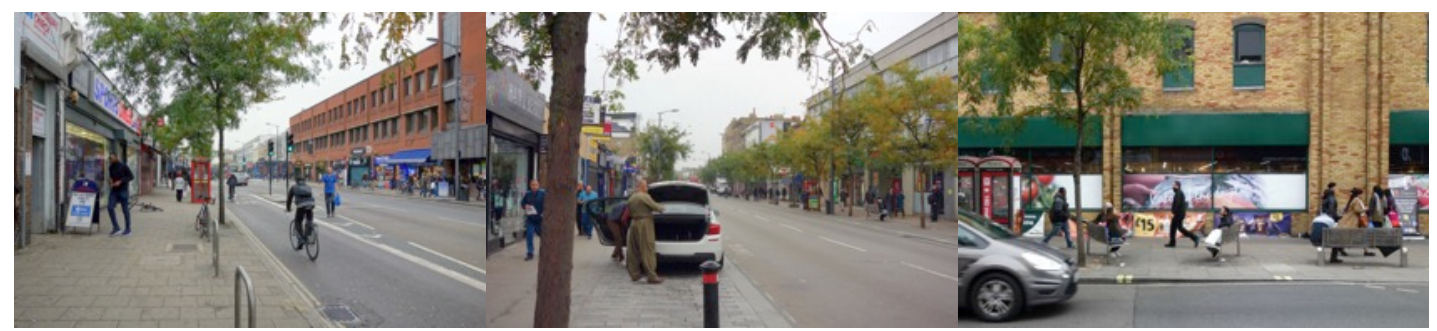

Figure 14a, b, c: Walworth street improvements

\subsubsection{The comparators}

For each improved street environment, a suitable location was chosen to act as the comparator for the analysis of the physical fabric, real estate and movement functions of the streets. Initial shortlists of potential comparators were compiled based on the range of GLA / TfL pre-existing classification tools relating to London's street network that have already explained. The final pairs were decided after also taking into account socio-economic indicators at ward and borough scales and initial testing with CoStar ${ }^{\mathrm{TM}}$ data to determine market comparability. The final selection making up ten street environments is shown in Figure 9, whilst the morphological character of the ten streets environments are compared in Figure 15. This shows that:
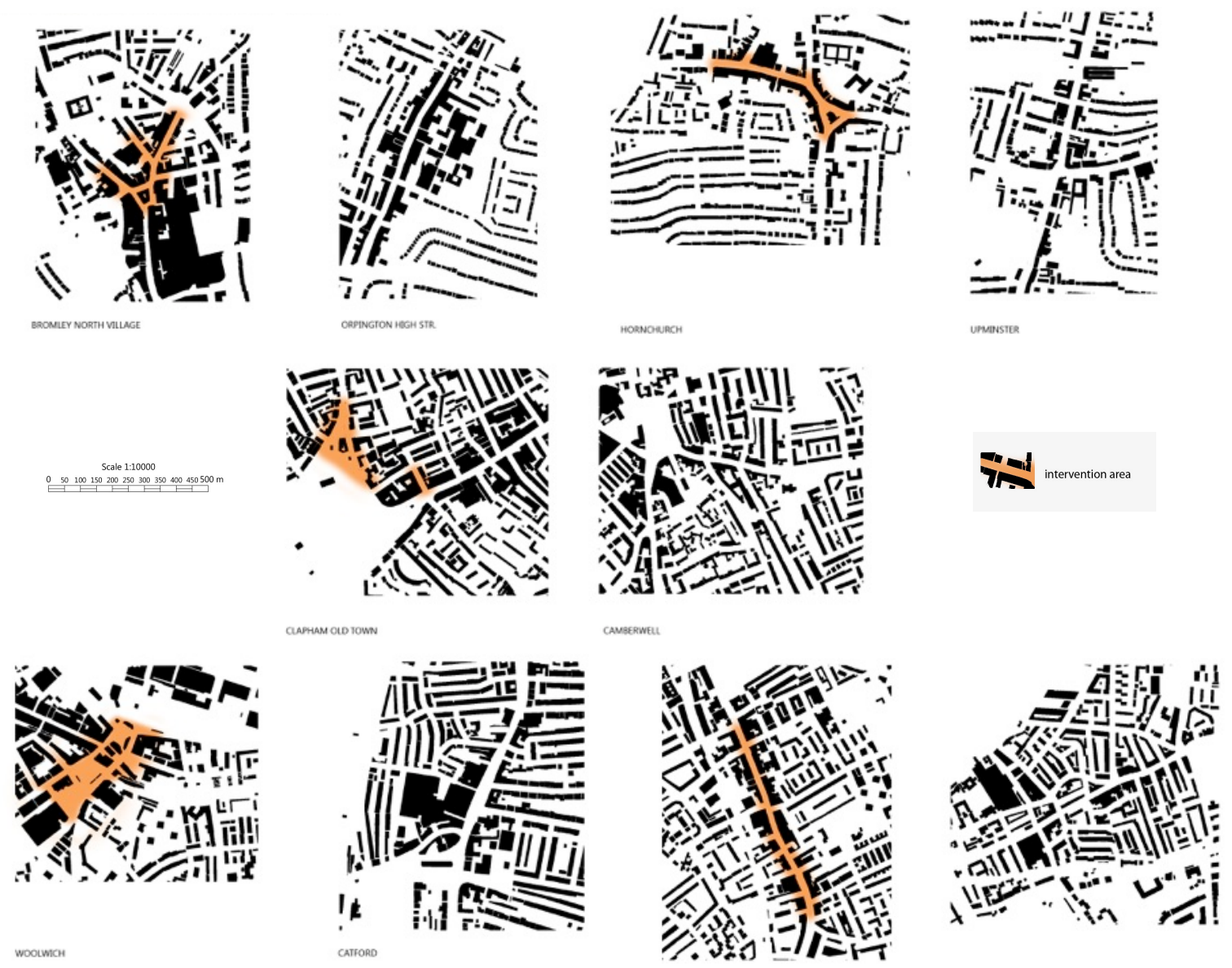

Figure 15: Figure / ground plans of the improved streets and their comparators 
- Bromley was compared with Orpington, an area focussed on the high Street which features a range of earlier, less comprehensive, street improvements

- Hornchurch was compared with Upminster focussed on Station Road

- Clapham was compared with Camberwell, the streets adjacent to Camberwell Green

- Woolwich was compared with Catford, the town centre adjacent to the Catford gyratory

- Walworth was compared with East Greenwich, focussed on Trafalgar Road

The comparators for the Outer London cases (Bromley and Hornchurch) were located within the same borough, while for the three Inner London cases, comparators were sought in neighbouring boroughs and in locations with similar positions in their wider area networks. The selection had less to do with physical proximity but instead with an effort to match the pairs in as many other ways as possible (Figure 16a, b, c, d, e).

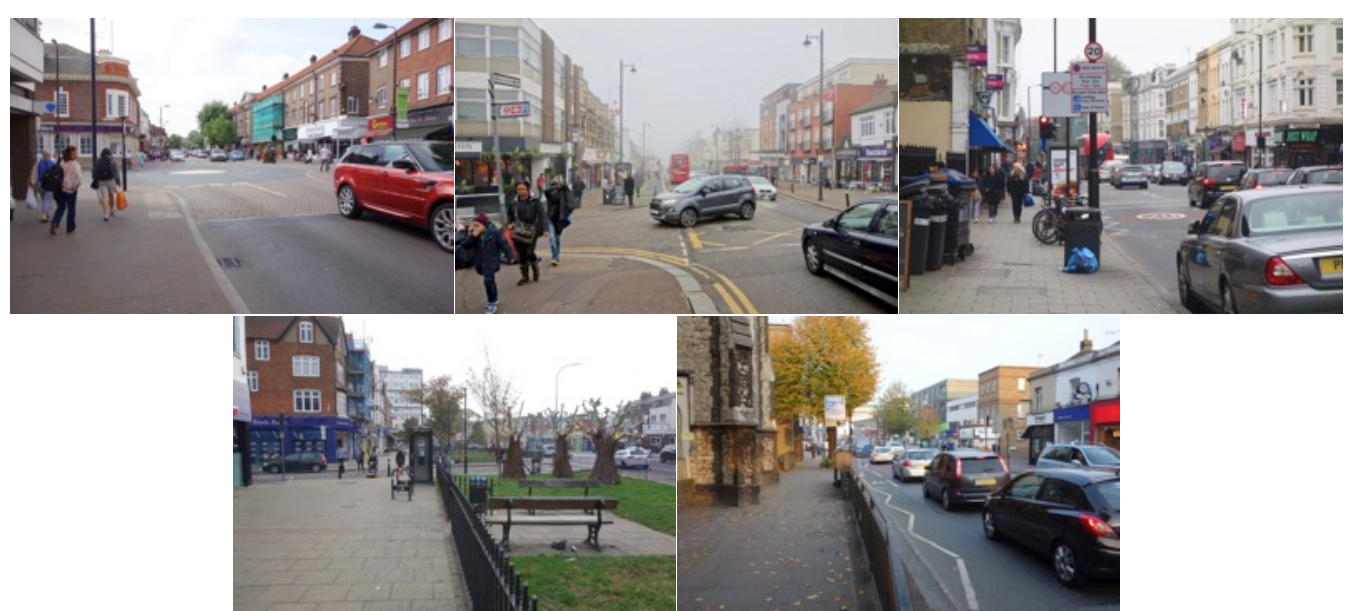

Figure 16: The comparators, Orpington (a), Upminster (b), Camberwell (c), Catford (d) and East Greenwich (e) 


\subsection{Physical fabric}

The analysis begins with the physical fabric because street improvements of the types being assessed by this research are made within the physical public realm. It is also there where any impacts are felt first. Of critical importance will be that the interventions are positive ones, in other words that they relate to and improve the physical context of which they are a part, but also that those physical impacts have knock on positive ramifications within the social realm by improving the experience of the space as a place to be and to use. Thus, in measuring this dimension of place quality, assessment is not purely physical, but includes aspects of the social public realm that is facilitated or impeded by the physical fabric.

\subsection{Physical fabric analysis}

Many approaches could have been adopted to measure the quality of the physical fabric in the ten cases and, as has previously been noted, variations on the potential checklists and indicators that might be chosen are potentially endless. Rather than inventing yet another tool to do the job, an existing tool, TfL's Healthy Streets Checklist, was instead adopted and modified. The framework for this is set out in Improving the Health of Londoners (TfL 2014) which utilises a ten part 'whole street' framework encompassing aspirations that streets: are easy to cross, and not too noisy; have clean air, shade and shelter, places to stop, things to see and do; are used by pedestrians from all walks of life; and are places that people chose to walk and cycle, feel safe, and feel relaxed. The checklist encompasses a set of indicators for each theme (or aspiration) and a scoring system with carefully calibrated parameters for each indicator.

Because the Healthy Streets Checklist had been devised to evaluate health with a particular focus on cycle and walking infrastructure, a range of modifications were made to the original checklist with two main goals. First, to simplify the indicators and make the scoring process more practical for use in the field, and second, to introduce a more holistic view of place quality that included aspects of street character and the physical adaptability of the street and its properties over time. To facilitate this some very technical indicators were omitted (e.g. aspects of noise and air pollution under an overarching category of environmental quality), some were merged, and some new ones were introduced to capture aspects of place beyond movement.

Overall, the modifications aimed to strike a better balance between the need for objective and measurable indicators, and the need to take into account aspects beyond merely technical concerns. This means that a degree of subjectivity is inherent in the resulting evaluations, but the approach is consistent across locations and works well for the purposes of comparative analysis. The operational logic of the $\mathrm{TfL}$ checklist was maintained so that the final result for each location is a spider chart representing how high the street scored across each of the ten revised themes: Easy to cross (a balance between pedestrian, cycle and vehicle users) 
- Shade and shelter (provided against the weather)

- Places to stop (to rest and for social interaction)

- People feel safe (against injury collisions and crime)

- Things to see and do (a range of activities)

- People feel relaxed (a sense of well-being and comfort)

- Pedestrians from all walks of life (a diverse mix of users)

- Environmental quality (greened and unpolluted)

- Place character (a distinctive and coherent character)

- Adaptability (capable of adapting to future demands)

Like the original tool, some indicators relating to cycling and walking were merged together and this carries the danger that the approach failed to capture the differential perceptions of the assessed streets from the perspective of the pedestrian and the cyclist. This was offset by the benefit of relative simplicity and ease of use which, field trials demonstrated, led to robust results in aggregate across each of the ten themes. The score for each theme is expressed as the percentage of the highest possible count calculated by combining the individual scores of the relevant indictors from the forty in the complete checklist, sorted into six crosscutting factors (safety, directness, coherence, comfort, attractiveness and adaptability). In this way, a single indicator can count towards more than one of the ten themes, if relevant. Each indicator can then be scored with 0, 1 or 2 following a set of predefined parameters for each score.

The assessments were conducted and scores generated in the field by a single researcher to avoid differential interpretation (between cases) and to ensure objectivity between the cases. Here it is important to acknowledge that the assessor was not blinded as regards the relative status of the streets (intervention versus comparator) and this may have lead to some inadvertent bias in scoring. Equally, given the very obvious differences between the streets with recent improvements and those without, this would have been impossible to overcome.

The results follow with each street improvement case presented alongside its comparator in the form of a spider chart within the ten point template. Each point is the percentage of the maximum possible score for the respective theme, calculated from the sum of scores for the indicators coded under that theme. Figure 17 shows the complete new Place quality checklist with all indicators (green column) and score parameters (blue columns), colour-coded against their respective themes (first columns from the left). Figure 18 shows the first few lines of the tool enlarged to show how indicators and scores were described. 

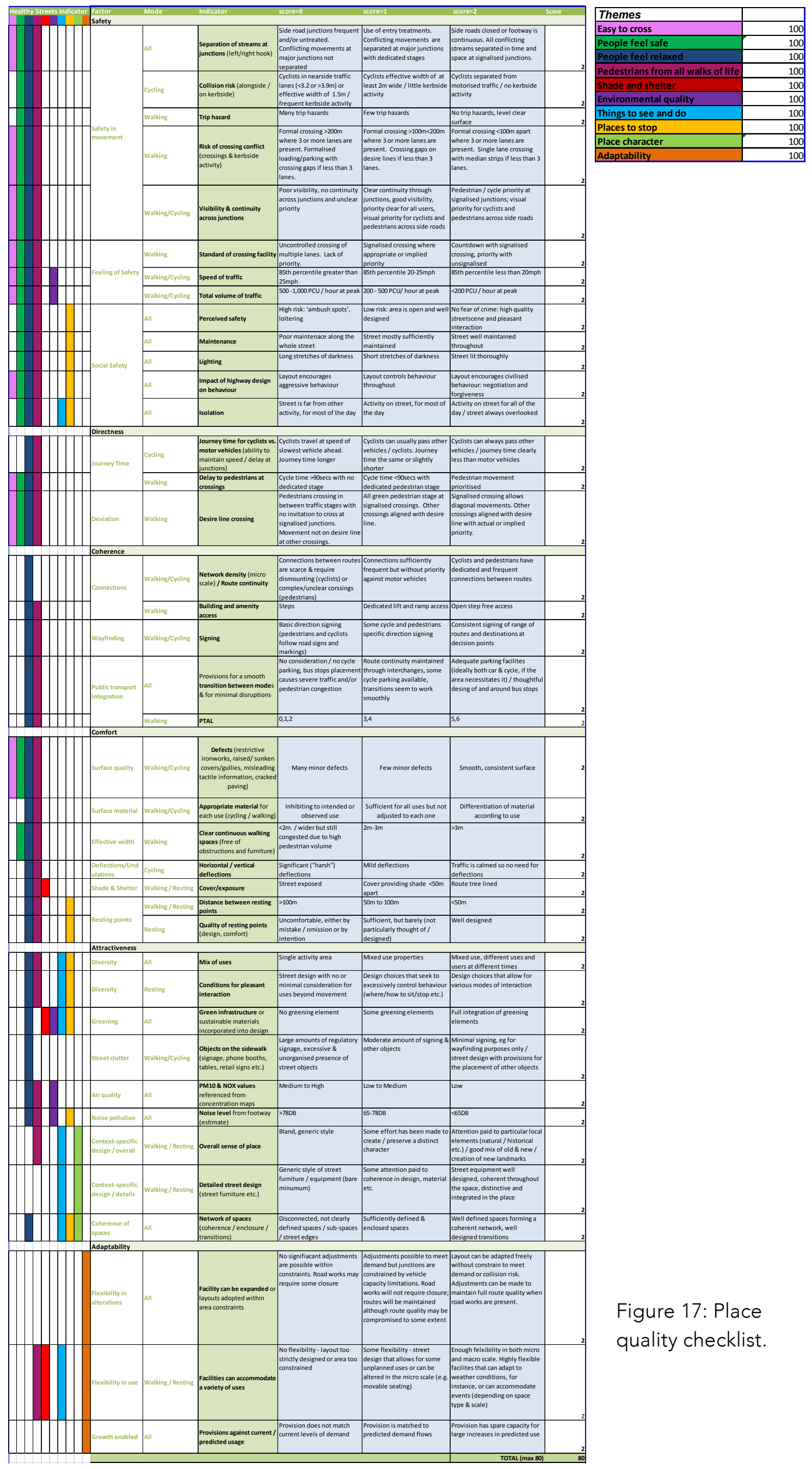

Figure 17: Place quality checklist. 


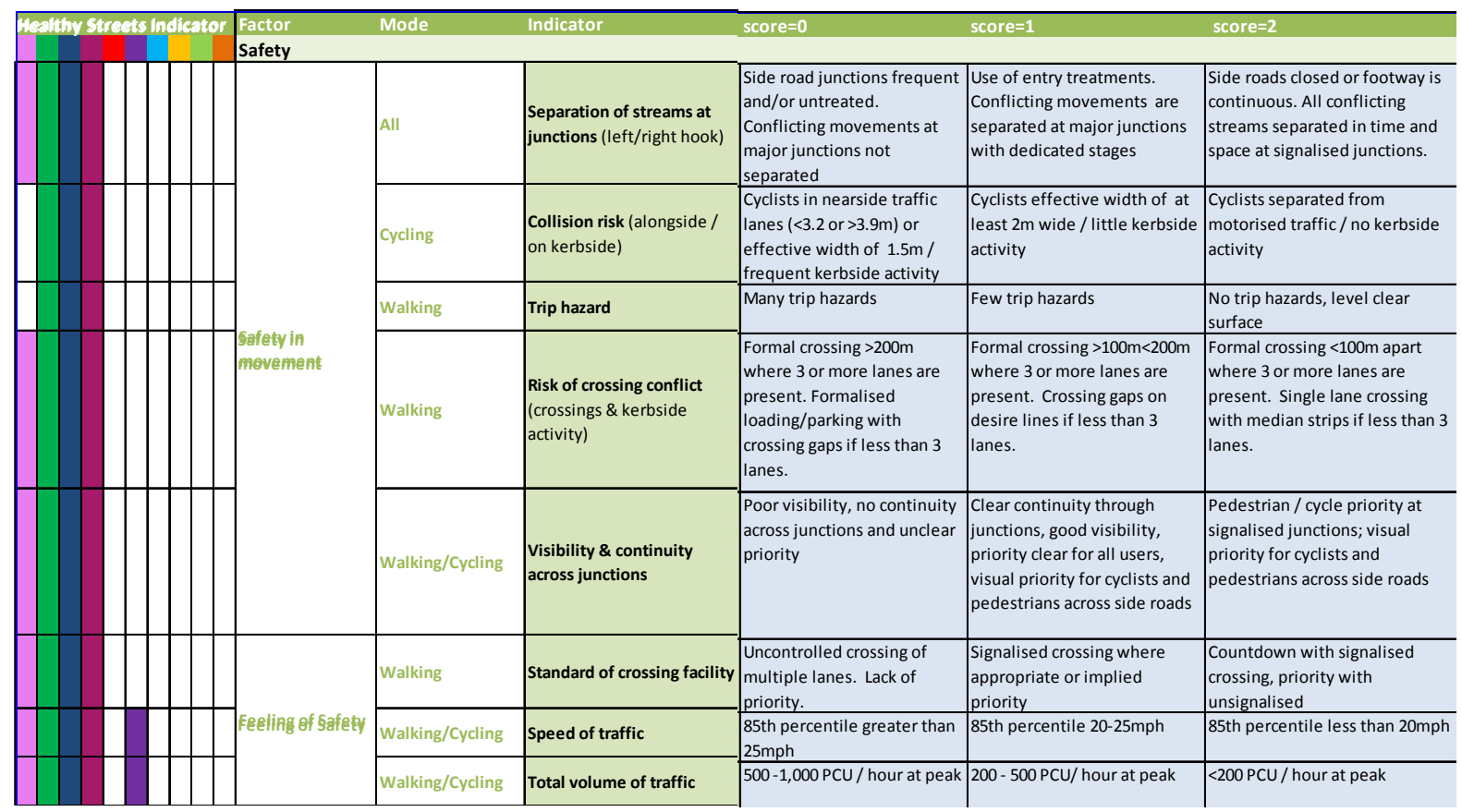

Figure 18: Enlarged extract and key from the Place quality checklist

\subsubsection{Bromley and Orpington}

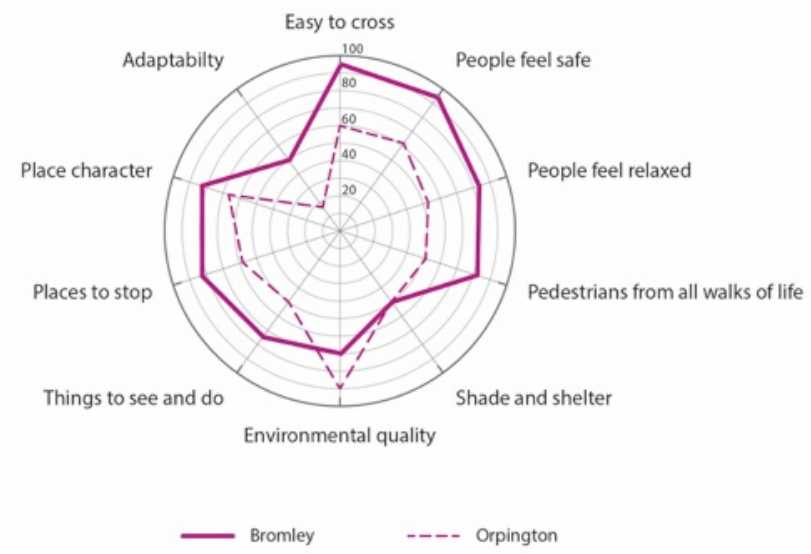

Figure 19: Bromley and Orpington place quality matrix

The analysis of Bromley North Village and Orpington High Street revealed a similar pattern of qualities, the main difference being the presence of more and better integrated green elements in Orpington which is still benefitting from an earlier suite of street improvements. This mainly impacts on the environmental quality and shade and shelter themes where greening carries a lot of weight and causes the comparator to equal the improved street in one of these regards and outscore it in the other. This difference will grow less stark over time as the newly planted street trees in Bromley grow and become more dominant.

Other than that, the analysis shows two streets with a similar distribution of strengths and weaknesses across the other eight themes, better at providing a safe, relaxed and inclusive environment, for instance, than at being adaptive in the face of 
potential alterations or unplanned uses. Despite this, the improved Bromley clearly outscores the unimproved Orpington on each of these counts.

\subsubsection{Hornchurch and Upminster}

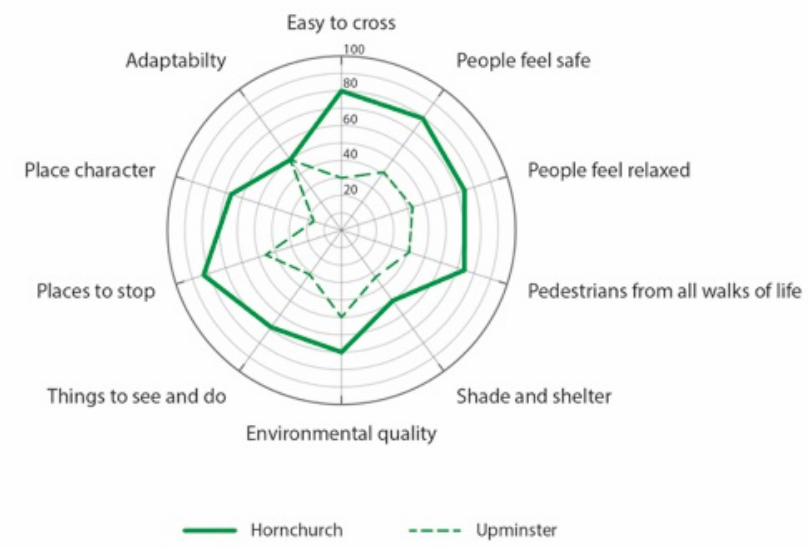

Figure 20: Hornchurch and Upminster place quality matrix

Compared to the neighbouring retail area around Upminster station, Hornchurch High Street performs much better in all areas except for adaptability reflecting the nature of the street physically constrained. Hornchurch, by comparison, is a street that is easy to traverse and which now exhibits a coherent and well thought through approach to the design and placement of street furniture. It features both ample resting points, by comparison, and an immediately recognisable identity.

The streets in Upminster, unfortunately, are strongly dominated by vehicular movement, with highly constrained pedestrian movement via pedestrian crossings with railings, traffic islands and other paraphernalia to divert pedestrians. Whilst parts of Hornchurch still exhibit similar characteristics, these are now relegated to the edges of the intervention area and are far more limited in their impact on the whole.

\subsubsection{Clapham and Camberwell}

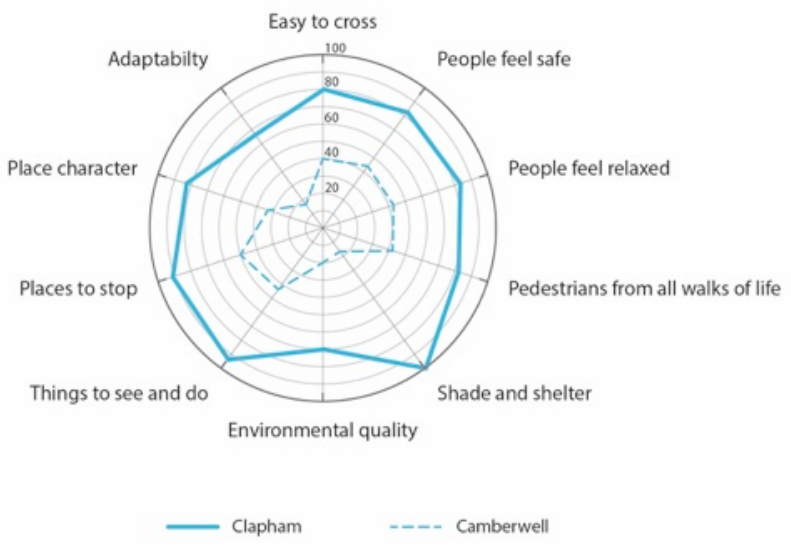

Figure 21: Clapham and Camberwell place quality matrix 
Because an earlier phase of improvements at Venn Street was included in the area of analysis for the Clapham case study, its spatial layout is more complicated than the others. The place quality matrix was nevertheless applied to the whole area with a similar approach taken in the Camberwell comparator as regards the main street and its feeders and the relationship to neighbouring green spaces (Clapham Common and Camberwell Green).

Generally Clapham scores very well across the board and consistently much higher than its comparator around Camberwell Church Street / Denmark Hill. Clapham also performs better in many aspects of the analysis than the other improved streets, with its careful detailed design often making the difference. In terms of shade and shelter, for example, the high score results from a combination of well-integrated green elements and a symbiotic relationship between the design of the public space and the businesses around it, with outdoor seating or canopies that are open for the public as well as for customers to use. Factors such as this, whilst not a direct product of the intervention, are facilitated by it, allowing a more flexible use of the transition between the private and public realm.

\subsubsection{Woolwich and Catford}

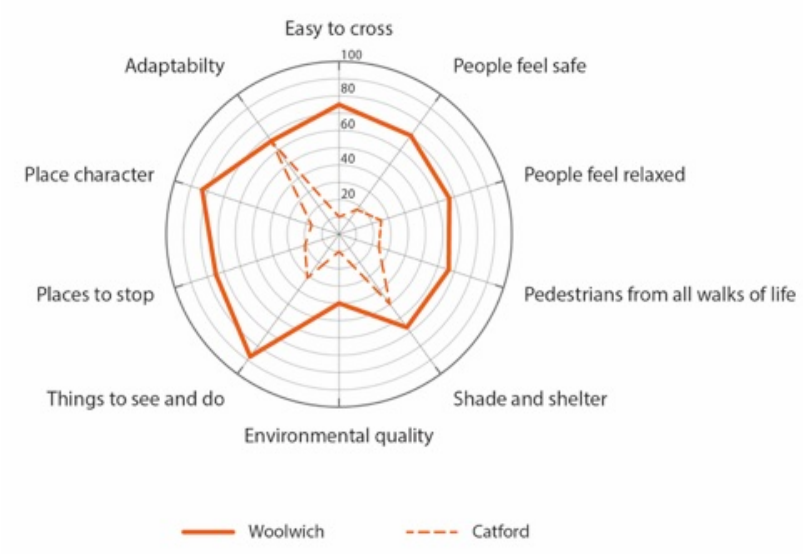

Figure 22: Woolwich and Catford place quality matrix

Woolwich town centre (post improvement) also provides a stark contrast to its comparator, the area around and to the north of the Catford Gyratory. Catford is an area that scores some positive 'spikes' because of specific elements: the (public) covered pathways leading into the shopping centre from Catford Broadway provide shelter, and the wide layout of the main roads provides more than enough space to accommodate potential alterations without significant route disruption. On the whole, however, Woolwich town centre provides an altogether superior physical fabric, despite the recent decline of the area's retail (see discussion of the retail market).

Woolwich town centre is physically unique amongst the improved cases as it represents a coherent network of sub-spaces, including a town square, pedestrianised streets, major arteries and smaller in-between space; all of which, to 
varying degrees, have been re-designed. Whilst Catford features a range of different spaces, they remain comparatively isolated: green areas are fenced off, seating is neglected and disconnected from major pedestrian flows, and the transition from one space to the next involves several indirect and highly constrained crossings. This analysis showed perhaps the starkest differential in the quality of the physical fabric.

\subsubsection{Walworth and East Greenwich}

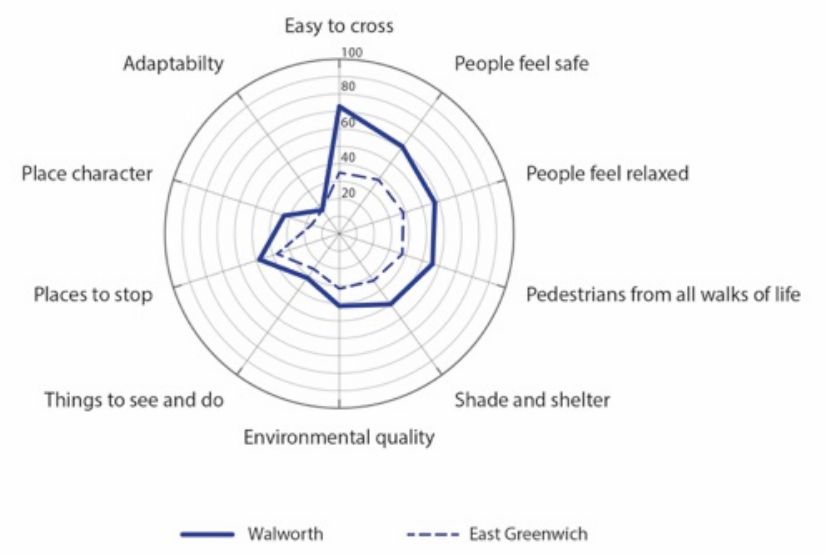

Figure 23: Walworth and East Greenwich place quality matrix

Walworth Road is the earliest of the improved street cases. It is also the one that scores the lowest in terms of its physical fabric and the closest to its unimproved comparator, Trafalgar Road in East Greenwich. These two facts may well be related. Walworth Road scores relatively highly in themes relating to pedestrian movement, but low in those that capture qualities beyond movement. The scheme was primarily envisaged as one to improve the balance between pedestrians and motor vehicles in the street, and seems to have been successful in that aim. Other aspects do not seem to have been prioritised.

The Walworth / East Greenwich comparison consequently reveals a pattern different to the other pairs. Whilst Walworth scores higher in the more technical aspects relating directly to pedestrian movement, and better overall, the similarities in the spider chart between the improved area and its unimproved comparator more closely resembles what might be expected when comparing two areas similar in qualities but without intervention.

\subsection{Physical fabric findings}

Looking across the analysis of physical fabric, it is clear that not all street improvements impact equally on all dimensions of the place quality matrix (Figure 24), and one of the improved streets (Walworth) even scored less well than one of the comparators (Orpington). At the same time each of the improved schemes scored substantially better than their unimproved pair, and typically this occurred across all, or almost all, of the ten themes. Aggregating and then averaging the place quality matrix scores for each of the improved schemes, Clapham came out top with a score of 83, followed closely by Bromley at 77 . Hornchurch and Woolwich each attained 70 
and Walworth trailed someway behind at 46 . The scores of their respective comparators were 36 (Camberwell), 57 (Orpington), 38 (Upminster), 28 (Catford) and 30 (East Greenwich). If converted to percentages, the street improvements have delivered, on average, a 31\% increase in the quality of the street environment when compared to their comparators.

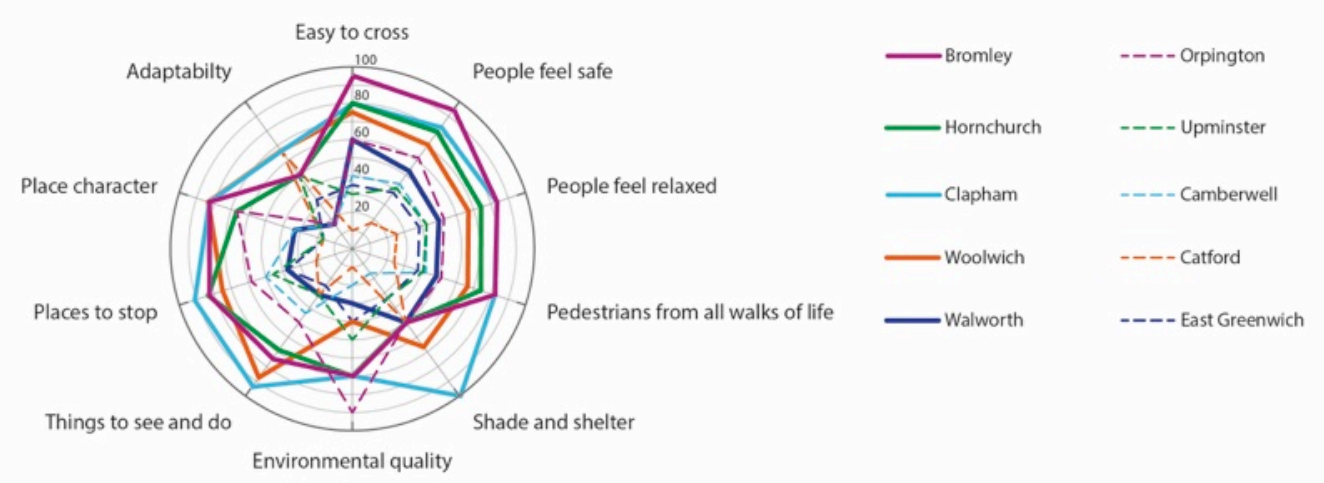

Figure 24: Street intervention cases compared

Drilling down further, the four best performing improvement cases (the exception being Walworth) exhibit a similar pattern, scoring high in two groups of the most closely interrelated factors. First, in the area of ease of crossing, and safety, comfort and inclusiveness in movement; and second, in the area of place character, resting opportunities and activity. By contrast, significantly different degrees of environmental quality and shade and shelter provision were achieved across the streets.

Environmental quality is heavily informed by the presence of air and noise pollution, both factors that are dependent on traffic flows which, alone, any public realm intervention can not solve. The failures to fully provide good shade and shelter suggests that this area, relating to such factors as the integration of green elements or the interplay between the street and ground floor frontages, is less developed as an aspiration in street interventions and harder to deliver than, for example, issues relating to crossings or street furniture. Adaptability is also often relatively poorly handled, where, the creation of spaces that are flexible in use and can easily accommodate potential alterations is difficult to achieve given the physical constraints of London's historic streets.

The findings suggest a hierarchy of interventions, starting with improving pedestrian and cycling flows, moving up to the creation and enhancement of social space (e.g. space for sitting, observing, socialising etc.), and ultimately, the most challenging, the creation of adaptable and environmentally clean and healthy spaces. Looking at the timeline of interventions impacting on the improved streets, this notion of a hierarchy is to some degree reflected in the five cases with Walworth Road (the earliest scheme) focusing on the basics and later design schemes being bolder and more multi-layered in their approach. 


\subsection{Real estate}

Whilst much value based research links the impact of better design or place-making to one real estate sector or another, a holistic view of impact from street improvements in mixed use environments can only be gauged by looking across sectors. For this reason analysis was conducted across the commercial office, residential and retail sectors using a snapshot of data from December 2016.

As has already been discussed, revealed preference methods, and in particular hedonic pricing, can be applied to property prices and rents in order to reveal a buyer's willingness to pay for specific property features such as physical attributes, location and access to various types of amenities. For hedonic pricing to give robust results requires a large dataset of property attributes at the level of the individual property, before and after an intervention (e.g. a street improvement) has occurred. Only on that basis can extrapolations be made about the impact of different levels of improvement across areas. Since, in this case, such data was not available, a simpler comparative analysis was adopted in order to give a broad idea of the association between street improvements and real estate values.

\subsection{Office market analysis}

Focusing on the office sector, real estate data from the CoStar TM data suite was analysed across three scales of analysis:

- Intervention area: the specific roads that were part of the area being improved

- Mid area: including the intervention area and the surrounding roads that might also benefit from the intervention, for example through better accessibility $^{6}$

- Postcode area: the entire three digit postcode area e.g. SE9

Rental trends in the intervention area before and after the improvement were analysed and these were compared to those within the mid area in order to have a broad idea of the impact on rental values at the aggregate level. The changes experienced by the improved mid area were then compared with those in the otherwise similar paired area (e.g. the comparator) that had not been improved. Finally comparisons were made at postcode level as a further check, although in the majority of cases this did not reveal anything different and therefore is not shown in the charts below.

Although data on yields and vacancy rates was available, the analysis focused on rental value. This reflected the fact that not enough transactions were present in the data series to obtain a meaningful picture from yields and vacancy rates, as well as the somewhat 'noisy' nature of these measures as indicators of real estate

\footnotetext{
${ }^{6}$ These areas were produced following site visits in early 2016 and so gave a recently updated view of the large concentration of retail (beyond the immediate area of intervention) within which the intervention area is situated. In most cases this is similar to the Local Data Company (LDC) data area.
} 
appreciation. It is nevertheless highly likely that they would strongly correlate with rental values.

\subsubsection{Bromley and Orpington}

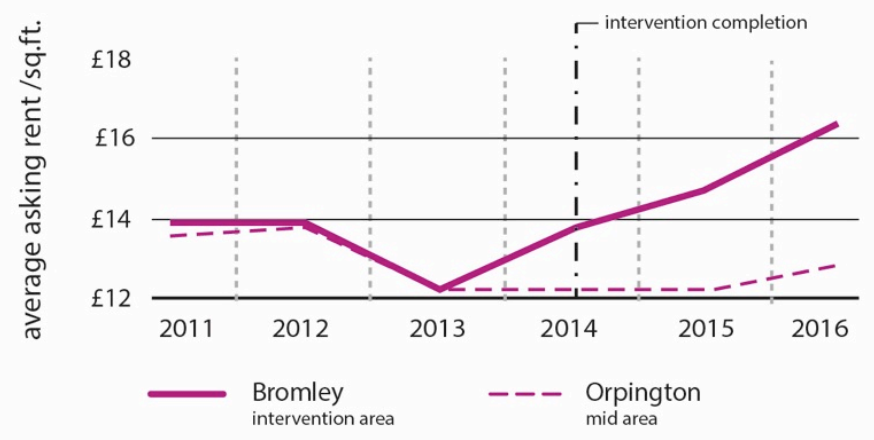

Figure 25. Bromley and Orpington office markets compared ${ }^{7}$

The improvements in Bromley were completed in 2014, and although the intervention area showed a declining trend until the middle of 2013 when the lowest value of $\mathrm{f} 12.05$ per sq. $\mathrm{ft}$ was reached, from then on growth of $35 \%$ raised values to f16.29. In the mid area rental growth was similar at 34\%, from f15.53 to f20.75. Whilst, after mid-2015, rental growth slowed down in the mid area (3\%, from $£ 20.15$ to $f 20.75)$ in the immediate area it increased (12\%, from $f 14.58$ to $f 16.29)$.

In 2013 rent levels in Orpington were very similar to those in the Bromley intervention

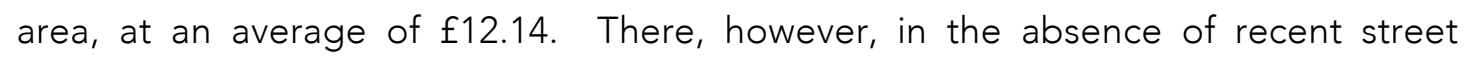
improvements, only very modest growth of $3 \%$ was recorded, with average rental levels sitting at just $\mathrm{f} 12.57$ by the end of 2016 .

\subsubsection{Hornchurch and Upminster}

In Hornchurch the intervention was completed in early 2013. Rents were constant at f13 from 2011 until mid-2014 before increasing steadily thereafter to reach almost double that level (£25.82) by late 2016. In the mid area rental growth started later, with an increase of $57 \%$ from $£ 12$ in mid-2015 to $f 18.82$ at the end of 2016 . This remarkable growth reflects levels of $66 \%$ seen in the submarket of the London fringe at the same time (mid-2013 to the end of 2016).

For its comparator, Upminster, rent levels were at $£ 13.75$ in mid-2013 following strong growth over the previous two years, but experienced virtually no growth after that. By the end of 2016 average rents remained at just $f 13.82$.

\footnotetext{
${ }^{7}$ Bromley intervention area: 22 properties in High Street, Market Square, East Street \& branches. Mid area: 87 properties in a polygon following the LDC data area, which includes the whole town centre down to Bromley South. Orpington mid area: 33 properties in a polygon around the High Street as in the LDC data area
} 


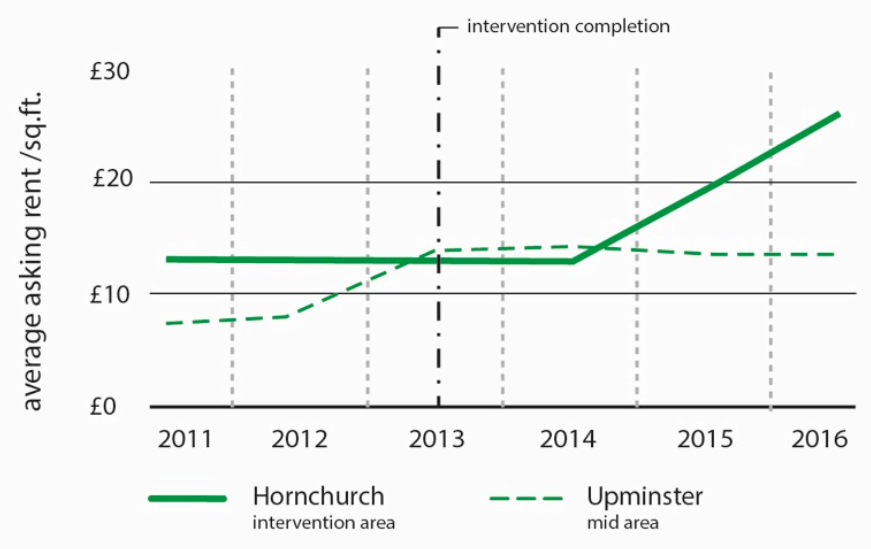

Figure 26. Hornchurch and Upminster office markets compared ${ }^{8}$

\subsubsection{Clapham and Camberwell}

The improvements in Clapham were completed in two phases, initially in 2011 and then again in 2014. The data shows a strong depreciation following the initial completion of works in Venn Street with rental values in the intervention area decreasing by $68 \%$ from $£ 20.54$ to $£ 6.57$ while in the mid area the depreciation was more modest at $20 \%$, from $f 19.29$ to $£ 15.54$. Data then shows very strong growth from mid-2013 with the intervention area showing increases of almost five times, from $£ 6.57$ to $£ 30.96$. In the mid area the increase was $45 \%$ from $f 15.54$ to $f 28.09$.

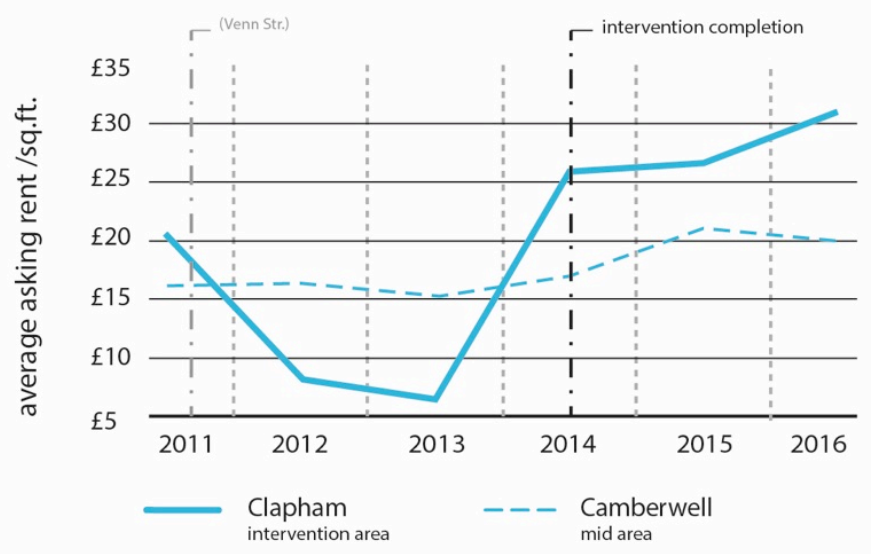

Figure 27. Clapham and Camberwell office markets compared ${ }^{9}$

The decline in rental values in the Clapham intervention area (and to a lesser degree the mid area) was particularly dramatic. This is a small office market dominated by small 3 star office buildings. Analysis of vacancy rates in the area shows that these

\footnotetext{
${ }^{8}$ Hornchurch intervention area: 8 properties in High Street and branches. Mid area: 15 properties in a polygon following the LDC data area in RM11 and RM12. Upminster mid area: there are only 5 office properties in the RM14 postcode area.

${ }^{9}$ Clapham intervention area: 22 properties in the Old Town B303, Venn Street \& branches; mid area: 64 properties in a polygon following the LDC data area, which includes Clapham High Street, Park Road, The Pavement and the Old Town. Camberwell mid area: 32 properties in a polygon centred around the junction of Camberwell New Road \& Camberwell Church Street, roughly correspondent to the LDC data area.
} 
peaked in 2011-13 showing the vulnerability of such small markets to a few business closures of moves. This in turn led to a dramatic fall in rental levels but these strongly recovered thereafter and quickly surpassed rental levels in both the mid area and comparator. For the comparator, Camberwell, rent levels were at $f 15.32$ in mid2013 after being steady for the two previous years. Moderate growth of $23 \%$ was then recorded for the following years, with average rent of $£ 20.00$ at the end of 2016 , considerably less than in Clapham and declining.

\subsubsection{Woolwich and Catford}

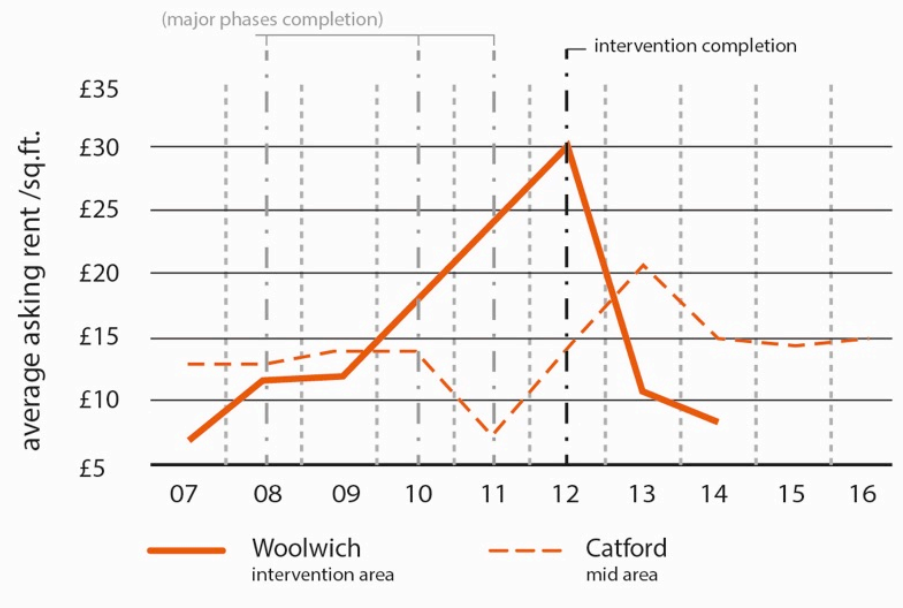

Figure 28. Woolwich and Catford office markets compared ${ }^{10}$

The street improvements in Woolwich were begun in 2008 but completed in 2012 with the data showing strong growth of $150 \%$ from $£ 12.14$ in 2010 to $£ 30.43$ in early 2014 for the intervention area, and similarly for the mid area but starting in mid-2011. Indeed the data shows that rental appreciates from the immediate area in a series of waves outwards, with the immediate area appreciating first, followed by the mid area and then the wider postcode area. This seems to indicate a particularly strong effect of the improvement on rental growth.

Surprisingly, after mid-2012, a strong depreciation occurred in Woolwich, with rent levels falling down to respectively $f 9$ and $f 8.60$ in the intervention and mid areas. This may be explained by a substantial increase in available space in Woolwich between 2010 (210,090 Sq Ft) and 2011 (347,212 Sq Ft), which corresponds to the construction of the very large Woolwich Centre. The subsequent move of the local authority into the new Woolwich Centre seems to have contributed to high vacancy rates between 2012 and 2013 (up to 7\%) which suppressed prices. As the period after 2013 was characterised by many new tenants (e.g. small service companies, arts and cultural activities, and start-ups) moving into the area, over time the rental market looks likely to recover. In the interim it may have fallen further without the substantial public realm improvements to help cushion the fall.

\footnotetext{
${ }^{10}$ Woolwich intervention area: 15 properties in Beresford Street, Woolwich New Road, Thomas Street and between; mid area: 31 properties in a polygon following the LDC data area. Catford mid area: 21 properties in a polygon centred around the junction of Rushey Green and South Circular Roads, following the LDC data area.
} 
For the comparator, Catford, rent levels grew similarly strongly at $155 \%$ over the same appreciation period, going from f7.92 in 2011 to 20.91 in early 2014, also followed by a depreciation. This, however, was less strong, with rent levels falling to $\mathrm{f} 15$ in recent periods. The short lived appreciation dynamics experienced by the two neighbourhoods around 2013 are similar although appear to have been more extreme in Woolwich.

\subsubsection{Walworth and East Greenwich}

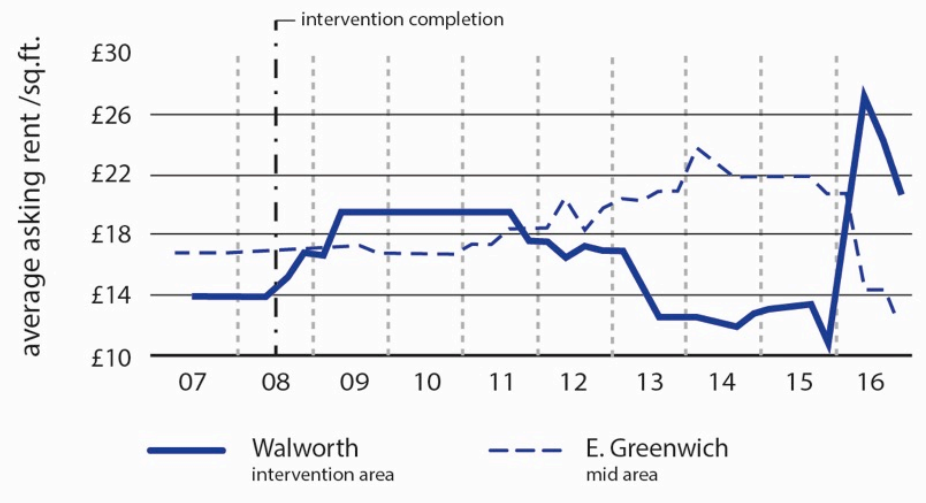

Figure 29. Walworth and East Greenwich office markets compared ${ }^{11}$

The street improvements in Walworth completed in 2008 with the data showing a significant appreciation soon after this occurred. Rent levels in the immediate area of improvement increased 41\% from f13.87 at the end of 2008 to f19.50 in 2009 and then remained at the higher level until late 2011. The same dynamic is obvious but less pronounced in the mid area where rent levels increased $18 \%$ at the end of 2008. It is worth noting that 2009 and 2010 are periods of general depreciation following the financial crisis and this is visible for the East Greenwich comparator where rent levels fluctuate around $\mathrm{f17}$ over the period 2008-2011.

Interestingly data for Walworth shows quite a significant depreciation from 2011 to late 2015 , but then a very strong appreciation of $60 \%$ up to $f 26.31$ in the first part of 2016, and a negative correction more recently. For the comparator, East Greenwich, the opposite dynamics are apparent with rent levels appreciating from 2011 to 2015, then strongly depreciating in 2016. Overall, however, since 2008 the Walworth area has seen significant appreciation in contrast to the depreciation seen in its comparator.

\subsection{Office market findings}

It is quite clear from the analysis that for Bromley, Hornchurch, Clapham and Walworth the street improvement is strongly associated with growth in rents; this growth seems to trickle from the intervention area to the wider area. By contrast

\footnotetext{
${ }^{11}$ Walworth intervention area: 19 properties on a corridor corresponding to Walworth Road; mid area: 33 properties on an offset of the road in both directions. East Greenwich. mid area: 41 properties in a rectangle centred on the core part of Trafalgar Road.
} 
comparators that have not experienced improvements do not experience such growth, and in some cases depreciate. Whilst it is not possible to apply any statistical tests (e.g. t-test) as data was only available for the average appreciation ${ }^{12}$, it is clear that the differences in these markets were extremely significant.

The comparative analysis that was employed to understand the office market cannot be conclusive about the specific impact of street improvements on rents as compared to other potential factors at play. The case of Woolwich is particularly difficult to interpret as the strong appreciation following the completion of the street improvements was then followed by a severe depreciation from 2012, which is strikingly different from the strong appreciation trend in the rest of the London market from mid-2013. In that case external factors relating to the market disruption and vacancies caused by the large scale redevelopments that occurred in Woolwich immediately following the street improvements, seem to have been more powerful than the impact of the street improvements themselves.

It seems plausible that improvements contribute to other endogenous factors, for example office refurbishments, that may in turn have a positive impact on rents. There may also be some reverse causality at play. In other words street improvements have a positive effect on rents, but areas that have higher potential for appreciation may be more likely to be improved. Despite this, when the figures across the case studies are aggregated then a significant effect from the street improvements seems clear. Thus over the course of the timescales for which data is available, and on average, office rents in the areas with improved street environments rose by $51 \%$. This reduces slightly when the wider (mid) areas are considered although is still very significant with a $41 \%$ aggregate uplift. When compared to unimproved areas the contrast is stark. In those locations, and over the same period, an aggregate uplift of just $8 \%$ was apparent.

\subsection{Residential market analysis}

The Land Registry House Price Index was used to measure the impact of the street improvements in the residential sector. This occurred across three different scales of analysis:

- Intervention area: this related to the postcode sector (the first four digits of the code e.g. SE9 1) corresponding to the roads that were improved. In most cases this represents a smaller version of the Local Data Company (LDC) data area and is the smallest scale at which the house price index is available.

- Postcode area: here the larger area encompassed by the three digit postcode was analysed e.g. SE9. In most cases this area is much broader than the LDC data area, and it is mainly used to compare the broad trends to the dynamics within the intervention area.

- Macro area: A check was made against data for the two digit postcode area e.g. SE in order to compare postcode area trends against broader trends.

\footnotetext{
${ }^{12}$ As opposed to on a property by property basis as would be necessary in order to show distribution.
} 
The price trends were analysed both before and after improvement and then compared with the comparator areas in order to understand any differences across the two areas. In the main the data focuses on the post 2010 period which has been a period of general appreciation, following a period (2008-2009) of general depreciation caused by the global financial crisis. Although other types of residential properties were considered in the analysis, the graphs that follow focus on blocks of flats which are typically more homogenous than houses and make comparisons across different areas easier to make.

\subsubsection{Bromley and Orpington}

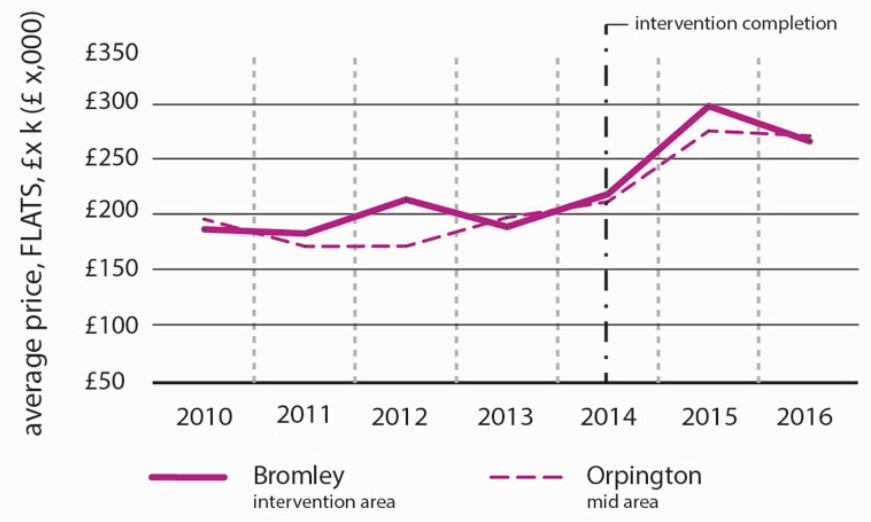

Figure 30 Bromley and Orpington residential markets compared

In Bromley the street improvements were completed in 2014 and in the corresponding mid area there were a total of 1829 flat sales from 2010 to 2016 with 921 after 2014. The data suggests three distinct market phases: flats appreciated 7\% from 2010 to 2013, 34\% from 2013 to 2015, and 1\% from 2015 to 2016. Aggregating all types of residential properties there have been a total of 5401 sales from 2010 to 2016, and 2402 since 2014 and these appreciate on average 4\% from 2010 to 2013, 26\% from 2013 to 2015, and 1\% from 2015 to 2016.

In the Orpington comparator there were a total of 542 flat sales from 2010 to 2016, and 199 after 2014. Flats appreciated 8\% from 2010 to 2013, 33\% from 2013 to 2015, and depreciated by $4 \%$ between 2015 and 2016. Aggregating all types of residential properties provided 4414 sales from 2010 to 2016, and 1783 after 2014 with appreciation of 16\% from 2010 to 2013, 29\% from 2013 to 2015, and a depreciation by $7 \%$ between 2015 and 2016.

Overall the two markets have similar price dynamics but Bromley experienced a higher proportion of flat sales. Considering the specific area of intervention, BR1 1 (and comparing to the otherwise similar area BR6 0), flats appreciated $17 \%$ as opposed to $8 \%$ (in the comparator) from 2010 to 2014, and by 22\% as against $29 \%$ after 2014. Aggregating all types of residential properties a small depreciation (-1\%) is obvious from 2010 to 2014 as opposed to a major appreciation in Orpington of 
$36 \%$, and subsequently an appreciation of $35 \%$ against a smaller appreciation of $18 \%$ after 2014.

The data suggests that the street improvements did not seem to have a strong effect on residential price dynamics in Bromley, although there may have been an immediate post-completion boost, with flat prices shooting up in 2014 before falling back in 2015. When compared to analysis of the other cases and the macro area, Bromley's broad market dynamics seem to be similar to those of other areas in South London, with a strong appreciation between 2013 and 2015, stable prices during 2016 and an increasing share of flat sales. It does not appear that the improvements had a strong effect on prices in the immediate area of improvement, as, post 2014, flats in the comparator area, albeit representing a smaller share of sold properties than in Bromley, seem to appreciate at similar rates.

\subsubsection{Hornchurch and Upminster}

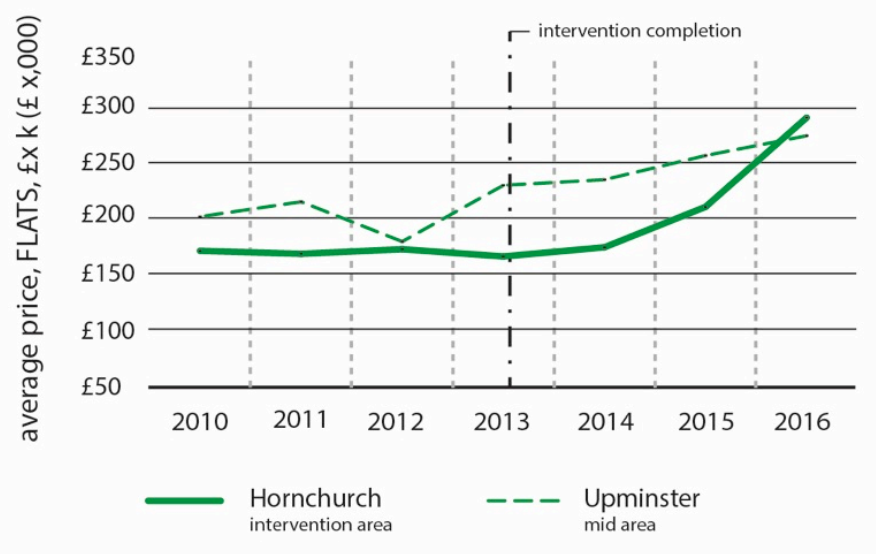

Figure 31 Hornchurch and Upminster residential markets compared

The improvements in Hornchurch were completed in April 2013, with the data showing that a total of 510 flat sales occurred between 2010 and 2016, with 338 since 2013. Flats depreciated by 2\% from 2010 to 2013 but then appreciated 44\% from 2013 to 2016. Aggregating all types of residential properties there was a total of 2895 sales from 2010 to 2016, and 1737 after 2013. Considering all properties, the residential sector appreciated on average 1\% from 2010 to 2013, and 34\% after 2013.

Taking the Upminster comparator there were 405 flat sales from 2010 to 2016, and 221 after 2013. Flats appreciated at 7\% from 2010 to 2013, and 26\% thereafter. Aggregating all types of residential properties for this area there was a total of 2386 sales from 2010 to 2016 and 1314 after 2013. This residential sub-market appreciated by $6 \%$ from 2010 to 2013 , and by $37 \%$ subsequently.

Overall the two markets are similar with flat sales representing just below $20 \%$ of the market in both areas before and post 2013. Taking flat sales only, there was a significant depreciation in Hornchurch in 2013, and a stronger post 2013 appreciation as compared to Upminster. Looking at the 'RM' postcode macro area, flat sales 
appreciated 3\% from 2010 to 2013 and 40\% between 2013 and 2016. Similarly, the residential sector at large appreciated on average by 2\% from 2010 to 2013 and 36\% thereafter. This suggests that Hornchurch seemed to experience a quite unique 2013 depreciation and a stronger post 2013 appreciation in flat prices than the nearby areas.

Taking the intervention area (RM113) and comparing it to the otherwise similar area (RM14 2), flats depreciated by 3\% against an appreciation of 14\% between 2010 and 2013, and appreciated by some $76 \%$ as opposed to just $20 \%$ afterwards. Aggregating all types of residential properties the figures for the intervention area against its comparator are an appreciation of 3\% against 1\% from 2010 to 2013, and $31 \%$ in both areas after 2013.

For Hornchurch it is possible to conclude that the street improvements did seem to effect the residential price dynamics, with the strong depreciation of flats in 2013 mirroring the period of disruption during the improvement works, whilst the very strong appreciation in the intervention area (significantly stronger than either the mid area or the comparator) shows the turning up of the fortunes of this area after being kick-started by the public realm interventions.

\subsubsection{Clapham and Camberwell}

The improvements in Clapham were completed between 2011 and 2014. For the related postcode area, SW4, a total of 3192 flat sales were recorded from 2010 to 2016, and 2262 since then. Flats appreciated at 11\% from 2010 to 2012, and 44\% thereafter. Aggregating all types of residential properties there were 4243 sales from 2010 to 2016, 2988 after 2012, and the same levels of appreciation (11\% for 2010-2012 and $44 \%$ post 2012 ).

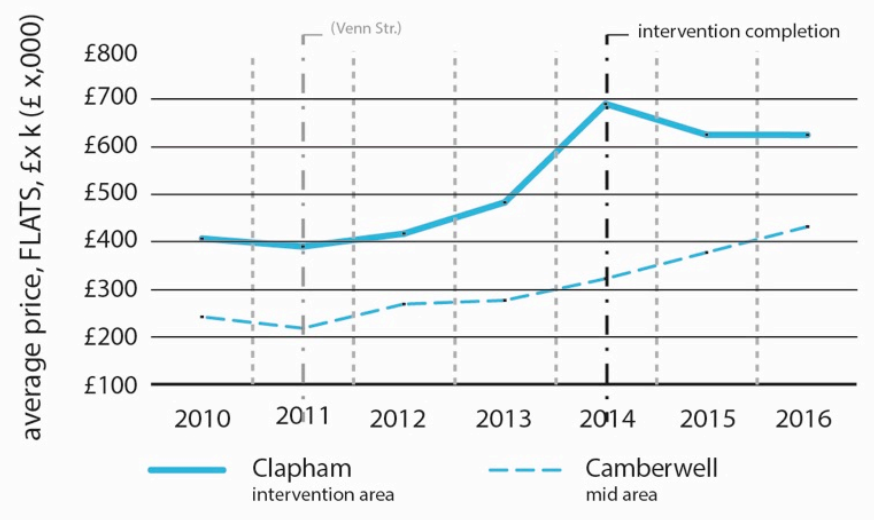

Figure 32 Clapham and Camberwell residential markets compared

Turning to the Camberwell postcode comparator, there were 2118 flat sales from 2010 to 2016, and 1586 after 2012. Flats appreciated at 8\% from 2010 to 2012, and $62 \%$ subsequently. Aggregating all types of residential properties there was a total of 2853 sales from 2010 to 2016, and 2115 after 2012. The corresponding residential sector appreciated by $17 \%$ from 2010 to 2012 , and 52\% thereafter. 
Overall the two markets seem to be quite similar with flat sales making up around $75 \%$ of transactions, both before and post 2012. Focusing on the sale of flats there was a stronger appreciation post 2012 in Camberwell than Clapham, although this was in line with trends in the larger macro areas. Focussing on the immediate area of improvement, SW4 0, and its comparator, SE5 0, flats appreciated by $3 \%$ and $11 \%$ between 2010 and 2012 and by 50\% and 61\% after 2012, although with a short-lived boost in Clapham after completion of the works in 2014. Aggregating all types of residential properties the figures are 27\% against 22\% between 2010 and 2012, and $27 \%$ and $49 \%$ thereafter.

From this it is possible to conclude that the street improvements did not significantly effect the residential price dynamics in Clapham. Instead we see a story of solid appreciation of flats in the intervention area after 2012 which is similar in both the mid and postcode areas, and weaker than the strong appreciation seen in Camberwell.

\subsubsection{Woolwich and Catford}

The improvements in Woolwich were completed in 2012. In the postcode district SE18 there was a total of 2482 flat sales from 2010 to 2016, and 2064 after 2012. Flats depreciated by 2\% from 2010 to 2012, and appreciated by 31\% thereafter. Aggregating all types of residential properties there was a total of 4792 sales between 2010 and 2016, and 3766 after 2012. These showed a depreciation of 1\% between 2010 to 2012, and an appreciation of 53\% after 2012.

The comparator postcode area, Catford, had 1489 flat sales between 2010 and 2016, and 1204 after 2012. Flats depreciated by 3\% between 2010 and 2012, and appreciated by $70 \%$ after 2012 . Aggregating all types of residential properties there were 3475 sales from 2010 to 2016, and 2646 after 2012. This group appreciated by 6\% between 2010 and 2012, and by 61\% subsequently.

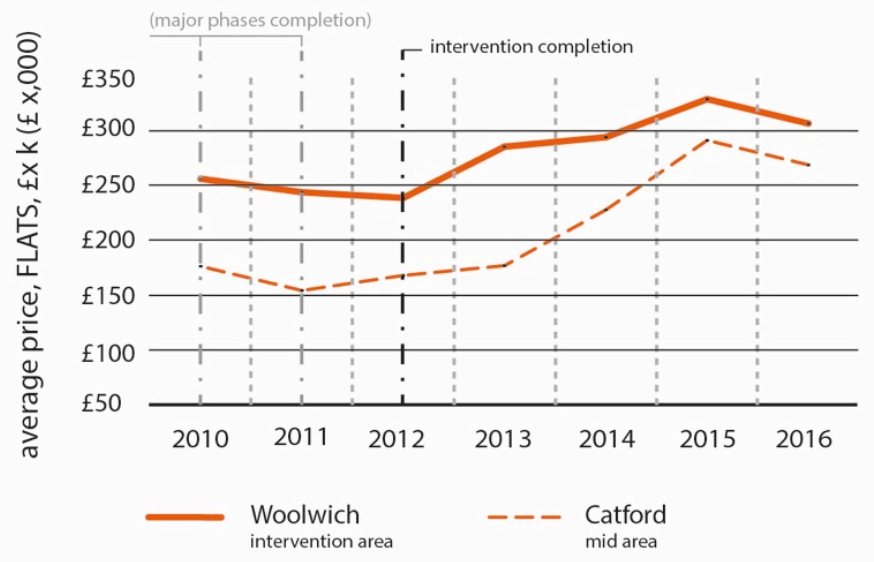

Figure 33: Woolwich and Catford residential markets compared

Overall the two markets are different in terms of the types of available properties, with flats as a proportion of total sales amounting to 55\% in Woolwich but only $45 \%$ 
in Catford, both before and after 2012. There was also much stronger appreciation of flat values in Catford than in Woolwich, the former being significantly above and the latter below averages in the mid area where flats appreciated at 50\% after 2012.

Taking the improvement area, SE18 6, and comparing it to the otherwise similar SE6 4 area; between 2010 and 2012 flats depreciated by 7\% in the intervention area compared to $5 \%$ in its comparator, and appreciated by $28 \%$ as compared to $59 \%$ after 2012. Similarly, when aggregated to all types of residential properties the figures show a 7\% depreciation as opposed to a 10\% gain between 2010 and 2012, and an appreciation of $31 \%$ and $66 \%$ after 2012.

The figures suggest that the street improvements did not seem to impact positively on residential price dynamics in Woolwich, with a moderate depreciation between 2010 and 2012 and a solid appreciation after 2012 which was stronger in the postcode and mid areas than in the intervention area, and which was a bit weaker than the strong appreciation seen in the comparator. In the Woolwich case it should be borne in mind that the opening of the Docklands Light Railway in 2009 (and the appreciation that preceded that) as well as the significant regeneration around and beyond the intervention area, both before and after the improvements, may be masking a more localised impact of the street improvements.

\subsubsection{Walworth and East Greenwich}

The interventions in Walworth Road were completed in 2008. Taking the postcode area, SE17, a total of 1309 flat sales were made between 2010 and 2016, including 994 after 2012. In this area, flats depreciated by 4\% from 2007 to 2008, appreciated 2\% between 2008 and 2010, depreciated again by 1\% from 2010 to 2012, and appreciate significantly, by some 58\%, after 2012. Aggregating all types of residential properties, there were 1551 sales from 2010 to 2016, 1165 of which were after 2012, with, again, a 4\% depreciation between 2007 and 2008, appreciation of $6 \%$ from 2008 to 2010 , a slower appreciation of $2 \%$ up to 2012 , and appreciation of $61 \%$ thereafter.

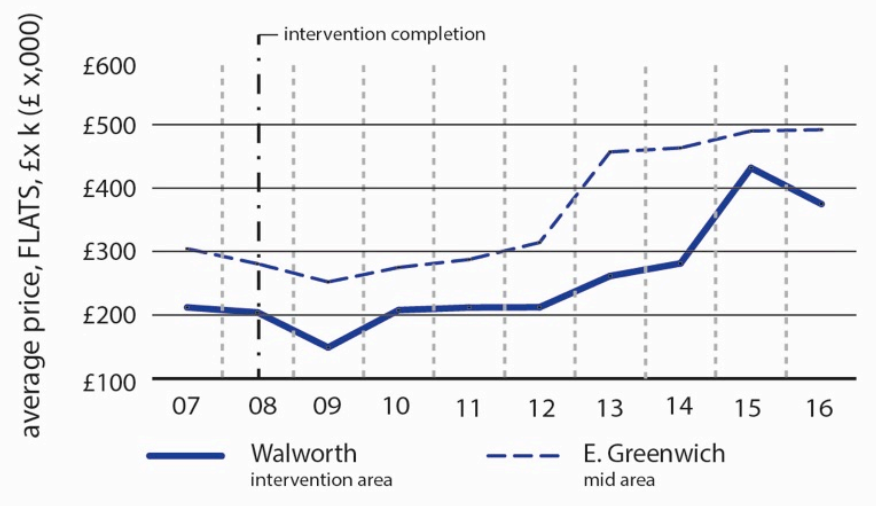

Figure 34: Walworth and East Greenwich residential markets compared

Considering the East Greenwich postcode area comparator, there was a total of 3430 flat sales between 2010 and 2016, and 2872 after 2012. In this location flats appreciated by 3\% from 2007 to 2008, by 5\% from 2008 to 2010, depreciated by 
some $8 \%$ from 2010 to 2012, and appreciate again by 51\% after 2012. Aggregating all types of residential properties there were 4600 sales between 2010 and 2016 of which 3652 were after 2012. There was a depreciation of 4\% between 2007 and 2008, an appreciation of 22\% between 2008 and 2010, depreciation after 2010 but before 2012 by $7 \%$, and an appreciation of $27 \%$ thereafter.

Overall the two markets are similar, with flats being the dominant component of sales in both areas (85\% in SE17 and 79\% in SE10) both before and post 2012. The moderate depreciation in flat sales between 2007 and 2008 and slow growth in the period immediately after indicates that the street based interventions did not alter the typical depreciation that was seen in London across the years of the economic crisis. After the market recovered, the moderate depreciation in 2010-2012 and rapid growth subsequently was merely in line with the rest of the 'SE' area, although it did show a marginal growth rate beyond its comparator.

Considering the immediate area of intervention, SE17 1, and comparing it to the otherwise similar area SE10 9, flats depreciate by $4 \%$ as against 8\%, between 2007 and 2008, appreciate by $2 \%$ against a 2\% drop from 2008 to 2010, appreciate by a further 2\% as opposed to a much larger 14\% growth between 2010 and 2012, and finally appreciate by $77 \%$ against $57 \%$ after 2012 . When the results for all types of residential properties for the same two areas are aggregated there is a $5 \%$ appreciation in SE17 1 against a 13\% drop in SE10 9 between 2007 and 2008, no price change from 2008 to 2010 against a $26 \%$ gain, appreciation of $5 \%$ between 2010 and 2012 instead of a 1\% drop, and thereafter appreciation of some $74 \%$ against $42 \%$ in the comparator.

From the analysis it is clear that the global financial crisis was the biggest influence on prices during and immediately after the interventions at Walworth Road, and any impact of the street improvements themselves (early on) was marginal, although may have helped to stabilise prices in Walworth when seen against its comparator. The dynamics from 2010 onwards in the intervention and postcode areas are quite similar to the comparator areas and the other areas of 'SE' with moderate appreciation between 2010 and 2012, although with some significant appreciation in the intervention area over its comparator thereafter. Thus, if the street works impacted, they did so over time, and in a manner that encouraged long-term appreciation after the effects of the financial crisis had worn off.

\subsection{Residential market findings}

The story of how, if at all, street improvements effect the residential real estate market is much less straightforward than in the office sector. The results from the cases were mixed, with no effect detected in either Clapham or Woolwich; a marginal effect noted in Bromley; and more significant impacts detected in Hornchurch and Walworth, both of which over time seem to have recorded a significant market boost in the intervention area. In this real estate sector, the overriding lesson seems to be that street improvements can effect market dynamics in a positive direction, but that impact is most likely to be small and is much smaller 
than impacts caused by other factors, including general swings in the market, or the arrival of significant new transport infrastructure as occurred in Woolwich. Again it was not possible to apply any statistical tests (e.g. t-test) to the data which was only available for the average appreciation ${ }^{13}$, but it is clear from the results that the differences were not very significant.

Aggregating the market responses across the different areas reveals an interesting picture. When compared to their comparators, the five areas (in aggregate across the study period) did not record any market boost, in fact they performed slightly less well at both postcode and intervention area scales (46\% against $50 \%$, and $53 \%$ against 55\%). However, when comparing the aggregate performance of the intervention area and its comparator against their respective postcode areas, there was a noticeable, but small, boost of some $2 \%$ in the value of all the improved areas over their larger postcode hinterlands, than against a similar comparison made between the non-improved comparators and their larger postcode hinterlands. In other words street improvements seem to effect residential prices, but only marginally and very locally to the interventions. Given other trends in the market this is almost inconsequential and certainly well below the extent that would impact on gentrification or any of the sometimes negative associations linked to public realm improvement in residential areas.

\subsection{Retail market and occupancy analysis}

Two forms of analysis were conducted for the retail sector, retail market analysis and retail occupancy analysis. CoStar rental data was rationalised across the same three scales and boundaries used for the office sector in the five pairs of cases. The links between street based improvements and shifts in rental and vacancy rates was then analysed and compared to the areas not experiencing any significant public realm changes. As previously, although such retail rental analysis cannot confirm clear causation between improvements and rental increases, correlations between what was happening in the locality and rent patterns are very likely to be interconnected due to the nature of the commercial real estate market. As, in the majority of cases, analysis at postcode level did not reveal anything different from that at mid level, this data is not shown in the charts below.

In addition the analysis of GOAD/Experian occupancy data from 22,498 data points (each representing a single retail outlet) across the ten areas provided a greater degree of granular detail for each case. To ensure consistency between the data sets used, each of the ten areas were matched to the postcode level boundaries established for the CoStar analysis. From this perspective, and in order to examine changes in the retail market, the following data points were considered:

- Year on year changes in the number of retail units per area

- Use class shifts year on year: A1 though to A5 and ASG sui generis ${ }^{14}$

\footnotetext{
${ }^{13}$ As opposed to on a property by property basis as would be necessary in order to show distribution.

${ }^{14}$ Use classes: A1: Shops; A2: Financial \& Professional Services; A3: Restaurants and Cafes; A4: Drinking establishments; A5: Hot Food Take-away; ASG sui generis (buildings falling outside of any use class and therefore
} 
- Occupier ratios year on year: multiple or chain retailers (with a network of nine or more outlets) and non-multiple retailers (independent with up to eight outlets)

- GOAD sub-class composition shifts year on year: defines retailers as comparison, convenience, financial \& business services, leisure services, public services, retail services, transport services, vacant retail (Table 3)

- Floorspace analysis year on year: largest and smallest units, mean and median floorspace across each area, and standard deviation of floorspace.

\begin{tabular}{|c|c|}
\hline Sub-class & Examples of retailer \\
\hline Comparison & $\begin{array}{l}\text { Antique shops, booksellers, charity shops, clothing, department stores, electrical } \\
\text { and other durable goods, florists, footwear, furniture, jewellery, newsagents and } \\
\text { stationers, photographic and optical, sports, camping and leisure goods, toiletries, } \\
\text { cosmetics and beauty products, toys, games and hobbies. }\end{array}$ \\
\hline Convenience & $\begin{array}{l}\text { Bakers and confectioners, butchers, convenience stores, fishmongers, frozen foods, } \\
\text { greengrocers, grocers and delicatessens, health foods, markets, off licences, shoe } \\
\text { repairs, supermarkets. }\end{array}$ \\
\hline Financial \& Business Services & $\begin{array}{l}\text { Building societies, building supplies and services, employment and careers, financial } \\
\text { services, legal services, property services, retail banks. }\end{array}$ \\
\hline Leisure Services & $\begin{array}{l}\text { Bars and wine bars, bingo and amusements, cafes, casinos and betting offices, } \\
\text { cinemas, theatres and concert halls, nightclubs, fast food and take away, hotels and } \\
\text { guest houses, public houses, restaurants, sports and leisure facilities. }\end{array}$ \\
\hline Other retail & Internet cafes. \\
\hline Public Services & Information and advice services. \\
\hline Retail Services & $\begin{array}{l}\text { Clothing hire, dry cleaners and launderettes, opticians, filling stations, photo } \\
\text { processing, post office, repairs, alterations and restoration, travel agents, vehicle } \\
\text { rental, vehicle repairs and services, video tape rental. }\end{array}$ \\
\hline Transport Services & Taxi hire. \\
\hline Vacant Retail & Unoccupied retail premises. \\
\hline & Table 3: GOAD/Experian Sub-Classes ${ }^{15}$ \\
\hline
\end{tabular}

The data was rationalised to allow for trends over time to emerge and establish connections between the street improvements and potential patterns in retailing. As with the CoStar data, it is not possible to accurately measure the direct impact of the improvements in view of the many other influences on the local commercial real estate markets. However, shifts in the retail data can be useful indicators for impact, and, as well as looking at the occupancy data at postcode level over time, the intervention areas were also isolated and compared with the more general trends to identify any strong localised effects as further indicators of impact ${ }^{16}$.

\subsubsection{Bromley and Orpington market analysis}

Bromley demonstrated some rental uplift in the intervention area in the years following the 2014 improvements (7\% in the 12 months following completion and 21\% until 2016); although this has not, as yet, exceeded the peak rental values seen in early 2013 (£32.12), nor was the effect immediate. The intervention led the immediate market to buck the general trend in the postcode and mid areas where

requiring planning permission for any change of use). (Town and Country Planning (Use Classes) Order 1987 (as amended), Town and Country Planning (General Permitted Development) Order 1995 (as amended).

15 This table of retailer types is not exhaustive. Its purpose is to broadly indicate the differences between retail subclasses

${ }^{16}$ The smallest levels of comparison were only used for the retail outlets directly connected with the urban realm intervention area. 
the rental levels have seen a small drop in absolute values and stagnation in average rental values since the completion of the street improvements. It is also helping to combat a continuing and long-term steady decline in values across the whole area, reflecting structural changes in a challenging retail market nationally.

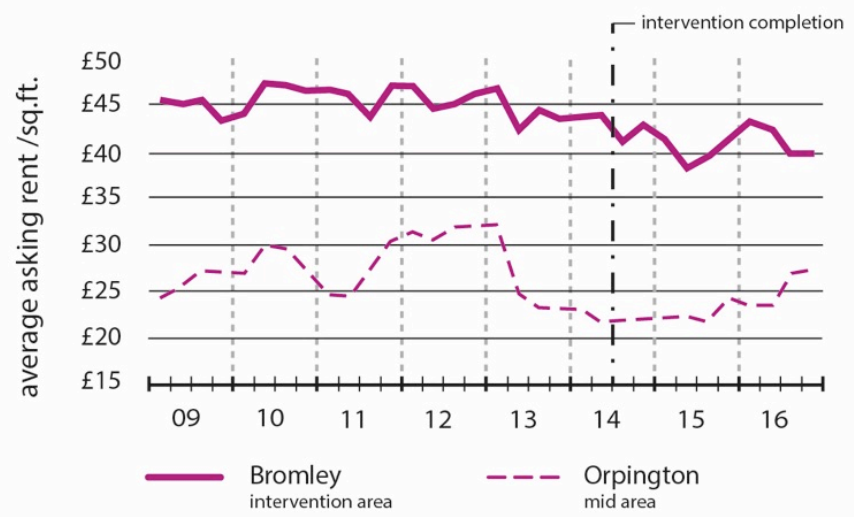

Figure 35: Bromley and Orpington retail markets compared ${ }^{17}$

Retail rental levels in the mid range comparator, Orpington, have been significantly lower than the mid-range in Bromley, and although the area demonstrates a longterm slight increase in percentage terms, since 2014 it has also been in decline and has witnessed none of the growth seen in the Bromley intervention area. Whereas both mid level areas have seen consistent trends, a greater fluctuation has been evident in the Bromley intervention area showing the likely impact of the construction necessary to achieve the street improvements.

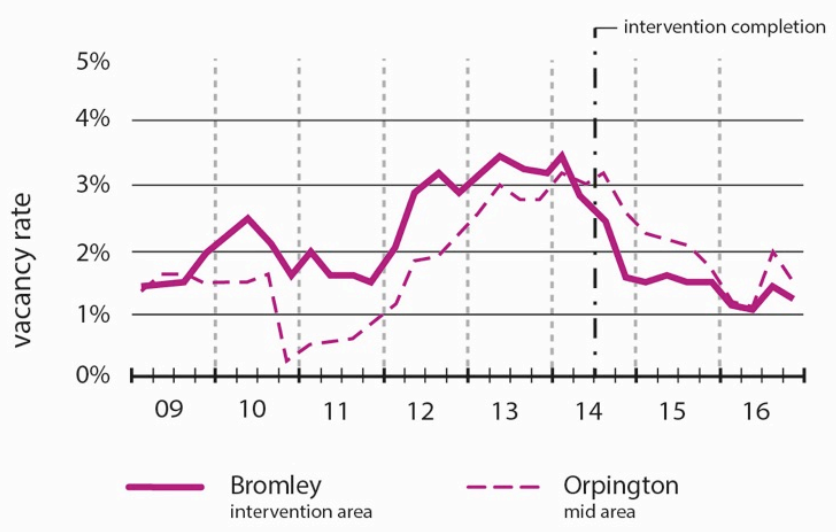

Figure 36: Comparing vacancy rates in Bromley and Orpington

Turning to vacancy rates, following the street improvements these have continued to drop on average in both the intervention and mid levels in Bromley. Notably the vacancy rates began to drop dramatically in the middle of 2014 suggesting a clear market response to the street improvements. Since early 2014 vacancy rates were consistently lower across the Bromley postcode area (just 1\% in late 2016) than in the intervention / mid areas, however following the improvements the apparent trend for

\footnotetext{
${ }^{17}$ Bromley postcode area (BR1): 369 properties \& 29 vacancies, mid area: 226 properties \& 24 vacancies, intervention area: 124 properties \& 9 vacancies. Orpington postcode area (BR6): 180 properties \& 21 vacancies, mid area: 119 properties \& 20 vacancies.
} 
continually increasing vacancy after 2011 was reversed; effectively halving by late $2016^{18}$. Vacancy in Orpington, by contrast, has been on a slow downward trend since 2011 , but reversed in 2016 reaching 3\% from a low of 2\% earlier in the year.

\subsubsection{Bromley and Orpington occupancy analysis}

Across the time period studied (2006-2016), neither Bromley nor Orpington have seen any substantial change in the stock of retail property. In terms of use class changes, Bromley saw a small and consistent drop in A1 uses from a peak of $74 \%$ (2007) to a low of 70\% (2016) whilst A3 (restaurants and cafes) saw an increase from 9\% (2006) to 12\% (2016), over half of which followed completion of the street improvement works in 2014. In Orpington there was a pronounced shift in A1 (shops) from 75\% (2007) to 66\% (2016), a decline of 9\%, with A2 (financial and professional services) and $A 3$ (restaurants and cafes) increasing respectively by $3.5 \%$ and $4 \%$ over the same period.

The changes in use classes represent distinct and locally particular changes in both Bromley and Orpington, although the timing and magnitude of the A3 changes in Bromley suggest a link to the completion of street improvements and the increasing identification of the area as a leisure location (perhaps facilitated by its higher quality built environment). This observation is supported by the growth in leisure services which have significantly increased from 80 in 2006 to 137 in 2016, with most of this growth occurring after 2015, and much of it replacing retail services. Similar declines in retail services were seen in Orpington, reflecting well documented retail market trends nationally (e.g. with post offices closing, photo services and travel services migrating online) rather than anything relating to the urban realm; in this case without similar gains in $\mathrm{A} 3$ uses.

General country-wide declines in comparison retailing seem also to have been cushioned in Bromley when compared to Orpington with, across the study period, a fall from $49 \%$ of the market in 2006 to $43 \%$ in 2016 as compared to $40 \%$ (2006) and $30 \%$ (2016). Part of this may be explained by a significant post-2014 increase in the number of non-multiple shops as a percentage of the retail market in Bromley (growing by 10.5\% between 2014 and 2016) and reflecting a confidence amongst small retailers to continue investing in the area. Orpington has seen a similar trend but far less substantial overall and with no post-2014 bounce.

\subsubsection{Hornchurch and Upminster market analysis}

Average rents across all three comparator levels in Hornchurch demonstrated consistent retail rental growth from 2009 to 2013 (when the intervention took place) followed by a small slump, with rents in the intervention and mid areas recovering quickly and continuing to increase by around $20 \%$ up to 2016 , whilst in the postcode area they fell until mid 2016, by some 31\%), before increasing. In the year immediately following the improvements rents in the intervention and mid areas rose

\footnotetext{
${ }^{18}$ It is worthwhile noting that these vacancy rates are substantially lower than both the national average retail vacancy rates, estimated at $12 \%$ (LDC, 2016) and also lower than the London vacancy rates of approximately $3 \%$. http://www.colliers.com/-/media/files/emea/uk/research/retail/201510-national-retail-barometer.pdf?la=en-gb
} 
respectively by 25 and $29.5 \%$, as opposed to a drop of $2 \%$ in the larger postcode area.

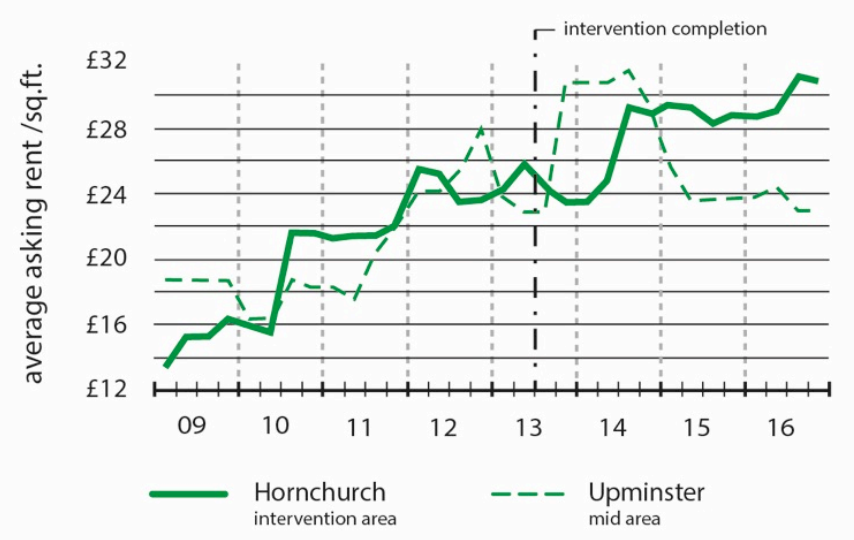

Figure 37: Hornchurch and Upminster retail markets compared ${ }^{19}$

Rents in the Upminster comparator show more fluctuation after 2013 and a fall from f31.61 to $\mathrm{f23.71}$ by mid 2015. Indeed on three occasions in recent years it has been significantly more expensive to rent retail space in Upminster than in Hornchurch. Since 2014, however, rents seem to have diverged considerably suggesting that a more permanent gap has opened up, and that the street based interventions may have contributed.

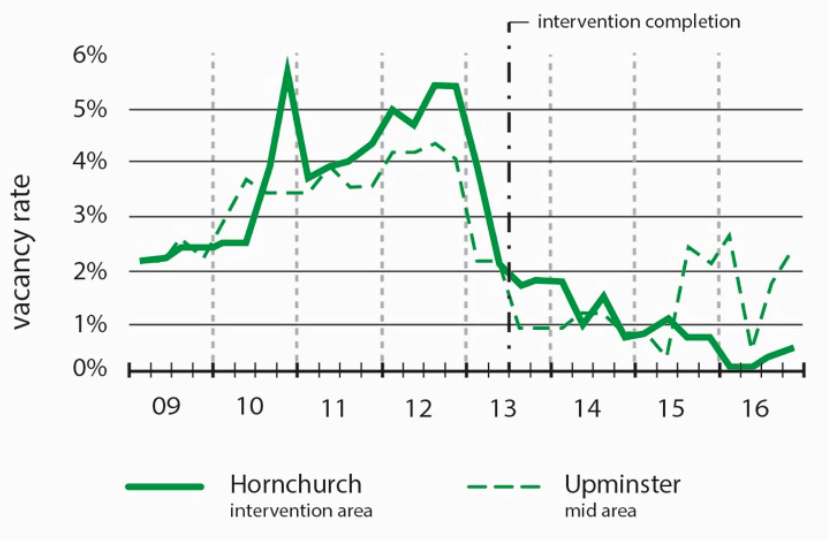

Figure 38: Comparing vacancy rates in Hornchurch and Upminster

Analysis of vacancy rates reinforce the picture. On average these clearly dropped from late 2012 onwards (perhaps anticipating the public realm investments) across all three levels in Hornchurch, although in the mid and intervention areas vacancy dropped further and had almost ceased to exist in late 2016 (whilst remaining at $1.3 \%$ in the postcode area). Vacancy in Upminster followed a similar trend although less marked and more volatile, with a significant increase in vacancy during 2016.

\footnotetext{
19 Hornchurch: postcode area (RM11 \& RM12): 188 properties, 13 vacancies; mid area: 66 properties, 3 spaces; intervention area: 67 properties, 4 vacancies; Upminster: postcode area (RM14): 67 properties, 4 vacancies; mid area: 52 properties, 4 vacancies
} 


\subsubsection{Hornchurch and Upminster occupancy analysis}

Across the time period studied (2007-2015), neither Hornchurch nor Upminster have seen any substantial change in the stock of retail property at the postcode level. Hornchurch saw a small and consistent drop across A1 uses from a peak of $61 \%$ (2007) to a low of $56 \%$ (2015), but a growth in A3 (restaurant and cafe) uses from 12\% (2007) to 20\% (2013), although with no obvious link to the completion of the street works. The area has experienced almost no change in the percentage of multiple and non-multiple retailers, at a time when Upminster has witnessed growing numbers of non-multiple retailers (a shift from 68\% in 2007 to $74 \%$ in 2015), perhaps suggesting that the street improvements in Hornchurch have helped to retain larger high street names in the area. Hornchurch has seen small decreases in the market representation of comparison, convenience and financial and business services across the period and at the postcode level, off-set by an increase in leisure services. However, much of this occurred prior to the street improvements and mirrored similar changes in Upminster.

The Hornchurch intervention area saw very similar use class trends to the postcode area suggesting that there were no significant changes in use class across the time period, apart from a similar small decline in A1 and increase in A3 uses. Only the percentage of multiple to non-multiple retailers seems to be different for the intervention area compared to the postcode area, where non-multiples had decreased from 62\% in 2007 to 58\% in 2015, demonstrating the continued desirability of the improved street for the large retail brands. As with the postcode area overall, comparison, convenience and financial and business services retailers had experienced a decline, with leisure services filling the gaps.

\subsubsection{Clapham and Camberwell market analysis}

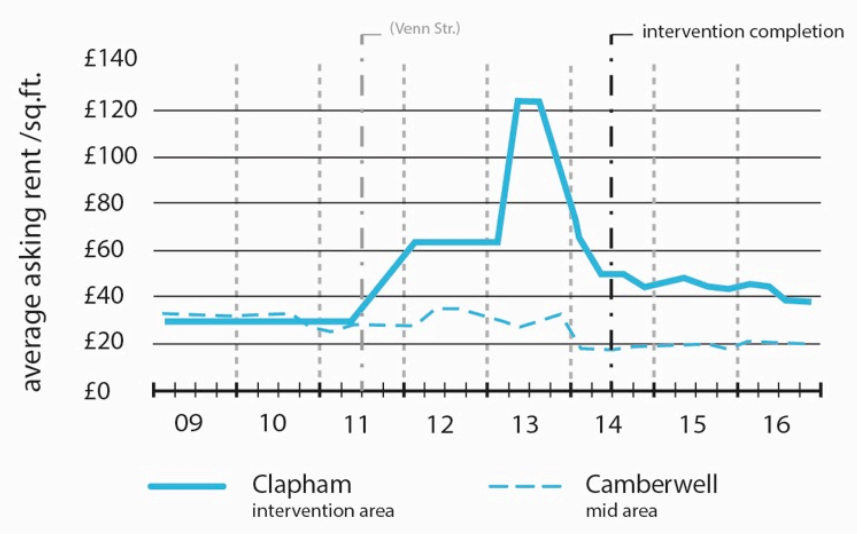

Figure 39: Clapham intervention area, Camberwell mid area, Clapham mid area ${ }^{20}$ average asking rent (per sq. $\mathrm{ft}$ )

\footnotetext{
${ }^{20}$ Clapham Old Town: Postcode area (SW4) 333 properties, 5 vacancies; mid area 242 properties, 3 vacancies; intervention area 53 properties, 0 vacancies. Camberwell: postcode area (SE5) 324 properties, 14 vacancies; mid area 135 properties, 10 vacancies.
} 
Clapham has experienced the largest fluctuations in retail rental levels, with a minimum rent of $f 29.91$ in 2009 and a maximum rent of $f 123.84$ in 2013, and is now the most expensive of the case study locations. There is clearly a pattern between rental increases in the intervention and mid areas of Clapham with the initial Venn Street improvements (of 2011) having a very significant effect on rent levels in the immediate areas (up 114\%), but not in the mid or postcode areas where rents decreased until the full works were completed in 2014, after which prices gradually increased.

Throughout the period of analysis the Clapham area consistently outperforms its Camberwell comparator although with rental levels fluctuating more severely, particularly in the intervention area where a bubble built from 2011 and burst in 2013. Camberwell, by contrast, is a particularly flat and non-responsive market with few obvious supply/demand issues. Whilst, post-2014, Clapham has settled down, it has settled at a level that is consistently higher than its comparator.

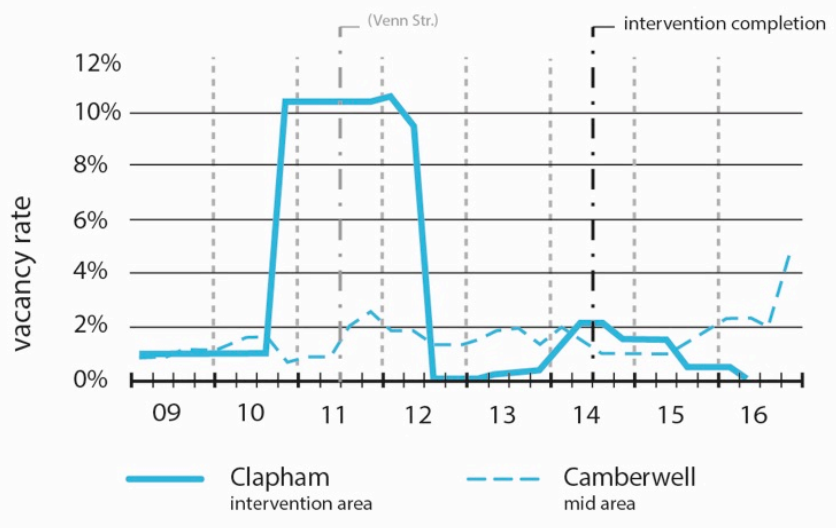

Figure 40: Comparing vacancy rates in Clapham and Camberwell

In Clapham, vacancy rates have been decreasing following the street improvements with both the intervention and mid areas experiencing rates of 0\% in 2013 (and again, in the intervention area, in 2016). Particular fluctuation can be seen at the intervention level with vacancy rates soaring between 2010 and 2012, during the period of the Venn Street works, and reaching a high of $10.5 \%$ before falling rapidly back. Camberwell, by comparison, has had relatively consistent vacancy rates since 2009 until 2016, when rates moved sharply upwards to 5\%.

\subsubsection{Clapham and Camberwell occupancy analysis}

Across the study period (2006-2015), neither Clapham nor Camberwell had seen any substantial change in the stock of retail property at the postcode level. Clapham did, however, see a small and consistent drop of A1 uses, from a peak of $53 \%$ (2006) to a low of $46 \%$ (2015), with small increases in $A 2, A 3$ and $A 4$ uses across the time period. This was mirrored in Camberwell where A1 uses decreased from 63\% to 56\% (2015) over the same period, with A3 (restaurant and cafe) uses increasing to fill the gaps and following patterns seen elsewhere across the different cases. 
Both Clapham and Camberwell witnessed a small increase in the number of nonmultiple shops, growing from 74\% (2006) to 78\% (2015) of the market in Clapham, and in Camberwell from $78 \%$ to $80 \%$. Both markets have a particularly high level of non-multiple retailers, whilst Clapham is different from other cases in the research in having a particularly low level of comparison retailers which declined further from $18 \%$ to $14 \%$ during the course of the study. Instead, leisure services are the dominant retail type at the postcode level, and have increased further from a low of $35.5 \%$ in 2013 to a high of $40 \%$ just two years later, indicating a further specialisation in leisure services following the completion of the street works. Camberwell, by contrast, has had a higher preponderance of comparison and convenience retailers, and a slower build up of leisure services to $32 \%$ by 2015, a trend spread across the entire period of study.

The Clapham intervention area was unique in experiencing a significant jump (post 2012) in GOAD data points, suggesting a significant increase in the number of retailers operating in the market immediately after the Venn Street alterations. These are dominated by $A 3$ uses, the numbers of which have increased as, unusually, so have the number of $A 1$ retailers in the area, from just 2 outlets in 2006 to 22 in 2012, and 12 in 2015. The intervention area also exhibits a much higher percentage of non-multiple retailers than the postcode area (89.5\% in 2014) whilst financial and business services now account for $22 \%$ of the market. In this area the street interventions have had a dramatic effect, diversifying and extending the retail offer and helping to buck the downward trend in $\mathrm{A} 1$ and comparison uses seen elsewhere.

\subsubsection{Woolwich and Catford market analysis}

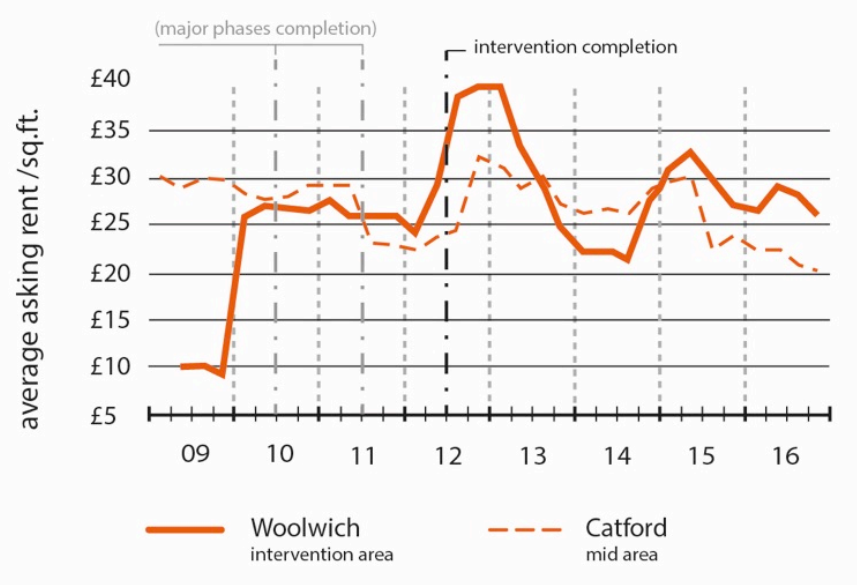

Figure 41: Woolwich and Catford residential markets compared ${ }^{21}$

Woolwich is characterised by significant fluctuations in retail rental levels across the scales of analysis, including an immediate and dramatic increase in rental levels of $157 \%$ ( $£ 10.15$ to $£ 26.04$ ) for the intervention area following the first improvements in 2009. A further significant increase was seen in 2012 following completion of the

\footnotetext{
${ }^{21}$ Woolwich: postcode area (SE18) 372 properties, 17 vacancies; mid area 183 properties, 14 vacancies; intervention area 152 properties, 5 vacancies. Catford: postcode area (SE6) 398 properties, 11 vacancies; mid area 208 properties, 10 vacancies.
} 
improvements in Woolwich, this time across all scales of analysis although with the intervention area again experiencing the highest uplift, this time of some $44 \%$. (against 16\% in the mid area and 11\% across the postcode).

After 2012 rents fluctuated in a downward direction and in the intervention area have returned to just above their post-2009 intervention levels, whilst elsewhere in Woolwich, perhaps reflecting national trends, rental values have continued to drop from an average of $£ 30$ in 2009 in the mid area to $£ 20$ in 2016. This mirrors trends in the larger postcode area where retail has been in long-term decline with, for example, a flagship Marks and Spencer store abandoning Woolwich in 2014.

Retail rents in the Catford comparator, by contrast, have been consistently lower than in both the intervention and mid areas of Woolwich. Currently rents in the Catford mid area are 120.30 on average and on a similar downward trend to Woolwich, although, since 2009, have been stagnant with a marginal increase over the period from the very low rents recorded at the start of the period of analysis. The analysis seems to reveal a significant boost in rental levels in the Woolwich intervention area when compared to both its own larger hinterland and the comparator, although this has not been enough to impact on the long-term story of decline in the town, with Woolwich declining from a town centre of regional importance to one of essentially local character and catchment similar to Catford, and now with comparable rental levels.

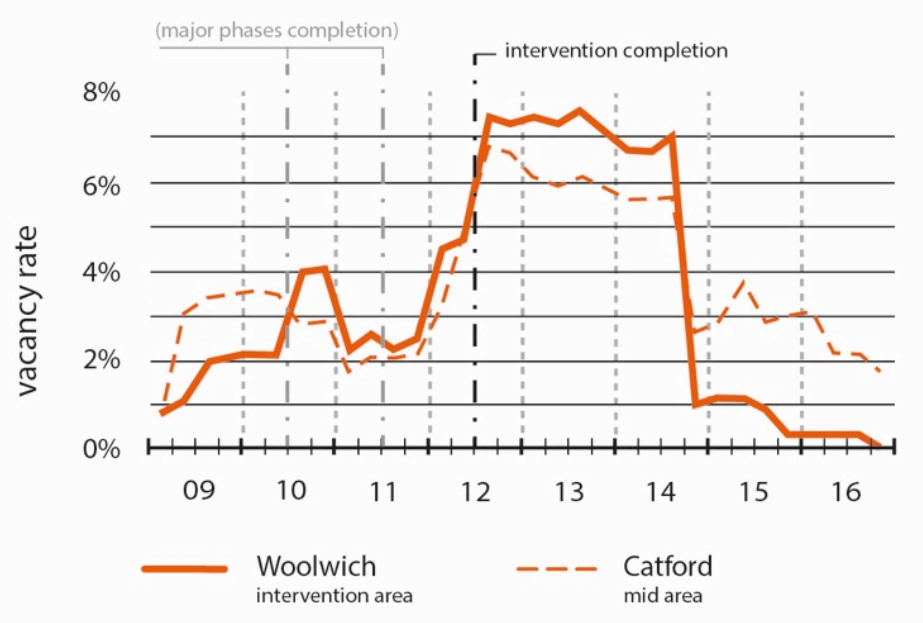

Figure 42: Comparing vacancy rates in Woolwich and Catford

Vacancy rates in Woolwich have been extremely volatile, with increases throughout much of the period of the works followed by a period of stabilisation after completion in 2012 and then, more recently, by a dramatic downwards adjustment as vacancy in the area of analysis has decreased from $7.6 \%$ at its height to $0 \%$ in 2016 , and to less than $2 \%$ in the mid area. To some degree the declining vacancy may be explained by falling rental levels and by occupiers being willing to take the space at the lower levels. It is also effected by the higher demand for space in the areas of improvement where occupiers are still willing to pay considerably higher prices. In 
Catford, by way of comparison, vacancy is on a slow upwards trajectory and is now above the levels seen in the Woolwich mid area.

\subsubsection{Woolwich and Catford occupancy analysis}

Across the study period, neither Woolwich nor Catford saw any substantial change in the size of their local retail market at postcode level, and only small fluctuations to their A1 offer and to the other use classes. The number of non-multiple shops as a percentage of the retail market in Woolwich grew by 7\% between 2006 and 2015, peaking at $72 \%$ in 2011 , with a similar increase of $6 \%$ recorded in Catford taking it to $74 \%$ overall by 2015 . In both, the proportion of retail services has increased by $4.5 \%$ and $4 \%$ respectively and appears to be continuing on a general upward trend whilst the representation of comparison and convenience retailers has remained very consistent with a small decline in financial and business services. All this suggests that as vacancies have occurred in Woolwich they have been filled rapidly, but by less well known retail brands and local retail services, with, ultimately, Woolwich becoming increasingly like Catford in its offer.

In the intervention area, by contrast (representing less than a third of the retail units in Woolwich), whilst the overall use class trends were similar, there was a boost in the numbers of A3 (restaurant and cafe) units which moved from $8.5 \%$ of the market in 2009 to 14\% in 2016. Compared to the postcode area, the intervention area exhibited consistently higher levels of non-multiple retailers (increasing by $7 \%$ to $88.5 \%$ in 2015) and comparison retailers (increasing from 13\% in 2007 to $23 \%$ by 2015) across the period. Whilst, it seems, the move from multiples to independents in Woolwich at large represents a story of going downmarket, in the intervention area the public ream works have given rise to higher order independent retailers, cafes and other leisure-based uses. Fluctuations in the data on floorplate sizes in the intervention area during the period also supports this narrative of change.

\subsubsection{Walworth and East Greenwich market analysis}

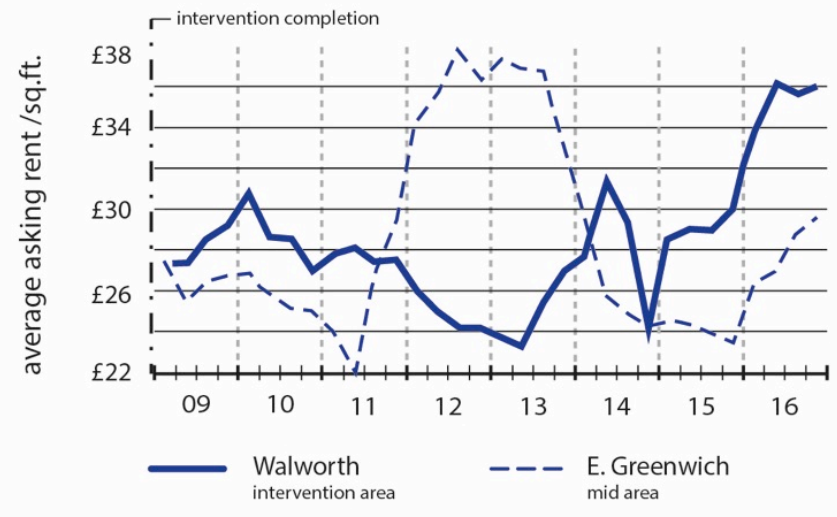

Figure 43: Walworth and East Greenwich residential markets compared ${ }^{22}$

\footnotetext{
${ }^{22}$ Walworth: postcode area (SE17) 220 properties, 9 vacancies; mid area 180 properties, 7 vacancies; intervention area 152 properties, 5 vacancies. Trafalgar Road: postcode area (SE10) 409 properties, 41 vacancies; mid area 277 properties, 39 vacancies.
} 
From an identical starting point in early 2009, the retail market in Walworth demonstrates an immediate uplift following the completion of the street improvements later that year, with a rise of $13 \%$ in the intervention and mid areas and a smaller uplift of $10 \%$ across the postcode. This compared to fluctuation but little substantive movement in the East Greenwich comparator over the same period. Quickly, thereafter, both areas seem to have been impacted by the acute effects of the global financial crisis leading to a long-term decline in Walworth and to a shorter decline in East Greenwich where recovery is much swifter and more dramatic, perhaps following the wider regeneration trends effecting Greenwich at large.

From mid 2013, whilst East Greenwich retail has dramatically declined, Walworth has turned the corner, with rental across all three scales of analysis performing well and in 2016 reaching the highest level of return for over a decade, and reversing a wellestablished historical trend with retail property in the intervention area outperforming that in the larger postcode area. Across the same period East Greenwich has crashed and begun to recover, and in 2016 rentals remained substantially below those being achieved in Walworth. The Walworth case seems to demonstrate an example of urban realm improvements becoming 'settled' into the environment and driving long-term positive market adjustments but in a context where other more general market shifts come and go, including those caused by the financial crisis or the mid-2014 rental dip that (as seen in the previous cases) was common across London.

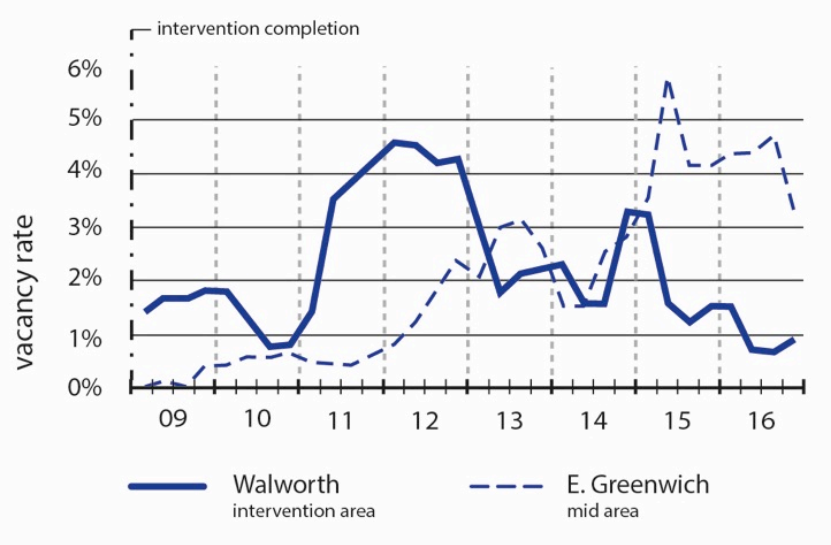

Figure 44: Comparing vacancy rates in Walworth and East Greenwich

In Walworth, vacancy rates have fluctuated but have generally tracked the rental market, with higher vacancy leading to a downward pressure on prices. In recent years, whilst vacancy in the unimproved East Greenwich has increased (from zero in 2009 to 3\% in 2016), those in Walworth have steadily declined, with the intervention area recording just $0.9 \%$ vacancy in 2016, down from almost 5\% following the financial crisis. Walworth, it seems, has become increasingly desirable as a retail location. 


\subsubsection{Walworth and East Greenwich occupancy analysis}

Across the time period (2006-2015), neither Walworth nor East Greenwich have seen any substantial fluctuations in the size of their respective local retail markets at postcode level, although both have seen a marginal reduction in the numbers of retail units. In terms of use class changes, Walworth has experienced very little change, with a small decline in the dominant $A 1$ use class, from a peak of $75 \%$ in 2009 to 72\% in 2015, and negligible increases in A2 and A3 use classes whilst ASG declined slightly. In East Greenwich, A1 has declined more over the time period, from $66 \%$ in 2010 to $58 \%$ in 2015 , being partially replaced by a $3 \%$ increase in A2 (financial and professional services).

Both street environments have seen similar small increases in non-multiple shops as a percentage of the retail market to in excess of $80 \%$ in recent years; and whilst comparison shopping has remained consistent in East Greenwich (from a much lower base), it has declined by $12 \%$ in Walworth, representing a reduction of 38 retailers, being replaced largely by retail services. Moving from the postcode level to that of the Walworth intervention area, changes are very similar, although with a higher increase in non-multiples from a low of 59\% of the market in 2006 to a high of $67 \%$ in 2015. In sum the use classes reveal little beyond the story already identified of a slowly changing retail market nationally, and local changes that are helping to make some centres more resilient than others.

\subsection{Retail market findings}

Changes to rental values (upwards), levels of vacancy (downwards), and the resilience of under pressure retail types all indicate a willingness to pay to occupy retail space which is more attractive by virtue of the street improvements and which may therefore prove more profitable to the occupier. Aggregating the market and vacancy data across the case studies demonstrates that rather than just seeing correlations on a case by case basis, in fact we are most likely seeing causations between street improvement and retail success. Thus over the course of the period of analysis, retail environments that have benefitted from street improvements have delivered an average rental uplift of some $54 \%$, reducing to $44 \%$ further away from the intervention into the mid area. This compares with their comparator locations where the aggregate results from the mid area comparison shows a $17 \%$ average decline in retail values. The vacancy data is equally compelling. Again, over the course of the study, intervention areas have seen a $58 \%$ fall in vacancy as compared to a $21 \%$ fall in their related mid areas. This compares to an average $116 \%$ increase in vacancy in comparator mid areas that have not been improved. Like the office market, whilst it is not possible to apply any statistical tests (e.g. t-test) to the retail data which was only available to show average appreciation ${ }^{23}$, it is clear that the differences in these markets were also extremely significant.

Examining the market and occupancy analysis across the cases and their comparators, the evidence suggests that there are clear market responses at the

\footnotetext{
${ }^{23}$ As opposed to on a property by property basis as would be necessary in order to show distribution.
} 
intervention area level (and frequently also across an expanded area), to the street improvements. These have led to a discernable uplift in rental values across all of the improved case studies; albeit uplifts that are also subject to the range of other factors that also effect local retail markets: local rent reviews, long-term market shifts in occupier types, regeneration impacts and, of course, swings in the economy.

In such a context it is difficult to completely attribute any specific value uplift to an intervention, or to determine the exact magnitude (on a case by case basis) of the influence of street improvements. Nevertheless the inference that the uplifts in rental value in the improved cases is a result of the street interventions is strongly reinforced by its observation in all five cases, and through associated observable positive impacts on reducing vacancy, again across the five 'improved' case studies. Reading impacts in the patterns of occupancy were harder to trace, although variously increases in A1 (traditional retail) and A3 (leisure) uses, increases in multiples and comparison retail (against trend), and greater resilience in face of wider market change were recorded in each of the improved areas. These market signals reinforce the evidence seen in the market analysis. 


\subsection{Movement}

If international evidence is to be believed, for example the work of Jan Gehl (2010) in Europe and the Project for Public Spaces in the US (MacKenzie 2015), then an attractive street environment should, in theory, lead to increased levels of walking, cycling and positive choices to use public transport. Over time there is also the potential to reduce private traffic volumes. 'Street life' studies can be used to understand these levels of activity beyond the relatively limited understanding which can be gained through static movement and traffic counts, and the essential element of such studies is to 'look and learn': observing and recording the behaviour of people in public spaces.

Because street activity is diverse and unpredictable and cannot be captured by automated methods or effectively modelled under different design scenarios, street life methods give an actual and nuanced understanding of what is going on. However, when linking the results of such studies to the impact of street improvements, care needs to be exercised in claiming causality between any improvements and the patterns observed. This is because many other factors can also impact on patterns of movement and activity, not least the quality of the attractions, the density and type of surrounding housing or employment, the transport infrastructure, and even the cultural and social norms surrounding walking and cycling in a particular population. In London, for example, recent strategic investments in new connected up cycle infrastructure is much more likely to have an impact on levels of cycling than local changes to individual streets. The analysis that follows attempted to assesses the impact of the street improvements for the five improved street environments and their comparator areas in relation to how movement behaviours have changed by examining both traffic movements and street activity.

\subsection{Movement analysis}

Traffic counts were assessed drawing on already available data from Department for Transport (DfT) National Road Traffic Census (NRTC) sites and TfL ad-hoc traffic counts located within or close to the study areas. To optimise results from this type of data, the location of traffic counts should ideally be situated within the intervention areas with close monitoring both before and after the improvements in order to give an indication of how movements had been effected by the interventions. Unfortunately traffic counts were usually not well matched to the locations of the streets improvements, and often sat beyond the mid area boundaries. The available data therefore gave an indication of surrounding traffic flows and whether any change had occurred following the interventions (e.g. a peak or trough in traffic caused by the intervention), but were not well suited to understanding the local impact of the work. They were also limited in their focus primarily on vehicle movements (including cycling) and for most cases (the exception being Bromley) there was no systematic monitoring of pedestrian movements. Transport for London collision data was also consulted from the London Collision 
$\mathrm{Map}^{24}$ in order to gauge whether levels of serious and fatal collisions within the intervention areas had been affected by the works. This data is freely available on line and when consulted mapped the eleven year period 2005-2015.

Street life analysis was therefore also undertaken to give a bespoke analysis for each of the five cases and their comparators. Ideally, again, this would have occurred both pre and post intervention but the timescale of the research and street improvements did not allow this. Instead a single snapshot of activity was observed for each pair, in the same or, if not possible, a similar day/time across the two locations; and avoiding weekday peak times. All the analysis was undertaken in the late summer / early autumn of 2016 with efforts made to ensure similar weather conditions pertained to each pair. Each snapshot amounts to approximately 30 minutes of observation - the time it took to cover each of the required areas in one walk and note activities. The areas covered were selected to include the whole of the intervention sites in the case studies and similar networks of streets and spaces in the comparator locations (Table 4).

\begin{tabular}{|c|c|}
\hline Location and day & Date and conditions \\
\hline \multirow[t]{2}{*}{ Bromley and Orpington: Weekday AM } & BR: Tue 23/8/16| 10.30 -11.00 | sunny \\
\hline & OR: Tue 23/8/16 | 12.00-12.30 | sunny \\
\hline \multirow{2}{*}{$\begin{array}{l}\text { Hornchurch and Upminster: Weekend } \\
\text { PM }\end{array}$} & HO: Sat 17/8/16| 15.00 - 15.30 | cloudy but warm \\
\hline & UP: Sat 3/9/16| 16.00 - 16.30| cloudy but warm \\
\hline \multirow{2}{*}{$\begin{array}{l}\text { Clapham and Camberwell: Weekday } \\
\text { PM }\end{array}$} & CL: Thu $25 / 8 / 16|\sim 16.00-16.30|$ sunny \\
\hline & CA: Wed 7/9/16 | 15.30-16.00 | cloudy but warm \\
\hline \multirow[t]{2}{*}{ Woolwich and Catford: Weekday AM } & WO: Wed 21/9/16 | 12.00 - 12.30 | sunny \\
\hline & CAT: Wed 28/9/16| 11.30 - 12.00 | cloudy but warm \\
\hline \multirow{2}{*}{$\begin{array}{l}\text { Walworth and East Greenwich: } \\
\text { Weekend PM }\end{array}$} & WA: Sun 2/10/16| 15.00 - 15.30 | cloudy but warm \\
\hline & TR: Sun 9/10/16 | 16.00 - 16.30 | cloudy but warm \\
\hline
\end{tabular}

Table 4: Street activity surveys

The observations were converted into combined activity counts for comparative purposes. Whilst these remain approximate, they provide a valuable indicator of the differences in levels of activity generated by the improvement cases when viewed against their comparators.

\subsubsection{Bromley and Orpington traffic analysis and collisions}

The Bromley traffic and pedestrian counts were not ideally located to monitor impacts from the street improvements as they are found on roads adjacent to the study area. A DfT (Tweedy Road) count showed the dominance of traffic, particularly car and taxi movements (82\% of trips) and goods vehicles (11-12\% of trips), whilst cycling remains very marginal (1\% of trips) and pedestrians were not counted. There was no change relative to the street improvement in 2014. The Orpington DfT (High Street/Perry Hall Road) count demonstrated a similar mode share, again with traffic movements dominating, and confirming the legitimacy of the comparison.

\footnotetext{
${ }^{24}$ https://tfl.gov.uk/corporate/safety-and-security/road-safety/london-collision
} 
A Bromley TfL (High Street) pedestrian count indicated that there was an increase in pedestrian movements in the area of some 5\% between 2014 and 2015, although this seems to be part of a long-term upwards trend and therefore can not be put down to the street improvements alone. Overall, the traffic data suggests that traffic flows in Bromley were not significantly effected by the improvements, but the data was limited and imperfect and definitive judgements are hard to make. Collision data in Bromley showed zero serious or fatal accidents in the intervention area either before or after the improvements.

\subsubsection{Bromley and Orpington street activity}
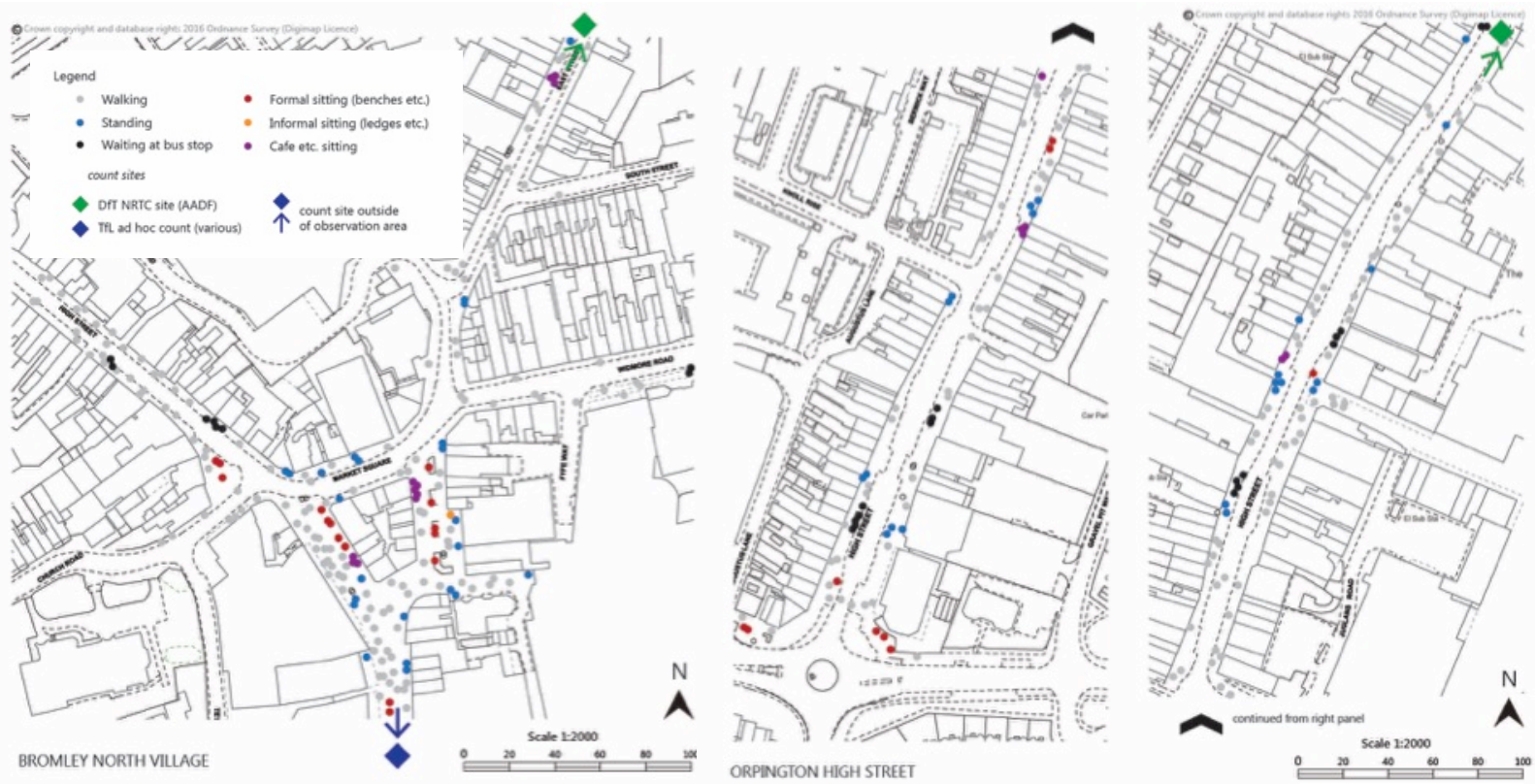

Figure 45: Bromley and Orpington activity analysis

In terms of street activity, Bromley has a higher level of pedestrian activity relative to Orpington, particularly around the Market Square. There is also more formal sitting on benches, sitting in cafes, standing and people walking - a $34 \%$ increase in overall street activity relative to the comparator study. This increased activity is likely to strongly reflect the higher quality of the built environment in Bromley and the opportunity to sit, dwell and spend time in the town centre. Given the similarities otherwise between the two areas, this difference associates strongly with the street improvements.

\begin{tabular}{|l|l|l|l|}
\hline Activity & Bromley & Orpington & $\%$ Difference \\
\hline Walking & 145 & 103 & $41 \%$ \\
\hline Standing & 24 & 22 & $9 \%$ \\
\hline Waiting at bus stop & 15 & 17 & $-12 \%$ \\
\hline Formal sitting (benches, etc.) & 15 & 9 & $67 \%$ \\
\hline Informal sitting (ledges, etc.) & 1 & 0 & - \\
\hline Café sitting (external) & 11 & 6 & $83 \%$ \\
\hline Total & 211 & 157 & $34 \%$ \\
\hline
\end{tabular}

Table 5: Street activity count comparison 


\subsubsection{Hornchurch and Upminster traffic analysis and collisions}

There were no available traffic counts near to the Hornchurch case study. In Upminster a TfL (Station Road North-St Mary's East) count indicated a high car and bus mode share, with few cycle movements. A second TfL (Corbets Tey Road) count showed an even higher car mode share. Informal observations at Hornchurch suggest a similar high car and bus mode share with a higher proportion of buses similar to UP1. Whilst the street improvements reduced the space for vehicles and increased that for pedestrians, vehicle flow capacity remains the same with a single lane of traffic in both directions. Collision data in the Hornchurch area showed an average of 0.3 serious or fatal accidents in the years prior to the intervention reducing to zero in the two years after the improvements.

\subsubsection{Hornchurch and Upminster street activity}
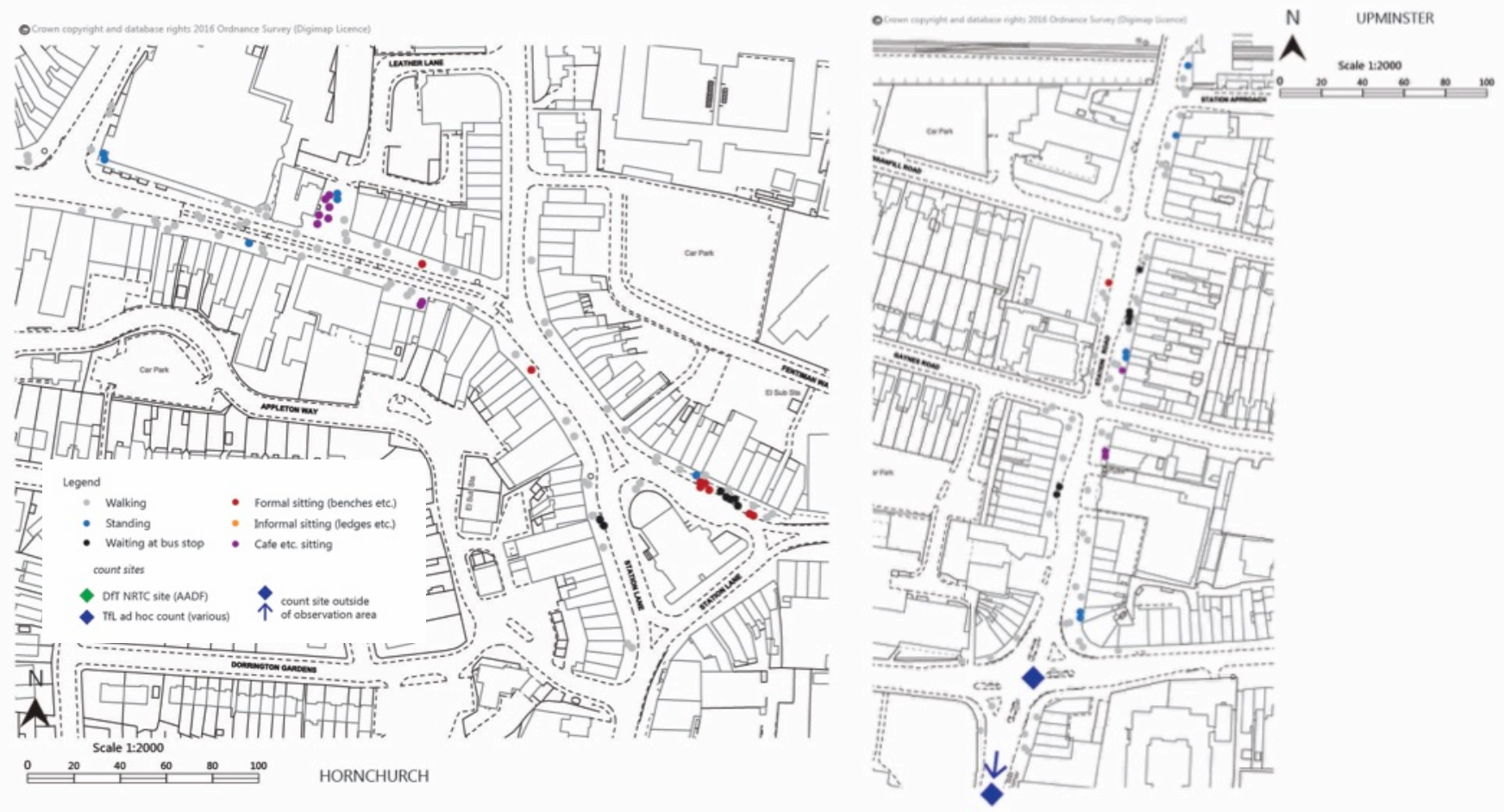

Figure 46: Hornchurch and Upminster activity analysis

\begin{tabular}{|l|l|l|l|}
\hline Activity & Hornchurch & Upminster & \% Difference \\
\hline Walking & 64 & 47 & $36 \%$ \\
\hline Standing & 6 & 6 & $0 \%$ \\
\hline Waiting at bus stop & 7 & 6 & $17 \%$ \\
\hline Formal sitting (benches, etc.) & 8 & 1 & $700 \%$ \\
\hline Informal sitting (ledges, etc.) & 0 & 0 & $0 \%$ \\
\hline Café sitting (external) & 8 & 1 & $700 \%$ \\
\hline Total & 93 & 61 & $52 \%$ \\
\hline
\end{tabular}

Table 6: Street activity count comparison

In terms of street activity, Hornchurch has a higher level of pedestrian activity relative to Upminster Station Road, particularly around Station Lane and the High Street. There is more formal sitting on benches, sitting in cafes, standing and people walking - a 52\% increase in overall activity relative to the comparator case study. This increased activity reflects the higher quality public realm and the opportunity to sit 
and spend time in the town centre. Given the similarities between the two areas, much of this difference seems likely to relate to the street improvements.

\subsubsection{Clapham and Camberwell traffic analysis and collisions}

As comparators, Clapham and Camberwell are more different than others in terms of the sorts of traffic they accommodate. Thus whilst Clapham has a much higher incidence of cycles, Camberwell copes with significantly greater numbers of heavy vehicles, both busses and goods vehicles. A first TfL (High Street) mode share count is located on the edge of the study area and the data precedes the street improvements, but demonstrates the relatively high cycle mode share (42\% northwards in the morning peak) and low car mode share (35\% northwards).

A second TfL (Old Town) count in Clapham focussed on cycles only and showed a dramatic increase in cycle movements (48\% northwards in the morning peak) from 2014-2015 suggesting a continuation of existing trends after the interventions rather than any dramatic switch in traffic loads. The comparator counts in Camberwell (one $\mathrm{DfT}$ and two TfL) indicated a greater dominance of traffic, particularly car and taxi movements (61\% of trips) and goods vehicles (11-12\% of trips). Cycling is relatively high at $9 \%$ and increasing, although from a much lower base. Collision data in Clapham showed just a single serious or fatal accident in the Old Town 2010 and none after the improvements.

\subsubsection{Clapham and Camberwell street activity}

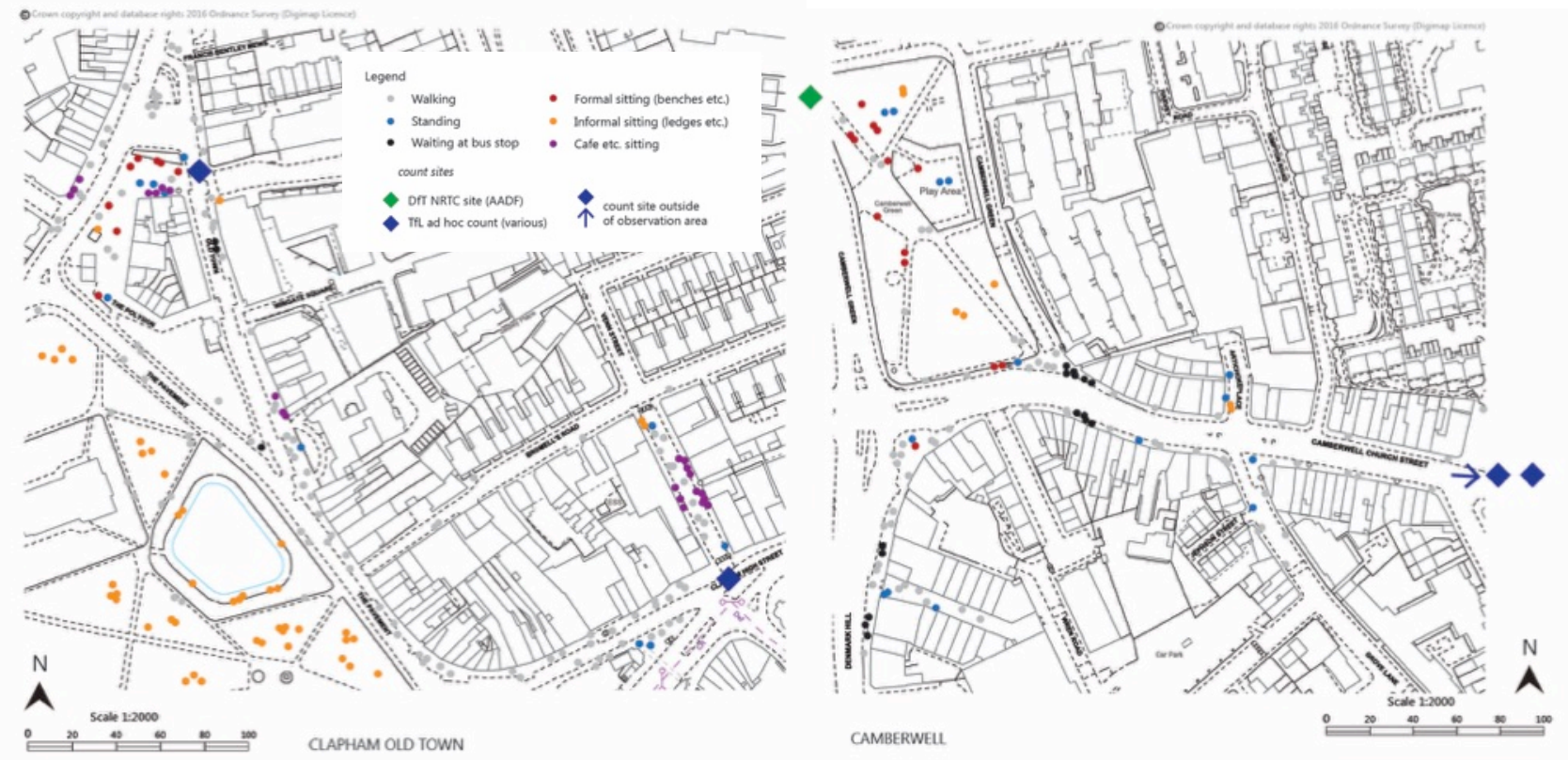

Figure 47: Clapham and Camberwell activity analysis

With regards to street activity, Clapham has a higher level of pedestrian activity relative to Camberwell, particularly around the Polygon, in Clapham Common near Cock Pond and at Venn Street. There is much informal sitting near the pond, and formal sitting on benches, sitting in cafes, standing and people walking near to the Polygon and at Venn Street - all amounting to a $82 \%$ increase in overall activity 
relative to its comparator. This increased activity seems likely to reflect the better street environment and the opportunities for sitting, staying and spending time that the area affords. Whilst traffic profiles are different between the two cases, the other similarities between them suggest that much of this difference is again likely to stem from the street improvements.

\begin{tabular}{|l|l|l|l|}
\hline Activity & Clapham & Camberwell & \% Difference \\
\hline Walking & 113 & 61 & $85 \%$ \\
\hline Standing & 10 & 14 & $-29 \%$ \\
\hline Waiting at bus stop & 3 & 15 & $-80 \%$ \\
\hline Formal sitting (benches, etc.) & 8 & 13 & $-38 \%$ \\
\hline Informal sitting (ledges, etc.) & 44 & 7 & $529 \%$ \\
\hline Café sitting (external) & 22 & 0 & - \\
\hline Total & 200 & 110 & $82 \%$ \\
\hline
\end{tabular}

Table 7: Street activity count comparison

\subsubsection{Woolwich and Catford traffic analysis and collisions}

Located beyond the Woolwich study area, a DfT traffic count was not ideally situated to monitor impacts from the street improvements. This (Beresford Street) count showed the dominance of traffic, particularly car and taxi movements (73\% of trips) and goods vehicles (20\%) whilst cycling remains very marginal. There is no significant change relative to the public realm improvements completed in 2012 (apart from buses becoming more frequent), but this is to be expected given the nature of Beresford Street as a major trunk road.

A Catford DfT (Rushey Green) count showed a similar mode share, again with car and freight goods vehicle movements dominating. Second TfL counts in both locations focussed only on pedestrians and only gave a snapshots of pedestrian flows in 2003 (Woolwich) and 2008 (Catford) respectively and were therefore not useful for the analysis. Overall the story is again one of no significant change caused by the street improvements to the traffic capacity and flows. Collision data in the Woolwich area showed an average of 2.4 serious or fatal accidents per year in the years prior to the intervention reducing to an average of 0.67 in the three years after the improvements.

\subsubsection{Woolwich and Catford street activity}

In terms of street activity, Woolwich has a much higher level of pedestrian activity relative to Catford, particularly around Gordon Square, Beresford Square and Powis Street. There is pedestrian activity throughout the town centre, with formal sitting on benches, sitting in cafes, standing and people walking all prevalent and, collectively representing a $116 \%$ increase in overall activity relative to the Catford comparator. Like the other cases, this increased activity reflects the better public realm and the opportunity to sit, rest and spend time in the town centre, all opportunities that would have been significantly improved through the street interventions. 

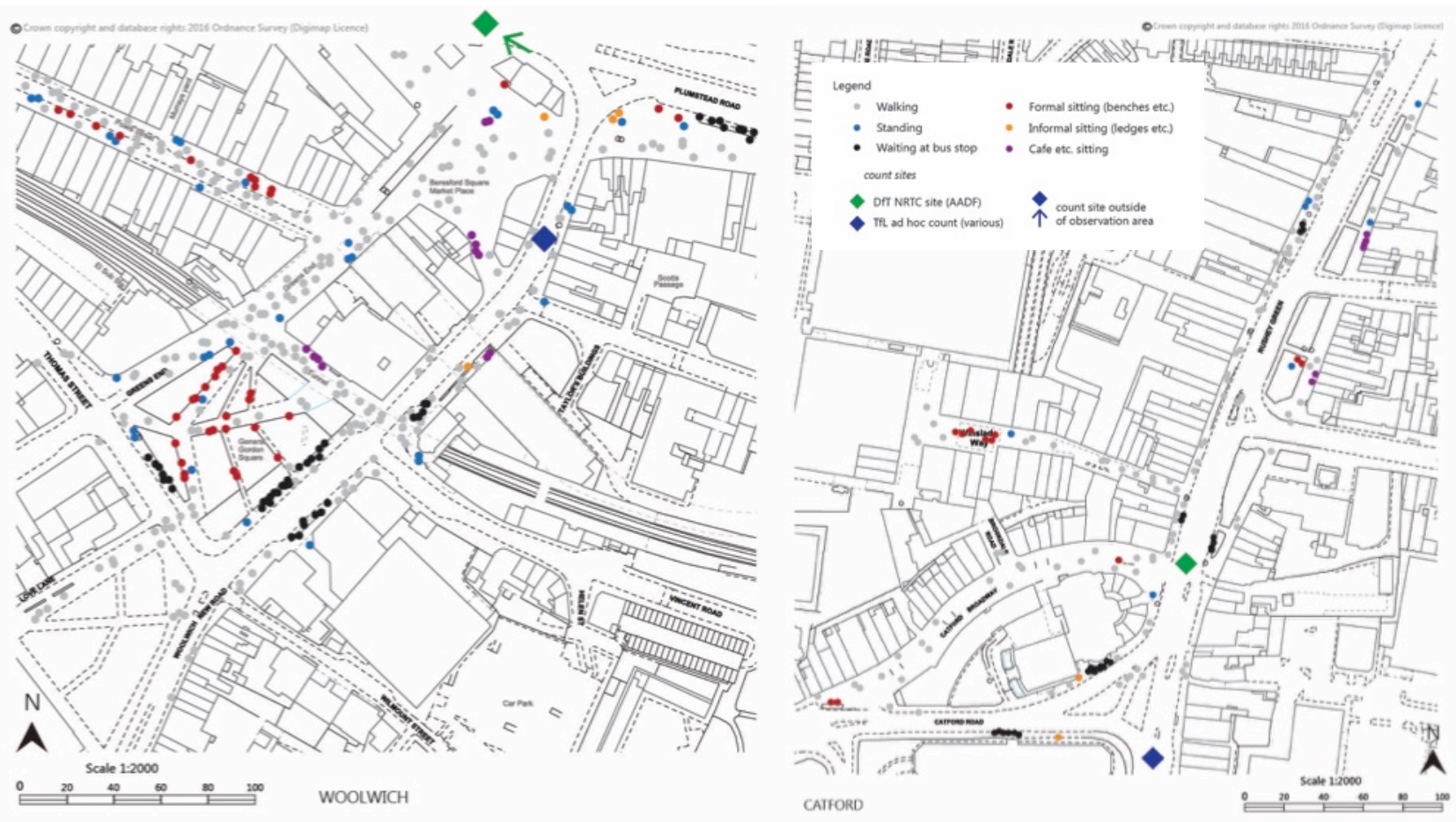

Figure 48: Woolwich and Catford activity analysis

\begin{tabular}{|l|l|l|l|}
\hline Activity & Woolwich & Catford & \% Difference \\
\hline Walking & 215 & 109 & $97 \%$ \\
\hline Standing & 31 & 7 & $343 \%$ \\
\hline Waiting at bus stop & 42 & 23 & $83 \%$ \\
\hline Formal sitting (benches, etc.) & 36 & 11 & $227 \%$ \\
\hline Informal sitting (ledges, etc.) & 4 & 2 & $100 \%$ \\
\hline Café sitting (external) & 14 & 6 & $133 \%$ \\
\hline Total & 342 & 158 & $116 \%$ \\
\hline
\end{tabular}

Table 8: Street activity count comparison

\subsubsection{Walworth and East Greenwich traffic analysis and collisions}

The most complete data from Walworth was from the TfL (Walworth Road) traffic count which gave a time series from 2006-2015, showing how cycling has increased from $9 \%$ to $14 \%$ of trips and car usage dropping from $56 \%$ to $47 \%$. Here the works leading to the completion of the Walworth Road improvements in 2008 seem to have led to a significant drop in car usage that never returned thereafter as the capacity of the road was reduced from a bus lane and general traffic lane in each direction to a single carriageway only. Two further TfL (Walworth Road) counts confirmed the continuation of this trend, showing a small increase in cycling from 2011 to 2013 and a drop in car use. Car movements remain dominant but are relatively low for the London context. A final TfL cycle count provided data for 2015 but with no time series and was therefore unusable. The East Greenwich DfT (Trafalgar Road) count indicated a higher and very dominant car mode share, with a slight decline between 2011 and 2014 and a small increase in cycling. Two TfL counts confirmed the picture.

Walworth was the only case study where traffic had been noticeably cut as a consequence of the street improvements. In this case the change stemmed from a deliberate reduction in road capacity on the A215 where two lanes in each direction 
had been reduced to one. Collision data in the Walworth area showed an average of 5 serious or fatal accidents per year in the years prior to the intervention reducing to an average of 3 in the seven years after the improvements.

\subsubsection{Walworth and East Greenwich street activity}
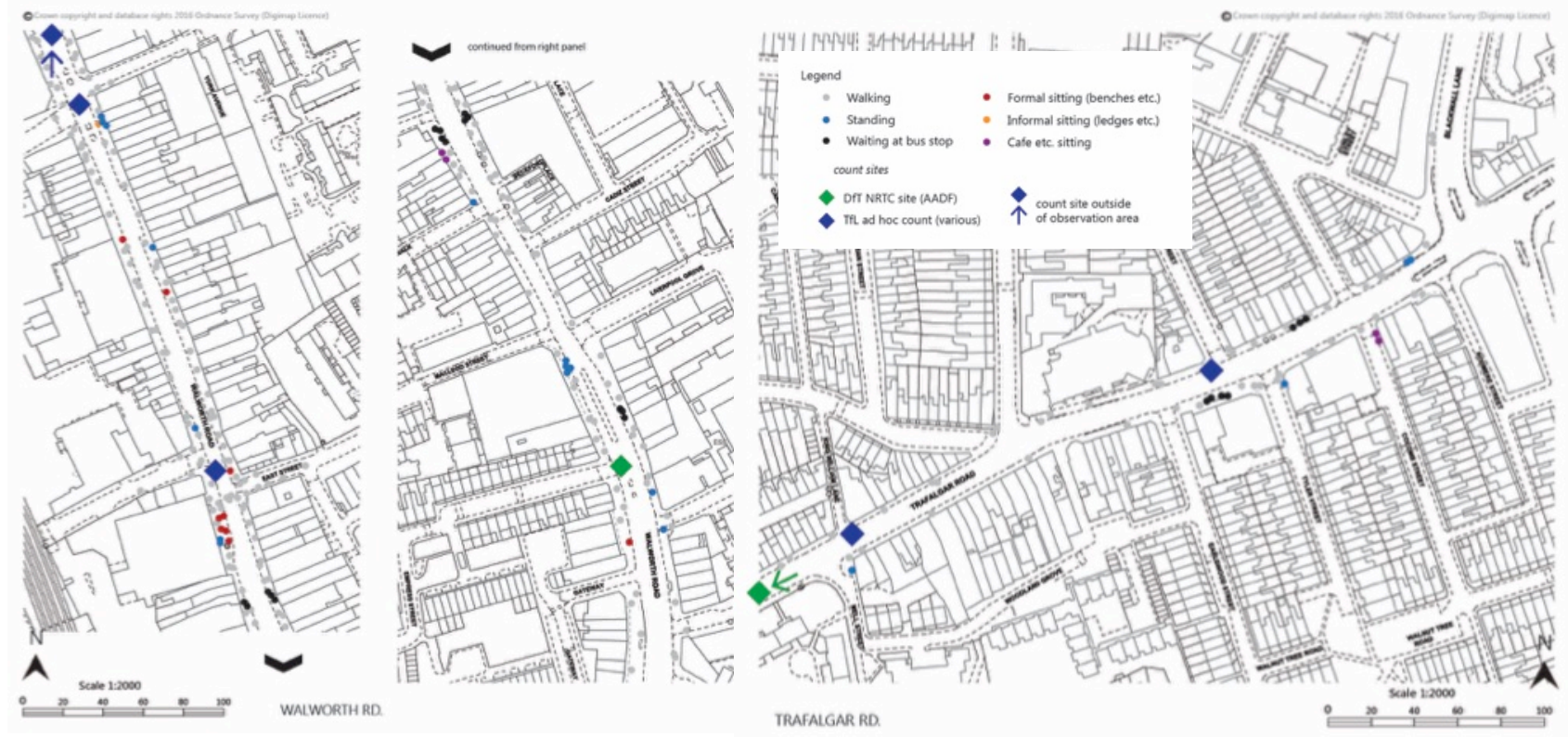

Figure 49: Walworth and East Greenwich activity analysis

Turning to street activity, Walworth Road had a significantly higher level of pedestrian activity relative to Trafalgar Road in East Greenwich, particularly near to the junction with East Street. There is much walking and some formal sitting on benches which altogether amounts to a very significant $256 \%$ addition to overall activity relative to the comparator. This increased activity reflects the better street environment and the opportunities it provides to rest and stroll along the street. Given the strong similarities between these two cases, these opportunities, particularly those associated with walking, can be confidently ascribed to the enhanced public realm.

\begin{tabular}{|l|l|l|l|}
\hline Activity & Walworth & E. Greenwich & $\%$ Difference \\
\hline Walking & 169 & 46 & $267 \%$ \\
\hline Standing & 14 & 4 & $250 \%$ \\
\hline Waiting at bus stop & 15 & 7 & $114 \%$ \\
\hline Formal sitting (benches, etc.) & 9 & 0 & - \\
\hline Informal sitting (ledges, etc.) & 1 & 0 & - \\
\hline Café sitting (external) & 2 & 2 & $0 \%$ \\
\hline Total & 210 & 59 & $256 \%$ \\
\hline
\end{tabular}

Table 9: Street activity count comparison

\subsection{Movement findings}

Whilst the traffic data was inconsistent, partial and often individually inconclusive, collectively across the improvement cases its analysis reveals a very clear story. This is that by itself, and without consequential reductions in road capacity, street improvements do not seem to impact on traffic flows or modes. 
The exception was Walworth where the removal of a dedicated bus lane in each direction on Walworth Road and the consequential reduction to one lane of general traffic had significantly reduced traffic capacity. Even there the reduction in traffic by less than $10 \%$ over the study period was not as much as might have been expected from the significant reduction in road capacity. Elsewhere, whilst traffic was partially removed from parts of Bromley and Woolwich town centres and completely from Venn Street in Clapham (which was pedestrianized along with partial pedestrianisation in the Old Town), the local and low traffic nature of these streets meant that they had little effect on traffic flows in their respective larger case study areas.

Beyond this significant finding there was some limited evidence from the traffic counts of rising levels of walking (in the only case where data was available) and particularly cycling. These findings were inconclusive however because of the poor and inconsistent quality of the available data. The evidence on safety related to traffic evidence was also inconclusive in Clapham and Bromley because of the generally very low (or non-existent) levels of serious or fatal accidents in the intervention areas either before or after the improvements. Hornchurch showed a slight reduction although the data following the intervention was only for two years. The data in both Woolwich and Walworth was more convincing with both showing significant reductions in serious or fatal accidents over longer periods equivalent to a reduction of around two collisions per year in both cases.

The evidence on street activity was far more conclusive. Without exception the cases with street improvements far outstripped their comparators in terms of the range of static and active street behaviours that they hosted (Figure 50). Bromley had 34\% more pedestrian activity than Orpington, Hornchurch had 52\% more activity than Upminster, Clapham had 82\% more than Camberwell, Woolwich had 116\% more than Catford, and Walworth had 256\% more than East Greenwich. The activity counts are approximate, but this is a consistent trend of very significantly higher activity in the improved locations.

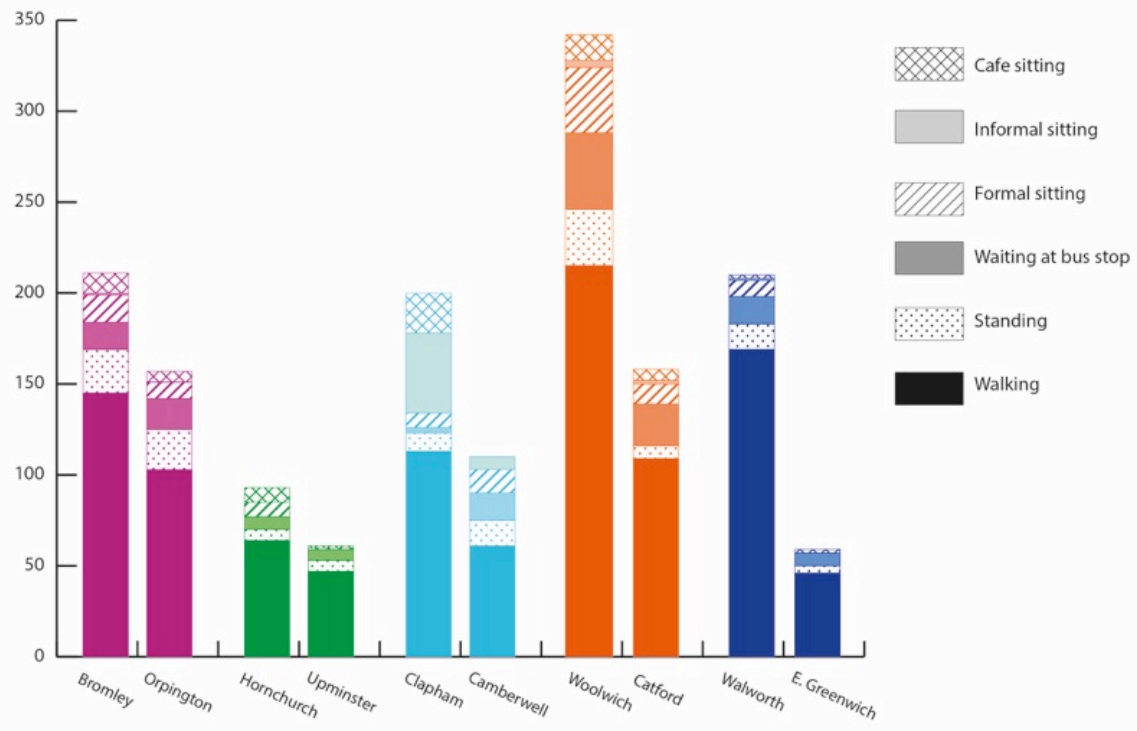

Figure 50: Street behaviours compared 
When these levels of street activity are aggregated across the five improved and five unimproved cases, some stark differences are obvious (Table 10). First, a sizable 93\% uplift in levels of walking overall in the improved cases when compared to those without intervention. Second, an almost identical increase of $96 \%$ in the volume of static activities (standing, waiting, and sitting of all types) associated with the improved cases. Moreover, if only the types of leisure activities such as sitting (formal and informal) or stopping at a café are considered, then this rises to a $216 \%$ difference over and above the unimproved cases (Figure 51). These are the types of activity that typically only take place when the environment is suitably conducive (aka of a high enough quality) (Gehl 1996).

\begin{tabular}{|c|c|c|c|c|c|c|c|c|c|}
\hline Activity & \multicolumn{3}{|c|}{ Improved cases } & \multicolumn{3}{|c|}{ Unimproved cases } & \multicolumn{3}{|c|}{ \% Difference } \\
\hline Walking & \multicolumn{3}{|c|}{706} & \multicolumn{3}{|c|}{366} & \multicolumn{3}{|l|}{$93 \%$} \\
\hline Standing & \multicolumn{3}{|l|}{85} & \multicolumn{3}{|c|}{53} & \multicolumn{2}{|l|}{$60 \%$} & \multirow{5}{*}{$96 \%$} \\
\hline $\begin{array}{l}\text { Waiting at bus } \\
\text { stop }\end{array}$ & \multicolumn{2}{|l|}{82} & \multirow{4}{*}{350} & \multicolumn{2}{|l|}{68} & \multirow{4}{*}{179} & \multicolumn{2}{|l|}{$21 \%$} & \\
\hline $\begin{array}{l}\text { Formal sitting } \\
\text { (benches, etc.) }\end{array}$ & 76 & \multirow{3}{*}{183} & & 34 & \multirow{3}{*}{58} & & $124 \%$ & & \\
\hline $\begin{array}{l}\text { Informal sitting } \\
\text { (ledges, etc.) }\end{array}$ & 50 & & & 9 & & & $456 \%$ & $216 \%$ & \\
\hline $\begin{array}{l}\text { Café sitting } \\
\text { (external) }\end{array}$ & 57 & & & 15 & & & $280 \%$ & & \\
\hline Total & \multicolumn{3}{|c|}{1056} & \multicolumn{3}{|c|}{545} & \multicolumn{2}{|l|}{$94 \%$} & \\
\hline
\end{tabular}

Table 10: Aggregate street activity count comparison

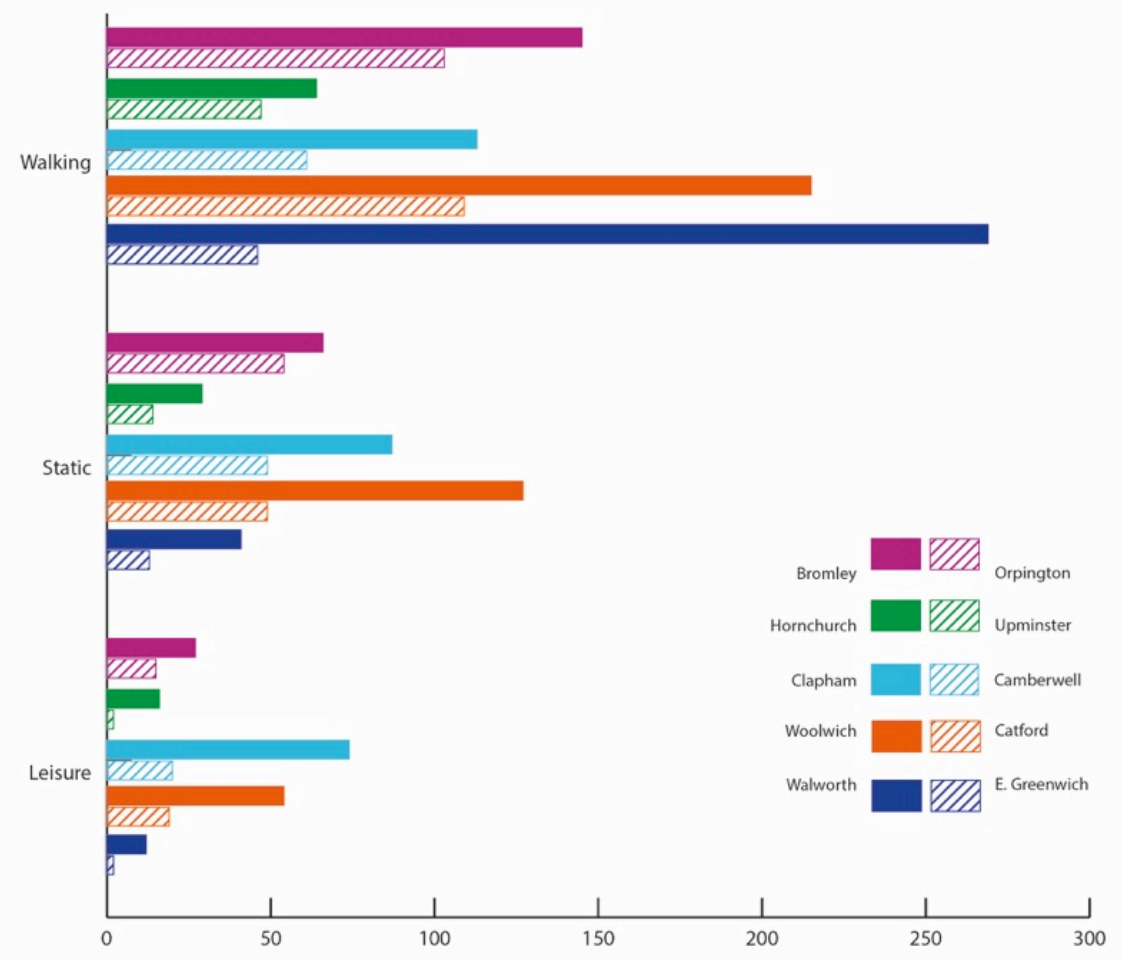

Figure 51: Walking, static and leisure activities compared

Finally, if all the mapped street activities are taken together across the cases then these give an overall difference between the improved and unimproved cases of some $94 \%$. This is a difference that is highly significant and can be strongly associated with the street improvements. 


\subsection{Exchange}

A critical component of street life is how streets are used as public venues for exchange: social exchange, economic exchange, even political and cultural exchange. Exchange is, to some degree, an overarching issue, and some of the contributory factors to a conducive environment for exchange have already been captured. Elements of the social context, e.g. places to meet and interact were picked up thorough the analysis of the physical environment, whilst the analysis of retail trends in the streets studied is also relevant, in particular how different retail uses have varied over the length of the study period.

To get a true understanding of streets as venues for exchange, it is necessary to speak with the users of streets, be those shoppers or passers by, or occupiers of surrounding properties. It is this that was captured as a final means to understand the impact of the street improvements.

\subsection{Exchange analysis}

Twelve interviews were conducted in each intervention area, split between street users and occupiers (owners/managers or employees of local businesses) with a questionnaire modified for each of these two groups. The sample size was adjusted to be equal amongst the cases and interviewees were selected in order to include different types of retail and services on the one hand, and different genders and age groups on the other. No interviews were conduced in the comparator cases as the objective of this part of the study was to get perceptions specifically of the street improvements and their impact. Both versions of the questionnaire included questions on four main categories:

1. The person's relationship to the place (how long they had been working in or visiting the area, how they travelled there and for how long, their main reason for visiting),

2. Perceptions of the physical environment, corresponding to the themes from the Place quality matrix

3. Perception of the local economy (range of shops, footfall / traffic, whether the shops seem to be doing well etc.)

4. Perceptions of both the design and the social aspects of the place before and after the intervention.

The street users' version covered the physical aspects of space more extensively, while the occupiers questionnaire focused more on perceptions of the local economy and included some additional questions on business-related issues relating to the ease of loading/unloading of goods. In both versions, questions asked people to either rate particular qualities of the space on a 1-10 scale or to state the extent to which they agreed with proposed statements, again on a scale of 1-10. Three open questions were also included inviting the interviewees to offer comments on anything they find particularly positive or negative about the area, whether they 
thought the intervention has had any negative side-effects; and concerning which element, if any, of the re-design they thought had the most impact.

Results are presented in this section for each street individually in the form of the average score that each question received, together with a summary of key comments / opinions extracted through the interviews, many of which relate to the dimensions already discussed: the physical fabric, real estate, and movement. The scores relating to the two groups of respondents were treated separately, except in the case of the before / after questions for long-term users or occupiers which were aggregated when the numbers answering those questions from the individual groups fell below a minimum acceptable level.

\subsubsection{Bromley}

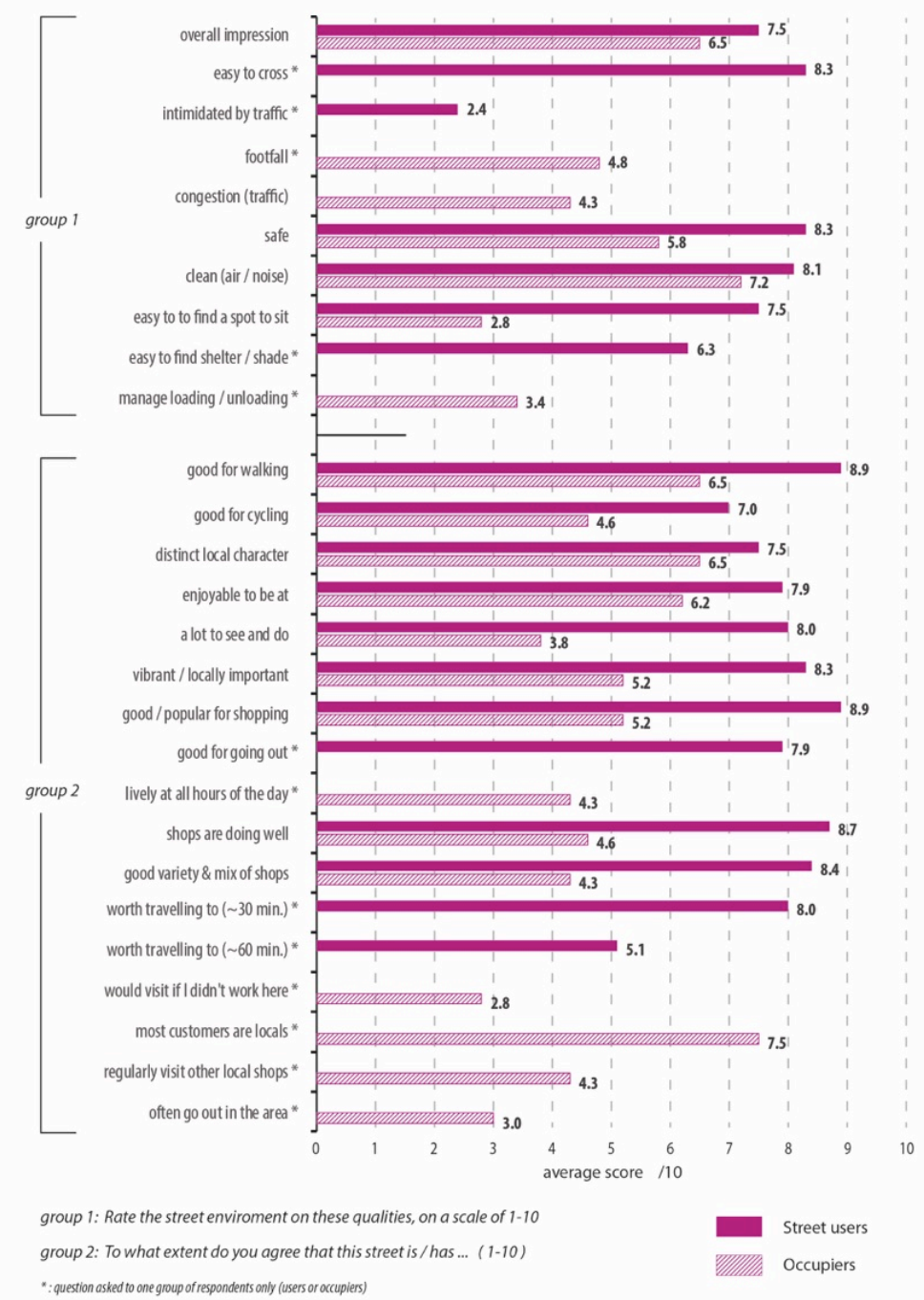

Figure 52: User and occupier perceptions of street quality in Bromley (i)

In Bromley responses tended to differ depending on the exact location of the business (for occupiers) or the spot where the questions were asked (for street users). The latter, for example, gave lower scores to questions relating to the availability of rest points, seating, or shelter when not directly in front of such elements, even 
though provision was often just around the corner from where they were standing. Retail managers and employees on East Street, which had been more radically altered, tended to be more positive about the changes than those on the High Street (north of Market Square), where the intervention was more low-key. Those situated directly on Market Square were also not as positive and tended to make comparisons with the lower part of the High Street (which had already been pedestrianised before the intervention) or with Bromley South, rather than with the area of Bromley North Village. There were indications that the intervention area is still not regarded as a coherent network of public spaces.

The issue of bus stop removal came up in the open question comments. One employee on Market Square, for example, thought that it reinforced a trend of people only visiting the shops around the (better connected) Bromley South station and not making their way up to Bromley North. Other occupiers mentioned that this had been a contentious issue. Further negative comments, both from street users and occupiers, related to car parking, in particular the reduced availability of onstreet places on the one hand, and a dissatisfaction with the larger car park facilities on the other.

More positively, multiple comments mentioned the new paving and the level surface on East Street as a welcome change. On the occupiers side, interviewees felt that the streets looked better and that the space now available for restaurant / cafe seating on the street made the area more lively and attractive. On the street users side, interviewees on Market Square commented positively about the pedestrianised shopping area and on the space being safe for children.

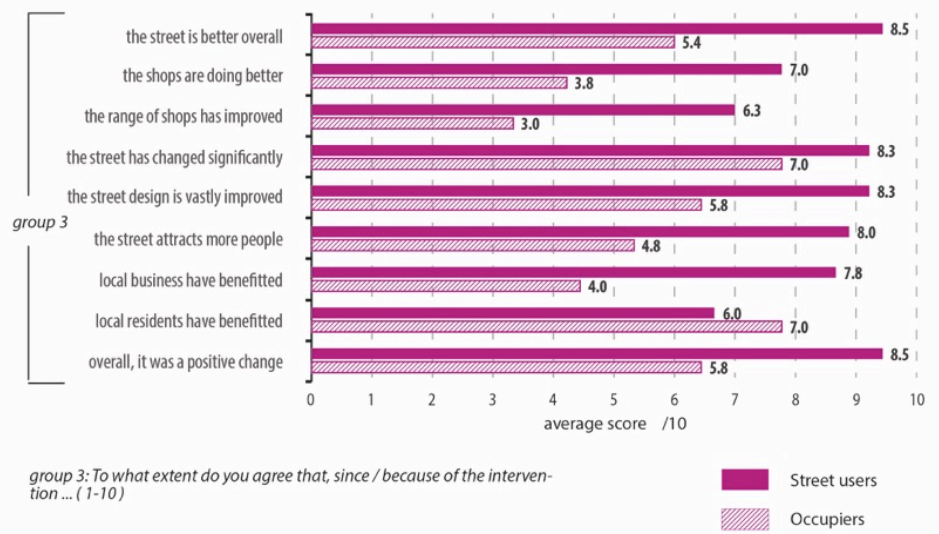

Figure 53: User and occupier perceptions of street quality in Bromley (ii)

Street users, most of whom were there for shopping, were significantly more positive overall in their perception of both the street environment and the local economy in Bromley, compared to occupiers. Indeed the street users in Bromley gave amongst the highest overall scores for the street - post intervention - with a strong sense that the street was both better designed and economically more successful as a result of the works. For their part, the occupiers were far less convinced that businesses had benefitted, despite real estate data that suggested the contrary. Instead, they pointed to local residents as the major beneficiaries of the scheme, although 
conceded that the street had significantly changed, and for the better. The divergence between the views of occupiers and users was at its greatest in Bromley.

\subsubsection{Hornchurch}

Multiple local occupiers with businesses situated at the edges of the intervention area in Hornchurch gave the same comment: that the new road layout, with the extra pedestrian islands in the middle and the narrower traffic lanes, made the street less safe. There were two concerns, the absence of space for vehicles to overtake each other which caused problems when emergency vehicles needed to get through, and that the new pedestrian crossings were confusing. Similar comments on pedestrian safety were reflected by a small minority of street users, with one occupier commenting that the street was now more difficult to cross because it requires greater attention from pedestrians. Other street users and occupiers were more positive in their answers, but it may be that the new elements cause confusion around the edges of the intervention area where there is a shift back from a model of informal crossings to formal signalised ones.

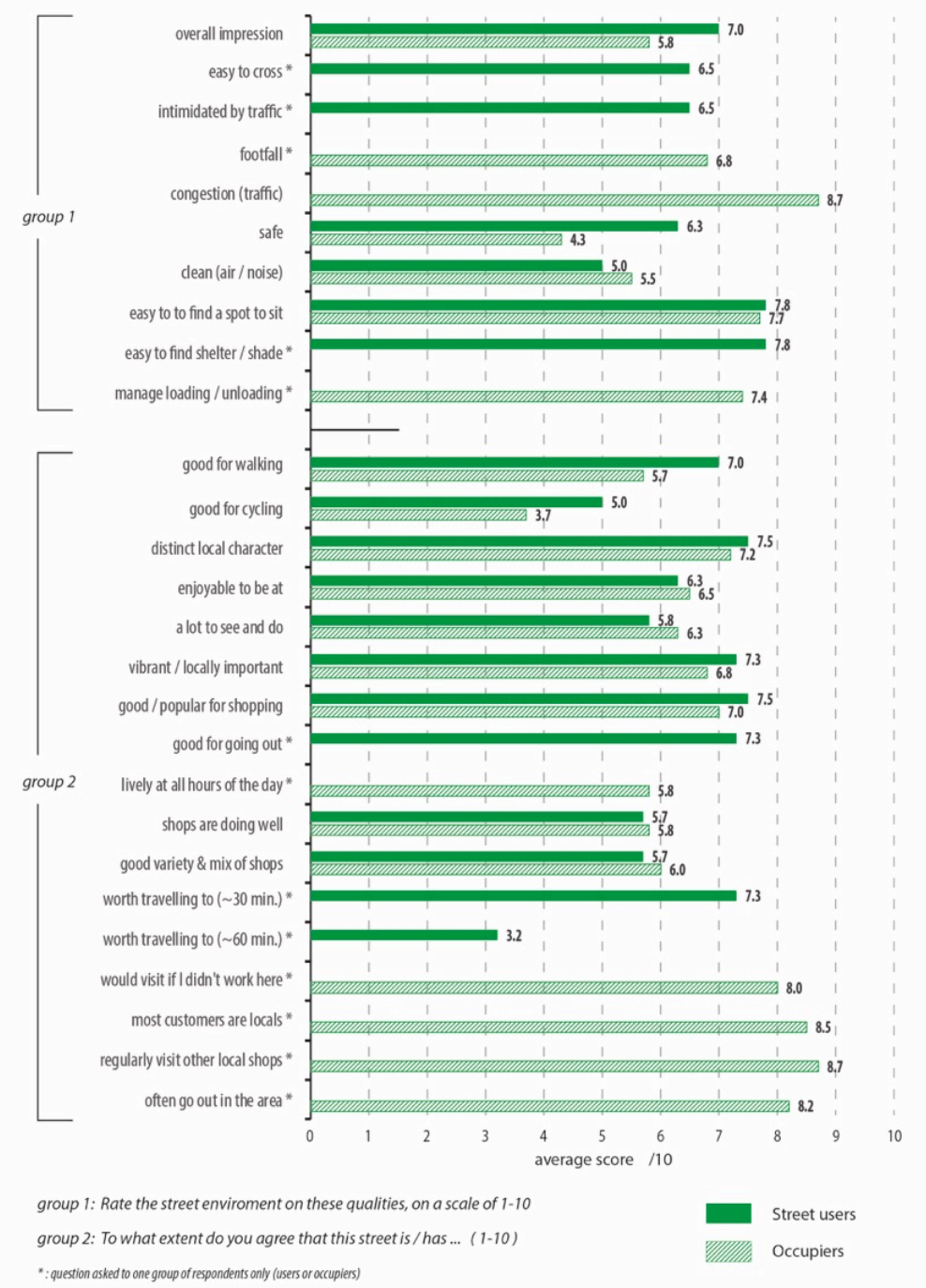

Figure 54: User and occupier perceptions of street quality in Hornchurch (i) 
Regarding the local economy, one long-term business owner in the area was keen to stress that the area was being overrun by restaurants and pubs at the expense of local retail, but did not link this trend to the intervention, arguing that it had started long before. There was also clearly an on-going concern around levels of traffic in the area, particularly for the occupiers of space who listed it as their number one concern.

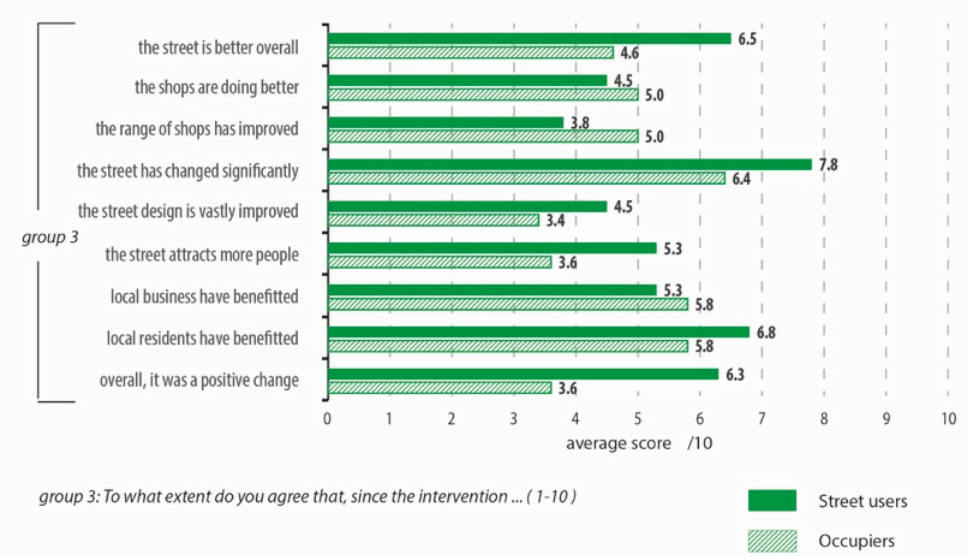

Figure 55: User and occupier perceptions of street quality in Hornchurch (ii)

Whilst both users and occupiers accepted that Hornchurch had substantially changed as a result of the street interventions, street users were again far more positive in their assessment of the benefits which it had brought, and that local residents in particular had benefitted. Occupiers were more circumspect in their praise for the design and the economic benefits, but felt that both residents and businesses had benefitted in equal measure. They were also, when compared to the other improved streets, far more invested themselves in the location as somewhere that they themselves chose to visit and shop outside of work hours.

\subsubsection{Clapham}

Responses in Clapham were generally very positive. Street users interviewed here were mostly local residents or workers on their break, and most perceived the space to be welcoming, open and relatively quiet. Local retail managers and employees also seemed positive about the changes while reluctant to link them directly to any economic impact on their businesses. They seemed engaged with the space and commented positively on the addition of trees and seating as well as on the increased pedestrian space. Some local residents were worried about the loss of parking, although this did not seem to be a major concern.

In Venn Street, occupiers were generally positive about the physical aspects of the street, but thought that there was a significant lack in the range in the shops directly on and around it, causing the street to feel empty in the mornings when cafes and pubs had not yet opened. Most were regular users of the local shops and facilities on the street and rated it particularly highly as a place of good local character that is pleasant to be and to walk through. 


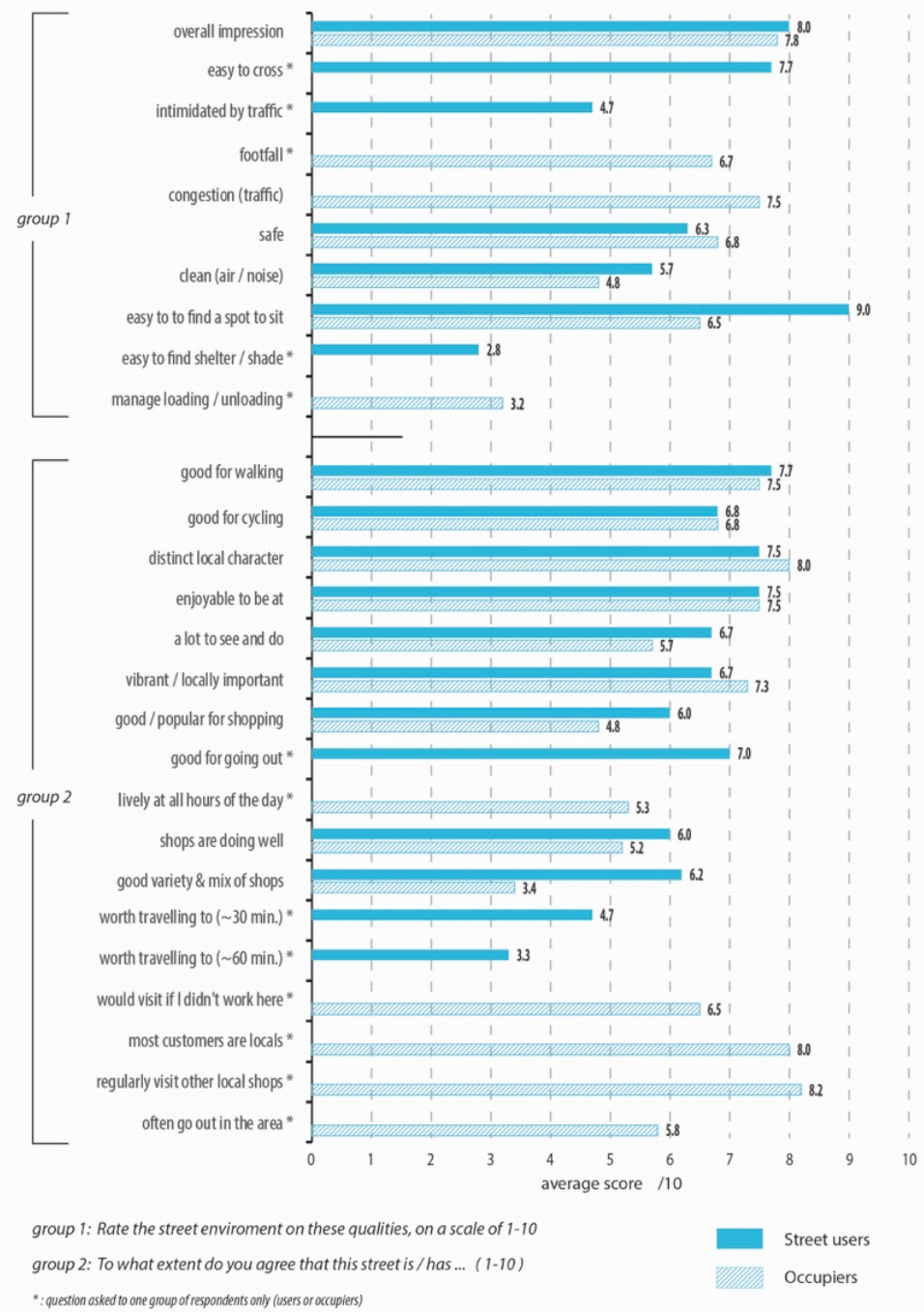

Figure 56: User and occupier perceptions of street quality in Clapham (i)

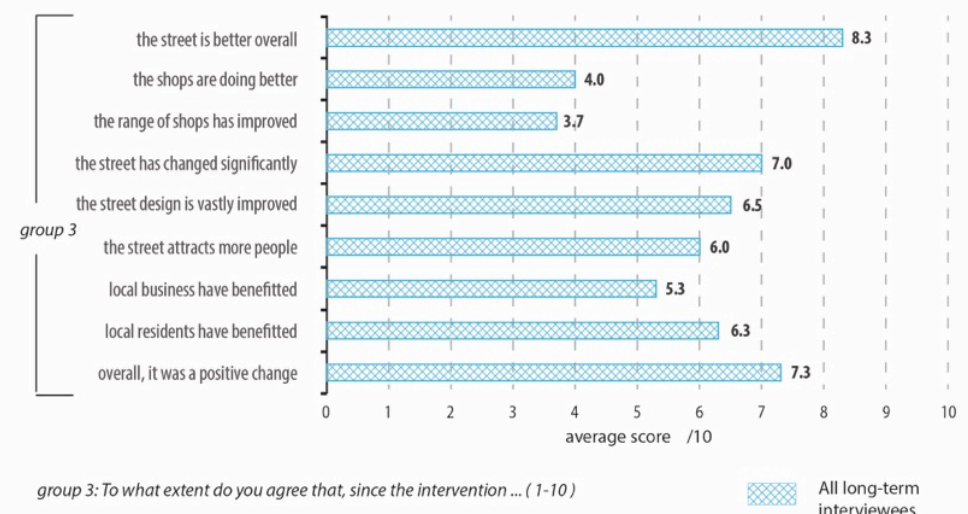

Figure 57: User and occupier perceptions of street quality in Clapham (ii)

Collectively both street users and occupiers rated the street highly, with one of the highest overall ratings for improvement pre and post-intervention. In large part the perception was that these changes were physical, and that the range of shops and economic circumstances had not improved to the same degree. Businesses, whilst in aggregate benefitting, were not seen as benefitting to the same degree as residents. 


\subsubsection{Woolwich}

In Woolwich, the works to General Gordon's Square were the focus of the greatest number of positive comments across both users and occupiers. One long-term resident and worker in the area described it as an attractive space that created a better sense of community in the area, and helped bring people together with events and screenings (on the big screen). Overall, even interviewees who were less enthusiastic about Woolwich at large seemed to have a positive opinion bout this central space.

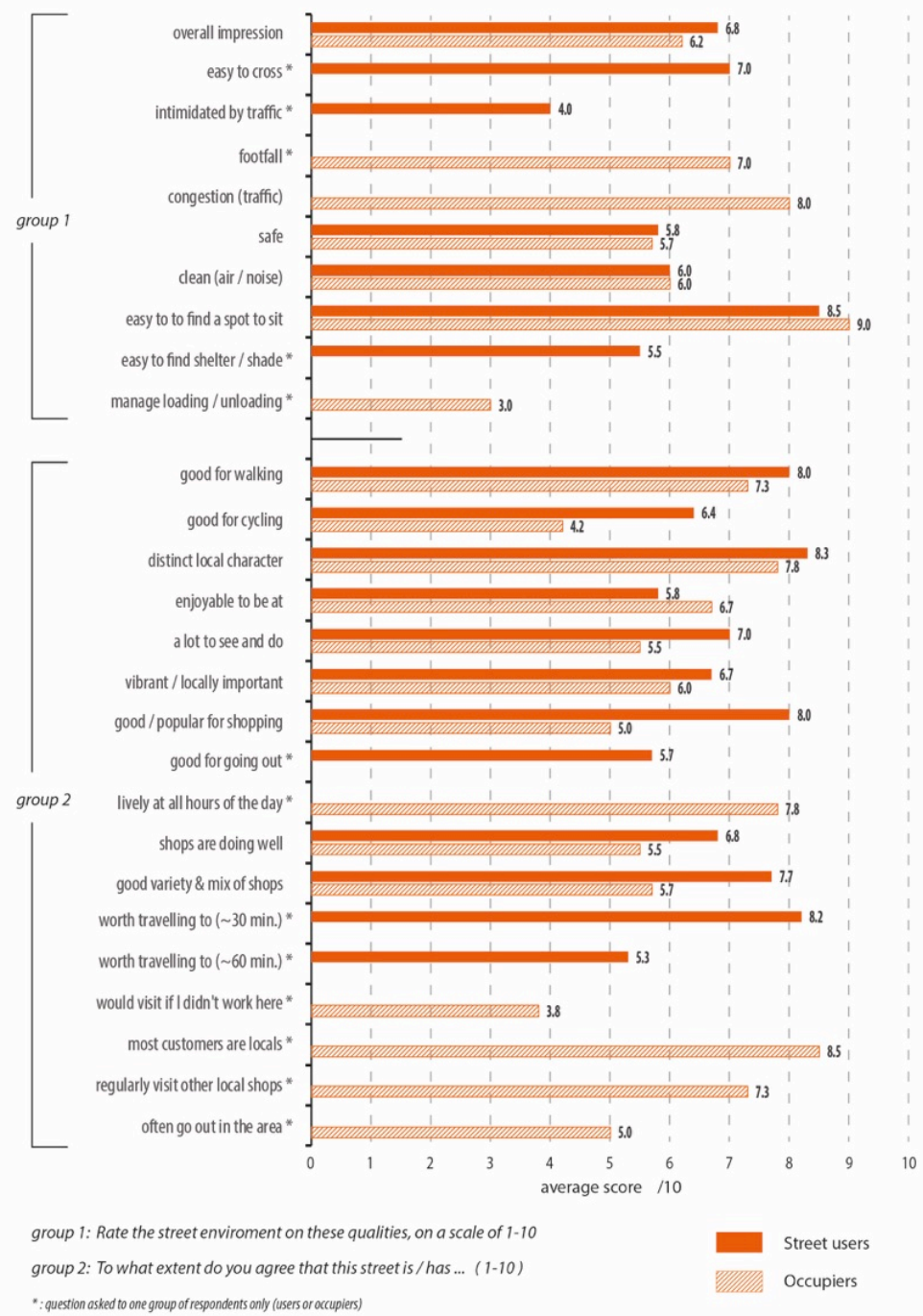

Figure 58: User and occupier perceptions of street quality in Woolwich (i)

A negative comment that came up multiple times was the diminishing nature of Beresford market. Both street users and occupiers commented on the stalls being fewer and with lower quality products. One local business manager hypothesised that this form of market (cheap clothes, household goods and discount foods) is being priced out (e.g. by discount supermarkets and the internet), while another thought the problem might be directly linked to the public realm interventions and the altered pedestrian flows that had resulted from them. 
Others suggested that the new bus stop arrangement around General Gordon Square was "more suited to Tesco [a huge new store as part of the Woolwich Centre] rather than to a town centre". Woolwich was also the only case study where any interviewee mentioned rising house prices as a negative effect of the intervention, although that was heard only once and described more as a parallel process rather than a result of the changes.

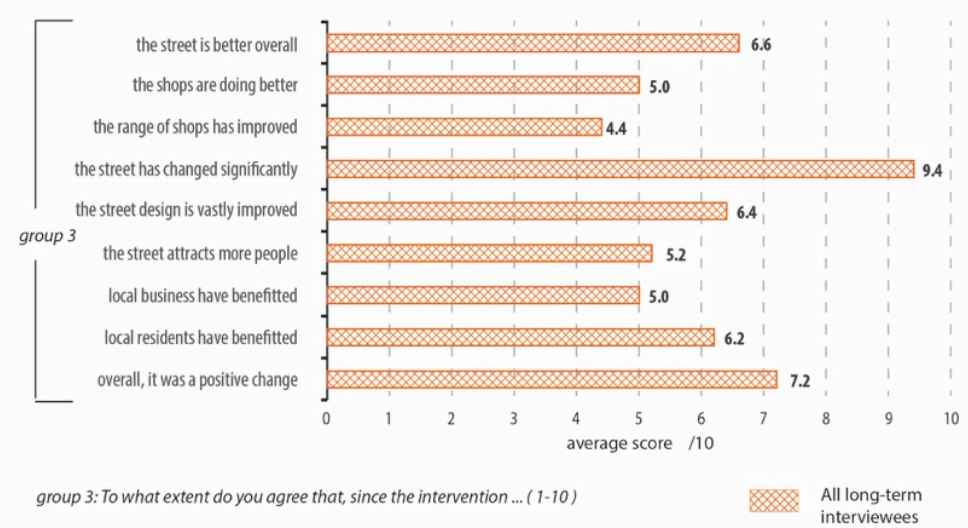

Figure 59: User and occupier perceptions of street quality in Woolwich (ii)

In Woolwich there was a remarkable consistency between the views of street users and occupiers about the street interventions, with a positive overall impression, but with lingering concerns over the traffic problems of the area. There was a sense that the area had a distinct local character, was good for walking and shopping, and was a good place to be. Whilst few felt that the range of shops had improved, there was overwhelming agreement that the street environment had changed, and a strong feeling that this was positive.

\subsubsection{Walworth}

Locals on Walworth Road seemed to be particularly connected to the space (emotionally) and whilst they described negative aspects of the physical environment, such as the lack of adequate seating, they were also very positive regarding the continued local importance of the street and their personal patterns of use. Street users had a stronger overall impression of the space than occupiers, but clearly felt that the street was now easy to cross and felt safe. Occupiers, for their part, remained concerned that congestion was a problem in the area.

Like the other cases, in Walworth Road responses changed depending on where in the street respondents were located. In the area of intervention interviewees were more positive, but attitudes gradually changed in a more negative direction the further away interviews were conducted. At the edges of the intervention area, both users and occupiers seemed much more negative about the space, describing it as "rather grim" or in similar terms. A couple of occupiers made a direct comparison between these areas and the central part of the street as they felt that local retail was performing much better in the improved area than elsewhere. With the exception of being a good location for going out, Walworth Road was largely judged positively by 
users, although a little less so by occupiers who felt that, if they didn't work there, they would be unlikely to visit.

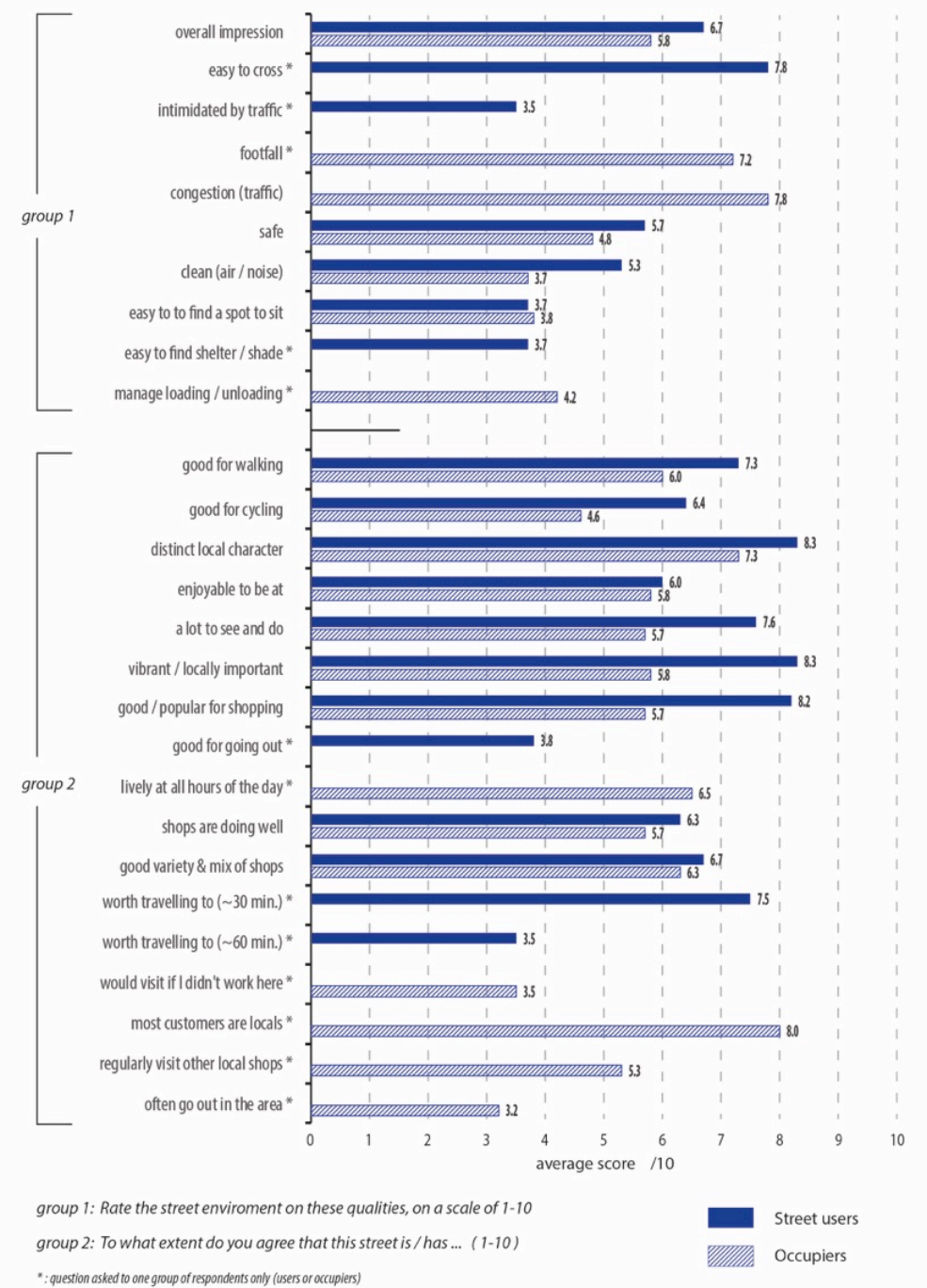

Figure 60: User and occupier perceptions of street quality in Walworth (i)

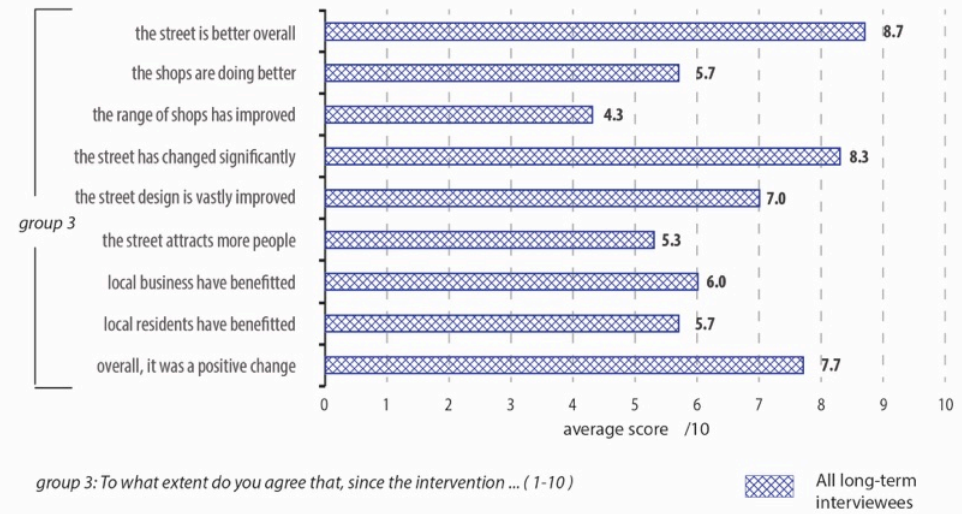

Figure 61: User and occupier perceptions of street quality in Walworth (ii)

In Walworth it was difficult to find long-term users or occupiers able to comment on the before and after questions in the survey. Those that did and who remembered the previous state of the street were generally positive about the changes without 
being very specific. Amongst this smaller group there was a strong feeling that the street was now better, although this had not necessarily fed into the range of shops on offer.

\subsection{Exchange findings}

Analysis of the survey data revealed some contrasting messages. Perhaps most interesting is the long-term perspectives of those who could remember the streets before and after intervention. Overwhelmingly, and in aggregate across the cases, these respondents perceived that their streets had changed significantly ( 7.9 average score), that they were now better (7.2) and that the changes had been positive for the street, its users and occupiers and for the area. A key component of these perceptions can be put down to the impact of the design which was considered to have 'vastly' improved by many (6.2) with the key beneficiaries being local residents and users (6.2). On whether local businesses had benefitted (5.6) whether more people had been attracted to the street (5.5), and whether shops were doing better as a result (5.0) views were more evenly split, perhaps because only a minority of respondents felt that the range of shops had actually improved over time (4.3).

Drilling down further into the findings, a number of reoccurring factors featured in the responses. First, respondents are more positive than negative about the qualities they see in the improved streets. Street character is seen very positively by both street users and occupiers alike, receiving some of the highest scores overall, and consistently across the cases. The walkability of all the streets was also very strongly endorsed across all of the cases by the street users, although more intermittently by occupiers who remained (in four out of the five case) strongly concerned about levels of congestion and (in three of the five) about facilities for loading and unloading.

For street users, key determinants of this walkability seem to be the ease with which streets can be crossed and the availability of good quality seating. For them, the streets offered good quality shopping facilities that they would be willing to travel at least 30 minutes to use (less so in the case of Clapham), and which were generally vibrant with plenty to see and do. In every case occupiers confirmed that most custom came from a reasonably local area around the streets, and they themselves remained more ambivalent about using the local facilities.

Returning to the long-term impressions of those who could remember the streets both before and after the street improvements (the final table/s for each street in this section), it is interesting to compare the aggregate of all these user / occupier impression scores against the results of the analysis of physical fabric discussed earlier in this paper. Here a conundrum becomes apparent. Whilst the worst performing case in the place quality matrix was clearly Walworth (46), this scores best in the aggregate analysis of user impressions (6.5). Similarly, although far less marked, the second worst performing case, physically - Woolwich (69.5) - performs second best in the aggregate analysis of before and after user opinion (6.2). The remaining cases perform less well against this aggregate measure of user opinion 
than would be envisaged from the analysis of their physical qualities, with aggregate scores of 6.0 (Clapham), 5.6 (Bromley) and 5.2 (Hornchurch) respectively.

This seeming contradiction appears to be a reflection of the degree of change experienced by the various case studies rather than because of their absolute level of quality - either physically or as a space of exchange - as perceived today. Thus areas that have journeyed from a very low base (e.g. Walworth with two lanes of traffic each way reducing to one lane) were scored better by those who remember that journey than those that have improved, but from an already higher base quality (e.g. Clapham). In this respect dealing with (aka reducing) the fundamental traffic problems impacting on such streets seems to be more important than some of the less prosaic factors. When, by contrast, the scores for only the qualities perceived today (the first and the second groups of tables for each case in this section) are aggregated, Walworth scores noticeably less well than the other cases, with an average score of 5.8 against a remarkably consistent 6.3 for each of the other four improved cases. 


\subsection{Conclusions}

The planning for, design of and ultimately the uses enabled by London's streets has been undergoing a radical change via a move from a network efficiency model to a movement and place-based one. This is a fundamental change that is also reflected a number of other cities around the world, and it is important to understand both the benefits and dis-benefits that result, not least as a feed into future street investment programmes. The research that underpins this paper represents an attempt to capture and understand these impacts and to address the question, what is the 'value', in the widest sense of the word, of place-based improvements in street design. This final section brings together a set of conclusions to address the question.

\subsection{The research methodology}

As a research problem, the study of street design and the value added by improvements is fraught with conceptual and practical challenges. Whilst it is difficult to entirely overcome such issues, the aim must be to sufficiently overcome them in order to deliver robust and testable results. The starting point is a robust research methodology.

In attempting to link the two fundamental concepts of 'design quality' and 'design value', most previous studies in this field isolate and focus on one or more parameters from each side of this dualism and, in various ways, attempt to correlate the various dimensions of quality and value. The trouble with such studies is that they present a fragmented or partial picture of a complex phenomena: street space. To avoid this a holistic framework for analysis was chosen in order to give a more rounded and nuanced picture of value than previously attempted in value of design studies. This goes for both the quality and value sides of the equation where, without sacrificing consistency and robustness, a mix of qualitative and longitudinal quantitative data was selected in order to best account for the reality of each street.

The key features of the approach were:

- Pairwise comparisons - the use of five paired street environments in London five improved cases against five unimproved comparators - as a means to track the impact of design interventions in comparable locations against value outcomes whilst controlling, as far as possible, for extraneous factors.

- A holistic analytical framework - a broad conceptualisation of the impact of the interventions was adopted, extending the simple place / movement street typology already adopted in London, into a four part framework that pulls 'place' apart into three further constituent functions of streets: as built fabric, for social/economic exchange, and as real estate.

- Data selection, gathering and analysis - guided by the analytical framework, quality and value data was gathered both in the field and from a range of existing available data sources. Once gathered the data was analysed both 
across the pairs, and within and across the dimensions of the analytical framework.

The selected improved street environments in: Bromley, Hornchurch, Clapham, Woolwich and Walworth encompassed street environments in Inner and Outer London, in more and less prosperous parts of the city, as well as streets of varying accessibility and prominence as retail destinations. Their unimproved comparators, respectively: Orpington, Upminster, Camberwell, Catford and East Greenwich, were geographically close and, as far as possible, similar in physical, socio-economic and functional terms.

\subsection{Physical fabric}

The quality of the physical fabric of the five improved and five unimproved street environments was measured and compared utilising a Place quality checklist formulated for the purpose. Using a carefully calibrated set of indicators for each theme, ten aspirational street qualities were assessed and scored in the field by a single researcher to avoid differential interpretation and to ensure objectivity between the cases. Factors ranged from perceptions of safety, to street pollution to aspects of street character.

This analysis demonstrated that across the five cases, the street improvements had delivered, on average, a $31 \%$ increase in the quality of the street environment when compared to their unimproved comparators. The analysis also suggested a hierarchy of interventions in order to improve the quality of street environments:

- The most straightforward encompass improving pedestrian and cycling flows

- More challenging is the creation and enhancement of a distinct character in streets and space for social activities

- Most challenging is the creation of adaptable and environmentally clean (unpolluted) spaces.

The evidence suggests that street improvement schemes in London are becoming better at addressing the more challenging levels in the hierarchy, although to achieve the highest scores all three levels need to be addressed together and in an integrated manner.

\subsection{Real estate}

Three real estate sectors were analysed in an attempt to achieve a more nuanced view of the property impact of street improvements, each across three scales: at the level of the intervention only, at a larger mid area including the surrounding streets, and at the scale of the entire postcode. The office market was analysed using rental values data from the CoStar TM data suite; the Land Registry House Price Index was used to measure the impact of the street improvements in the residential sector; whilst the retail sector was analysed using rental and vacancy data from the CoStar ${ }^{\mathrm{TM}}$ data suite supplemented with GOAD/Experian occupancy data. The latter offered a 
greater degree of granular detail in each case as regards shifts in the retail market and the resulting sub-classes of retail occupation.

\subsubsection{Office}

In the office market street improvements are strongly associated with growth in rents which trickle outwards from the immediate areas of intervention to surrounding streets. When the figures across the different cases are aggregated, office rents in the areas with improved street environments rose by $6.5 \%$ per annum over the study period. This reduced slightly when the wider (mid) areas were considered, although is still very significant with a $5 \%$ aggregate uplift. Whilst there will be other factors at play, often far more powerful than the street improvements themselves (e.g. the impact of the general economy or factors relating to the supply of office space locally), this latter figure represents a $4 \%$ per annum increase in rental values in improved areas over and above that achieved in the unimproved comparator locations.

\subsubsection{Residential}

The story in the residential real estate sector is quite different. In this sector street improvements can effect market dynamics in a positive direction, but that impact is most likely to be small and much smaller than impacts caused by other factors such as general swings in the market, or investments in new transport infrastructure in an area. The research revealed a boost relating to the street improvements (over and above that caused by other factors) of just $0.25 \%$ per annum across the period of analysis. It seems that public realm works effect residential prices, but only very locally and marginally and not to the extent that would impact on gentrification or any of the sometimes negative associations linked to public realm investments.

\subsubsection{Retail}

Turning to the retail sector, changes to rental values (upwards), levels of vacancy (downwards), and the resilience of under pressure retail types indicate a willingness to pay to occupy retail space which is more attractive by virtue of its street location and which may therefore prove more profitable to the occupier. Here there were clear market responses at the intervention area level and often across an expanded area to the street improvements, and these resulted in a discernable uplift in rental values across all of the case studies, albeit uplifts that then become subject to the wide range of other factors that also effect local retail markets. Over the period of analysis, retail environments that have benefitted from street improvements have delivered a rental uplift of $7 \%$ per annum, reducing to $5.5 \%$ when the wider (mid) areas are considered. This compares with their comparator locations where the aggregate results from the mid area comparison shows a $2 \%$ per annum average decline in rental values; or a difference of $7.5 \%$ between improved and unimproved locations.

The vacancy data is equally compelling. Again, over the course of the study, intervention areas have seen a $7 \%$ per annum fall in vacancy rates as compared to a $2.5 \%$ fall in the larger mid areas. This compares to an average $14.5 \%$ per annum 
increase in vacancy rates in comparator mid areas that have not been improved; or a huge difference in vacancy rates of some $17 \%$ between improved and unimproved locations. Further market signals to reinforce the evidence provided by the market analysis was also seen in the greater resilience, against trend, of traditional (A1) and comparison retail, and the higher growth in A3 (leisure uses).

\subsection{Movement}

Three forms of analysis attempted to assesses the impact of the street improvements against their comparator areas in relation to how movement behaviours have changed. Static traffic counts were assessed drawing on the available Department for Transport (DfT) National Road Traffic Census (NRTC) site counts and TfL ad-hoc traffic counts. This data was not ideal as it was often poorly matched to the intervention areas and largely focussed on vehicle movements (including cycling), only rarely including pedestrian movement. Consequently street life analysis was undertaken to give a more bespoke analysis for each of the five cases and their comparators. These observations were converted into combined activity counts for comparative purposes as a valuable indicator of the differences in levels of activity generated by the street improvements against their unimproved comparators. An assessment was also made of injury collision levels in the intervention areas both before and after the improvements.

\subsubsection{Traffic analysis}

Whilst the traffic data was inconsistent, partial and often individually inconclusive, collectively across the improvement cases it revealed a very clear story. By themselves, and without consequential reductions in road capacity, street improvements do not seem to impact on traffic flows or modes of travel. Some limited evidence was found of rising levels of walking, and particularly cycling, in improved streets, but this was inconclusive and (from this data alone) could not be tied directly to the street improvements. In the streets with higher pre-existing levels of collisions (prior to the interventions), evidence was also found of a reduction in levels of serious or fatal accidents in the improved streets, equivalent to a reduction of two collisions per year in the two cases concerned.

\subsubsection{Street activity}

The evidence on street activity was far more conclusive. Without exception the cases with street improvements far outstripped their comparators in terms of the range of static and active street behaviours that they hosted: in aggregate a $94 \%$ difference between the improved and unimproved cases. This is a difference that is highly significant and, given the other similarities between the cases, is very strongly associated with the street improvements. Breaking it down further, the analysis demonstrated a $93 \%$ uplift in the improved cases relating to levels of walking over and above the levels seen in the unimproved cases, a $96 \%$ uplift in static activities such as standing, waiting, and sitting of all types and a huge $216 \%$ increase in the incidence of leisure activities, such as sitting and relaxing or stopping at a café. These latter types of activity are particularly sensitive to the quality of the built environment and are therefore a strong indicator of place quality. 


\subsection{Exchange}

A critical component of street life is how streets are used as public venues for exchange: social exchange, economic exchange, even political and cultural exchange. To get a true understanding of this it is necessary to speak with users of streets. Twelve interviews were conducted in each of the improved street cases (60 in total), split between street users and occupiers (owners / managers or employees of local businesses) with a questionnaire modified for each of these two groups. No interviews were conduced in the comparator cases as the objective of this part of the study was to get perceptions specifically of the street improvements and their impact. Interviewees were asked to rate particular qualities of the space or statements about the space on a 1-10 scale and answers were later aggregated to give an overall impression.

Overwhelmingly, and in aggregate across the cases, respondents felt strongly (scoring 7.2/10) that the various street interventions had led to streets that were now better, bringing with them positive benefits for the street, its users and occupiers, and for the area at large, even if this did not always manifest itself in a better range and quality of shops. Key qualities that have improved were street character, walkability, ease of crossing, good seating and the vibrancy of the streets. Levels of congestion and facilities for loading and unloading remained particular concerns in most of the cases.

For interviewees the degree of change seemed to be particularly important, and perhaps more important than the absolute level of quality experienced. Thus areas that have journeyed from a very low base were scored better by those who remember that journey than those that have improved, but from an already higher base quality. In this respect dealing with (aka reducing) the fundamental traffic problems impacting on such streets seems to be more important than some of the more intangible factors already mentioned. This reinforces the idea of a hierarchy of interventions already outlined and now discussed in a little more detail.

\subsection{A hierarchy of interventions}

Collectively the findings suggested that to have most impact, viewing possible schemes in terms of a hierarchy of interventions would be beneficial (Figure 62). The most important level of intervention, and the foundation for everything else, should involve improving the pedestrian experience by making adequate space for pedestrian movement and activity. Next comes the enhancement of social space, notably the creation of attractive and comfortable space for sitting, observing, socialising and so forth. Finally, and perhaps the most challenging to achieve, are interventions relating to the creation of environmentally unpolluted (sound and air) and more adaptable spaces (that can be used in multiple ways with a good interplay between the street and ground floor frontages).

If finances are tight, this suggests that interventions should focus first on the lower levels of the hierarchy, with the safety, ease, comfort and inclusiveness of pedestrian 
movement coming before enhancements to the physical and / or social character of the street, or the pursuit of environmentally unpolluted and adaptable space. In terms of generating street appeal by enhancing the place qualities of streets, this is where most 'bang for the buck' will be achieved.

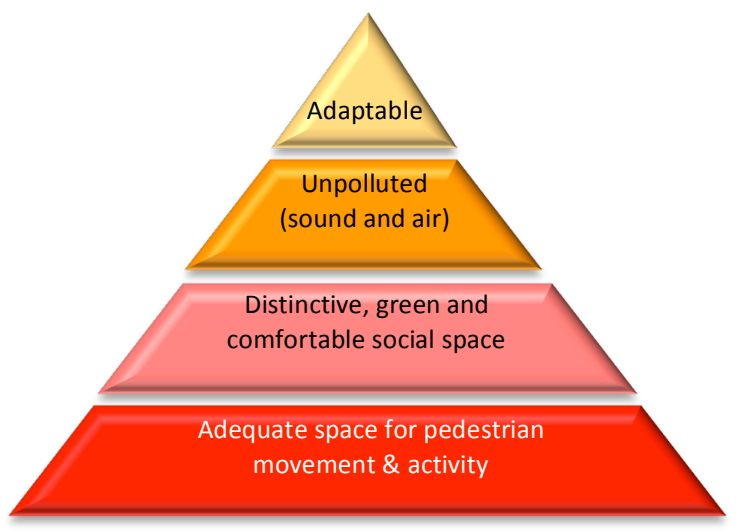

Figure 62: A hierarchy of street improvement interventions

As, ultimately, all these factors are intimately inter-linked, the most sophisticated design schemes will take a bolder multi-layered approach that tries to tackle all levels in the hierarchy. Thus more space for pedestrians and bicycles and less space (and slower speeds) for cars will open up the opportunity to deliver on the other factors that make for the highest quality street experience for all.

\subsection{The potential costs of street improvements}

At this point it is interesting to note that these findings fit squarely within a now overwhelming body of evidence from a large volume of value of design studies (discussed in the second part of this paper) that consistently demonstrate tangible links between higher place/design quality and, in different ways, the value added to users. One aspect that has been little studied, but is often raised in discussions about such studies is whether there are also costs associated with better design.

Clearly, there are costs to implement street improvement schemes of all types, and these will vary depending on the extent both of the intervention and how transformative it seeks to be. The street improvement cases examined in this research varied in cost from almost $f 6$ million in Woolwich to $£ 2.5$ million in Hornchurch. As a proportion of total property values (and likely increases following interventions) or even income from business rates in the effected areas, these figures are very small. For example, with average rateable values from retail premises across

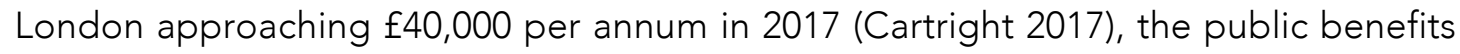
(even in narrow economic terms) will quickly outweigh the costs. Whilst the current study did not seek to compare impacts against the costs of implementation (data which was not always available in a comparable form), it was very clear that earlier schemes with a less transformative impact on their street environments, generally scored less well on all aspects of value added. Thus the more fundamental placebased strategies that are now being implemented in London (like elsewhere) are delivering more for the streets, communities and businesses effected. 
Despite this, one fear raised right at the start of this paper and commonly expressed in discussions about whether or not to invest in public realm schemes concerns whether improvements to the built environment will stoke up gentrification pressures and lead to irrevocable social changes in the effected communities. In this respect the research revealed some interesting findings. Whilst there had been huge price appreciation in the residential market across London during the period under investigation, the street improvement works themselves seemed to have only an extremely minor impact on prices ( $0.25 \%$ per annum) and only in the area immediately adjacent to the improvements. Beyond that, no impact was detected. Given an average house price increase across the city of around $12.5 \%$ per annum since the financial crash $^{25}$, this suggests that street improvements works, by themselves, do not have a major impact on either house prices or economically driven gentrification.

The story in relation to office and retail property is quite different. In these two markets the street improvements had a direct and significant impact on raising rental levels and (in the case of retail) on reducing vacancy. Whilst, on the face it, rising rental levels in any sector may not seem to be to anyone's advantage (except property investors), as a very clear and tangible market signal that street improvements are delivering a rising willingness to pay to occupy retail and office space in improved locations, it may also provide a ready means to counter other recent trends that have been undermining traditional mixed streets in London as elsewhere. These include the tendency to convert viable office / business space to more profitable residential uses (London Councils 2015), and the pressures the retail sector faces care of the relentless rise in on-line shopping (Barrett 2015: 17). If street improvements can, once again, make traditional mixed (high) streets more investable and viable, then rental hikes may be a necessary price to pay.

\subsection{Final (methodological) reflections}

This paper has presented a wide range of analyses for five localities across London that have benefitted from recent improvements in their designed street environments, and compared those against five comparable streets that have not. Whilst any one piece of the analysis might be individually open to challenge in terms of the robustness of the data or the interpretation of the evidence, collectively across the cases and across the holistic array of data sources gathered and presented, a range of robust and convincing findings have been revealed. These suggested that in relation to street improvements in the sorts of mixed local high street locations investigated, investments in the quality of the street environment return substantial value to street users, occupiers and investors in multiple ways. As well as the empirical findings themselves which extend a body of literature that has examined the 'value added' by improvements to the public realm (ECOTEC 2007; Sheldon et al

\footnotetext{
${ }^{25}$ Office for National Statistics data shows average house prices in London in January 2009 were $£ 247,000$ compared

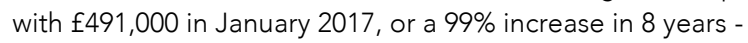

https://www.ons.gov.uk/economy/inflationandpriceindices/bulletins/housepriceindex/jan2017\#house-price-index-byenglish-region
} 
2007; Sheldon et al 2010; Lawlor E 2013; Nase et al 2013a; CABE Space 2007; New York City, Department of Transportation 2012; New York Department of transportation 2012; UN-Habitat 2013), the unique contribution of this paper lies in the multi-disciplinary methodology which cuts across sources of evidence that much of the existing literature in the field examines in isolation. This reinforces an argument made in this paper and elsewhere (Carmona 2015) that in order to understand the multi-layered complexities of urban space, we need to first start from a perspective that explicitly recognises that complexity and the inter-connectedness of the parts - the physical fabric, with the exchange, real estate and movement functions.

For a study of this nature, where multiple cases are examined and data is aggregated from multiple sources, the methodological approach has proven to be both reliable and rigorous. It is nevertheless recommended that London and other cities with a public realm investment programme consider the development of more systematic approaches to monitoring these sorts of impacts in the future in order to build a better body of evidence about which sorts of interventions deliver most benefit, where, for whom, why and how. To achieve this, and indeed to deliver more reliable case by case estimates of the value added by interventions, perhaps as a feed into the generation of business cases for future projects, some refinement of the approach is considered desirable. Ideally this would incorporate the systematic adoption of longitudinal (before and after) analysis. How this might be addressed in relation to each of the four dimensions of the analytical framework is dealt with in Table 11.

\begin{tabular}{|c|c|c|}
\hline Dimension & Methodological limitations & Possible refinements \\
\hline $\begin{array}{l}\text { Physical } \\
\text { fabric }\end{array}$ & $\begin{array}{l}\text { Ideally the quality of the physical } \\
\text { fabric needs to be measured before } \\
\text { and after interventions and in a } \\
\text { manner that gives appropriate } \\
\text { weight to both tangible and } \\
\text { intangible aspects of quality and } \\
\text { ensures they are both explicit (in } \\
\text { relation to one another) and } \\
\text { quantifiable. There is also the } \\
\text { possibility of unintentional bias of } \\
\text { distortion creeping into any such } \\
\text { assessment, given the nature of the } \\
\text { tool which needs to be interpreted } \\
\text { by a researcher in the field, and } \\
\text { which can be influenced by the } \\
\text { weather, mood, relative familiarity, } \\
\text { and by a whole host of other factors. }\end{array}$ & $\begin{array}{l}\text { Many tools for analysing the quality of the physical built } \\
\text { environment are either too crude (e.g. counting benches } \\
\text { without analysing whether anyone might wish to sit in them), } \\
\text { or too subjective (reporting intangible qualities in a manner } \\
\text { that precludes quantification and therefore comparison). } \\
\text { Whilst it was not possible to measure the actual physical } \\
\text { improvement that the various street improvements } \\
\text { delivered (before as well as after) the Place quality index } \\
\text { handled the challenges well, and did so in a manner that } \\
\text { could be used quickly and cost effectively. Given this, it, or } \\
\text { a similar tool, might be adopted to more systematically } \\
\text { measure the quality of street environments and to build a } \\
\text { longitudinal database of that changing quality. }\end{array}$ \\
\hline Real estate & $\begin{array}{l}\text { Disentangling the key influences on } \\
\text { the real estate market and the impact } \\
\text { that such influences have on price } \\
\text { movements at a local level (in terms } \\
\text { of rents and capital values) can be } \\
\text { challenging to determine, in both the } \\
\text { commercial and residential sectors. } \\
\text { One would ideally need detailed }\end{array}$ & $\begin{array}{l}\text { In the office market, physical attributes (age, location, size), } \\
\text { type and length of tenancy, energy certification and other } \\
\text { attributes (car park share, gym facilities) are usually } \\
\text { important influences that affect office values and (if } \\
\text { available) could be controlled for by hedonic pricing or } \\
\text { other revealed preference methods. Data on individual } \\
\text { property attributes would be useful in the case of analyses } \\
\text { estimating willingness to pay for specific attributes. }\end{array}$ \\
\hline
\end{tabular}


data on all attributes of a property before and after the intervention in order to more accurately isolate the specific impact on real estate values due to street improvements whilst being careful to avoid issues of endogeneity (e.g. how property attributes may change in anticipation of street improvements, and how much distance from an intervention is required to overcome such issues). This level of data may not be available in many localities.

\section{Movement}

Exchange Seeking single snapshot views about how places are used and have changed over time relies on finding participants with good reliable memories and with a long association with the place. In dynamic areas such as those investigated where there is a lot of population churn, this is not always easy, nor is it easy to tap into memories that are strongly influenced by what is seen today. In addition, surveys about intangible factors such as character can be difficult for participants to both understand and engage with.
Although similar indicators would also be useful for the retail market, monitoring changes can be further enhanced by consulting additional data sources. Using observational techniques, market valuations conducted by property consultancies, and the more detailed data available through sources such as Experian/GOAD, insight into discrete market shifts over longer time periods could be gained and monitored in order to build up greater intelligence about street quality impacts. For example, changes in occupiers, changes in use value, and shifts in the types of retailers occupying space could be analysed in greater depth to offer insight into the local market, both before and after any street improvements. These types of observations can combine to offer an indication of the type of changes occurring in the retail market and the speed at which the retail market responds to particular stimulus. This approach to retail market analysis in a locality could be integrated into the wider evaluation of case study areas.

Evaluating the impact of an intervention on movement patterns in an area is difficult without data on the preexisting conditions. Ideally monitoring would be taking place in target areas well before the implementation of a scheme, including not only traffic and cycle counts but also various assessments of pedestrian behaviour. More systematic traffic counts should be set up to monitor improvements, with a rigorous and consistent process of measuring pedestrian, cycling and traffic movements before and after interventions (e.g. two years before and five years after). Either by more strategically placed automatic counters, or by a series of manual counts, the scope of traffic monitoring could be expanded to capture movement patterns in relation to streetscape improvements and should cover the main affected and surrounding routes. Street life analysis is a particularly useful tool for such questions, as is pedestrian tracing, time-lapse sequences, GPS tracking, photo stacking and so forth. In the These can be carried out on a before and after basis, to understand the nuanced behaviour of people in the affected streets. Public realm improvements are likely to lead to more active streets, but often the diversity of the activity is not well captured by automated traffic counts or who benefits and who doesn't. More innovative monitoring approaches are required.

As with the other dimensions, capturing data about views both before and after interventions is the key to obtaining truly reliable information about their impact on social, economic and other exchange activities. Conducting such work before street improvements occur also has the distinct advantage that views can be fed into the design process, with schemes modified to reflect local aspirations and concerns.

Whilst street survey work is both quick and cost effective, more fundamental questions around perceptions can be better tacked through the use of focus group techniques, bringing street users together to properly explain and then dissect issues of concern. What people say and what they do can be very different things, and so backing up such work with on-site observations can help to reveal actual patterns of use and preferences for comparison with perceptions. Such techniques also record the activities of otherwise hard to reach groups.

Table 11: Possible methodological refinements 
Ultimately, as this study has shown, investing in the quality of the built environment can deliver manifold benefits to a very wide range of those with a stake in those local environments. Whilst every street is unique and a whole host of local contextual factors will impact on how improvements are experienced in different locations, the consistency of the findings across the cases discussed in this paper gives strong reason to suppose that the findings would be generalisable elsewhere in London, across the UK and most likely beyond. The UN-Habitat (2013) study - a quote from which this paper began - sets out very clearly the critical and universal role that mixed street environments play around the world to delivering social, economic and environmental benefits to urban populations. This paper shows that those responsible for making decisions about how and where investments in the public street environment occur need to get much smarter at making the case for a strong quality dimension in what they do. It is hoped that this research, both methodologically and through its findings, will help in providing some of the ammunition that so many of these professional and political actors still so badly need. 


\subsection{References}

Ahlfeldt, G. \& Mastro, A., 2012. Valuing Iconic Design: Frank Lloyd Wright

Architecture in Oak Park, Illinois. Housing Studies, 27(8), pp.1079-1099.

Ahlfeldt, G. \& Holman, N., 2015. Distinctively Different: A New Approach to Valuing Architectural Amenities, London: Spatial Economics Research Centre (SERC), London School of Economics. Available at:

http://www.spatialeconomics.ac.uk/textonly/SERC/publications/download/sercdp017 1.pdf [Accessed October 5, 2016].

Amion Consulting \& Taylor Young, 2007. Economic Value of Urban Design. Report for NWDA/RENEW Northeast, Liverpool: RENEW Northeast.

Barrett, A., 2015. Retail in London, Looking Forward, London, GLA Economics

CABE, 2000. The value of urban design, London: CABE.

CABE, 2006. The cost of bad design, London: CABE.

CABE Space, 2005. Does Money Grow on Trees?, London: CABE. Available at:

http://webarchive.nationalarchives.gov.uk/20110118095356/http://www.cabe.org.uk/f iles/making-the-invisible-visible-full.pdf [Accessed May 5, 2016].

CABE Space, 2007. Paved with Gold: The real value of good street design, London:

CABE. Available at:

http://webarchive.nationalarchives.gov.uk/20110118095356/http://www.cabe.org.uk/f iles/paved-with-gold.pdf [Accessed May 5, 2016].

CABE Space, 2009. Making the invisible visible: The Real Value of Park Assets, London: CABE. Available at:

http://webarchive.nationalarchives.gov.uk/20110118095356/http://www.cabe.org.uk/f iles/making-the-invisible-visible-full.pdf [Accessed May 5, 2016].

Carmona, M., 2015. London's local high streets: The problems, potential and complexities of mixed street corridors. Progress In Planning, 100, pp.1-84.

Carmona, M., De Magalhães, C. \& Edwards, M, 2001. The value of urban design: a research project commissioned by CABE and DETR to examine the value added by good urban design, Tonbridge: Thomas Telford.

Carmona, M., De Magalhães, C. \& Edwards, M., 2002. Stakeholder Views on Value and Urban Design. Journal of Urban Design, 7(2), pp.145-169.

Carmona, M., De Magalhães, C. \& Natarajan, L., 2017. Design Governance, The CABE Experiment, New York, Routledge.

Cartright C (2017) London Business Rates to Increase up to $120 \%$ and Kill More Businesses. https://www.linkedin.com/pulse/london-business-rates-increase-up-120kill-more-carl-cartwright

Chee Keng Lee, A., Jordan, H. \& Horsley, J., 2015. Value of urban green spaces in promoting healthy living and wellbeing: prospects for planning, Risk Management and Healthcare Policy, 8, pp.131-137

Chiaradia, A.J. Schwander, C., Gil, J., \& Friedrich, E., 2008. Mapping the intangible value of urban layout (i-VALUL): Developing a tool kit for the socio-economic valuation of urban area, for designers and decision makers. In 9th International Conference on Design \& Decision Support Systems in Architecture and Urban Planning. Eindhoven, Netherlands. Available at: http://cumincad.scix.net/data/works/att/ddss2008-32.content.pdf [Accessed May 5, 2016]. 
Cho, S.-H., Poudyal, N.C. \& Roberts, R.K., 2008. Spatial analysis of the amenity value of green open space. Ecological Economics, 66(2-3), pp.403-416.

CJC Consulting, 2005. Economic Benefits of Accessible Green Spaces for Physical and Mental Health: Scoping study. Report for the Forestry Commission, Oxford: The Forestry Commission. Available at: http://www.forestry.gov.uk/pdf/FChealth102final.pdf/\$FILE/FChealth10-2final.pdf.

Clifton, K., Ewing, R., \& Gerrit-Jan, K., 2008. Quantitative analysis of urban form: a multidisciplinary review. Journal of Urbanism: International Research on Placemaking and Urban Sustainability, 1(1), pp.17-45.

Department of National Heritage (DNH), English Heritage \& The Royal Institute of Chartered Surveyors, 1996. The Value of Conservation: A Literature Review of the Economic and Social Value of the Cultural Built Heritage, London: RICS.

Diao, M. \& Ferreira, J., 2010. Residential Property Values and the Built Environment. Transportation Research Record: Journal of the Transportation Research Board, 2174, pp.138-147.

DoE \& RICS, 1996. Quality of urban design: a study of the involvement of private property decision-makers in urban design, London: Royal Institution of Chartered Surveyors and the Department of the Environment.

ECOTEC, 2007. Economic Impact of the Public Realm: A Final Report to the East Midlands Development Agency, Birmingham: ECOTEC. Available at:

http://www.vspsomerset.org.uk/sites/default/files/attachments/resources/Economicl mpactofThePublicRealm.pdf [Accessed May 5, 2016].

English Heritage, 1999. The Heritage Dividend: Measuring the results of English heritage regeneration 1994-1999, London: English Heritage.

Gehl, J., 1996 (first published 1971). Life Between Buildings: Using public space (third edition), Skive, Arkitektens Forlag

Gehl, J., 2010. Cities for People, Washington DC, Island Press

Gibbons, S., 2015. Gone with the wind: valuing the visual impacts of wind turbines through house prices, Journal of Environmental Economics and Management, 72: 177-196

GLA Economics, 2003. Valuing Greenness. Green spaces, house prices and Londoners' priorities, London: Greater London Authority. Available at: https://www.london.gov.uk/sites/default/files/valuing_greenness_report.pdf [Accessed May 16, 2016].

Hack, G. \& Sagalyn, L.B., 2011. Value Creation Through Urban Design. In S. Tiesdell \& D. Adams, eds. Urban Design in the Real Estate Development Process. WileyBlackwell, pp. 258-281.

Henneberry, J., Lang, E., Moore, S., Morgan, E., \& Zhao, N.,, 2011. Physical-Financial Modelling as an Aid to Developers' Decision-Making. In S. Tiesdell \& D. Adams, eds. Urban Design in the Real Estate Development Process. Wiley-Blackwell, pp. 219-235. Henneberry, J., Lange, E. \& Moore, S., 2010. Modelling The Relationship Between Development Design And Financial Viability, St. Louis, United States: Federal Reserve Bank of St Louis. Available at: http://search.proquest.com/docview/1697565871?accountid=14511 [Accessed May 10, 2016]. 
Herath, S., Choumert, J. \& Maier, G., 2015. The value of the greenbelt in Vienna: a spatial hedonic analysis. Annals of Regional Science, 54(2), pp.349-374.

Kahne, J., 2015, Does Placemaking Cause gentrification? It's Complicated, https://www.pps.org/blog/gentrification/ [Accessed March 17, 2017]

Lawlor, E., 2013. The pedestrian pound: the business case for better streets and places, London, Living Streets

London Councils, 2015. The Impact of Permitted Development Rights for Office to Residential Conversion, A London Councils Briefing, London, London Councils Luttik, J., 2000. The value of trees, water and open space as reflected by house prices in the Netherlands. Landscape and Urban Planning, 48(3-4), pp.161-167.

MacKenzie, A., 2015. Reimagining our streets as places: From transit routes to community roots, https://www.pps.org/reference/reimagining-our-streets-as-placesfrom-transit-routes-to-community-roots/ [Accessed March 23 2017]

McConnell, V. \& Walls, M., 2005. The Value of Open Space: Evidence from Studies of Nonmarket Benefits, Washington DC: Resources for the Future. Available at: http://www.rff.org/files/sharepoint/Worklmages/Download/RFF-REPORTOpen\%20Spaces.pdf [Accessed May 5, 2016].

McCann, B., \& Rynne, S., 2010. Complete Streets, Best Policy and Implementation Practices, Chicago, American Planning Association

Ministry for the Environment, 2005. The Value of Urban Design: The economic, environmental and social benefits of urban design, Wellington NZ: Ministry for the Environment. Available at: http://www.mfe.govt.nz/sites/default/files/value-of-urbandesign-full-report-jun05_0.pdf [Accessed May 5, 2016].

Mulgan, G., 2005. Public Value: Physical Capital and the Potential of Value Maps. In CABE, ed. Physical Capital: How Great Places Boost Public Value. London: CABE, pp. 8-27. Available at:

http://www.futurecommunities.net/files/images/CABE_physicial_capital.pdf. Nase, I., Berry, J. \& Adair, A., 2013a. Hedonic modelling of high street retail properties: a quality design perspective. Journal of Property Investment \& Finance, 31(2), pp.160-178.

Nase, I., Berry, J. \& Adair, A., 2013b. Real estate value and quality design in commercial office properties. Journal of European Real Estate Research, 6(1), pp.4862.

Nase, I., Berry, J. \& Adair, A., 2015. Urban design quality and real estate value: in search of a methodological framework. Journal of Urban Design, 20(5), pp.563-581. New York City, Department of Transportation, 2012. Measuring the Street: New metrics for 21st century streets, New York: New York City Department of Transportation. Available at: http://www.nyc.gov/html/dot/downloads/pdf/2012-10measuring-the-street.pdf [Accessed May 10, 2016].

NYC Department of Transportation, 2013. The Economic Benefits of Sustainable Streets, New York: New York City Department of Transportation. Available at: http://www.nyc.gov/html/dot/downloads/pdf/dot-economic-benefits-of-sustainablestreets.pdf [Accessed May 5, 2016].

Rods Task Force, 2012, Roads task Force, Progress report: A Successful First Year, http://content.tfl.gov.uk/roads-task-force-update-report-april-2015.pdf [Accessed March 19, 2017] 
Savills, 2007. Valuing Sustainable Urbanism: A report measuring and valuing new approaches to residentially led mixed use growth, London: The Prince's Foundation. Sheldon, R. Buchanan, P., Dosad, C., \& Ubaka, D., 2007. Valuing Urban Realm: Business Cases in Public Spaces. In European Transport Conference. Netherlands: Association for European Transport. Available at:

http://abstracts.aetransport.org/paper/index/id/2781/confid/13 [Accessed May 5, 2016].

Sheldon, R., Orr, S., Buchanan, P., Dosad, C., and Ubaka, D., (2010) "Incorporating Health and Social Benefits in the Valuation of Urban Realm Improvements", ETC conference paper. Available at:

https://www.scribd.com/document/46723083/Incorporating-Health-and-SocialBenefits-in-the-Valuation-of-Urban-Realm-Improvements [Accessed January 10, 2017] Sinnett, D., Williams, K., Chatterjee, K., \& Cavill, N., 2011. Making the case for Investment in the Walking Environment: A review of the evidence, Bristol: Living Streets. Available at: http://www.livingstreets.org.uk/media/1394/2011-making-thecase-full-report.pdf [Accessed May 5, 2016].

Smith, D., 2010. Valuing Housing and Green Space: Understanding local amenities, the built environment and house prices in London, London: Greater London Authority. Available at:

https://www.london.gov.uk/sites/default/files/gla_migrate_files_destination/GLAEwp-42.pdf.

Song, Y. \& Knaap, G.-J., 2003. New urbanism and housing values: a disaggregate assessment. Journal of Urban Economics, 54(2), pp.218-238.

Southworth, M., 2003. Measuring the Liveable City. Built Environment (1978-), 29(4), pp.343-354.

Stantec Consulting Ltd., 2011. Vancouver Separated Bike Lane Business Impact Study, Vancouver: Vancouver Economic Development Commission. Available at: http://council.vancouver.ca/20110728/documents/penv3-

BusinessImpactStudyReportDowntownSeparatedBicycleLanes-StantecReport.pdf. Stops, V., 2015, Place is as Important as Movement, 13 September, http://cycleandwalkhackney.blogspot.co.uk/2015/09/place-is-as-important-asmovement-tale.html [Accessed March 17, 2017)

The Young Foundation and UCL, 2006a. Assessing Values Created by the Built Environment: A Methodological and Analytical Review: A Report to the Commission for Architecture and the Built Environment, London: The Young Foundation. The Young Foundation and UCL, 2006b. Mapping Value in the Urban Built Environment: A Report to the Commission for Architecture and the Built Environment, London: The Young Foundation. Available at: http://youngfoundation.org/wp-content/uploads/2013/06/mapping-value.pdf [Accessed May 5, 2016].

Tiesdell, S. \& Adams, D., 2011. Connecting Urban Design to Real Estate Development. In S. Tiesdell \& D. Adams, eds. Urban Design in the Real Estate Development Process. Wiley-Blackwell, pp. 282-298.

Transport for London, 2013, Better Streets Delivered, Learning from Completed Schemes, http://www.urbandesignlondon.com/wordpress/wpcontent/uploads/better-streets-delivered-web-version.pdf 
Transport for London, 2014, Improving the Health of Londoners, transport Action Plan, http://content.tfl.gov.uk/improving-the-health-of-londoners-transport-actionplan.pdf

Transport for London, 2016, Better Streets Delivered 2, Learning from Completed Schemes, unpublished

Transport for London, 2016, Streetscape Guidance, Third Edition, http://content.tfl.gov.uk/streetscape-guidance.pdf

UN-Habitat, 2013. Streets as Public Spaces and Drivers of Urban Prosperity, Nairobi, UN-Habitat

Vandell, K.D. \& Lane, J.S., 1989. The Economics of Architecture and Urban Design: Some Preliminary Findings. Real Estate Economics, 17(2), pp.235-260.

van Wee, B., 2012, How suitable is CBA for the ex-ante evaluation of transport projects and policies? A discussion from the perspective of ethics, Transport Policy, 19(1), pp.1-7

Varma, A., 2003. Working Paper 3: Valuing Greenness. Is there a segmented preference for housing attributes in London?, London: Greater London Authority. Available at:

https://www.london.gov.uk/sites/default/files/valuing_greenness_paper.pdf [Accessed May 16, 2016].

Webster, C., 2010. Pricing accessibility: Urban morphology, design and missing markets. Progress in Planning, 73(2), pp.77-111. 


\subsection{Acknowledgements}

Particular thanks are due to Transport for London $(\mathrm{TfL})$ who funded this work most notably to Bruce McVean, Robin Buckle, Bridget Elliott and George Weeks for all their invaluable support and assistance during the conduct of the research. 
